\title{
THE URBAN PLANNING PROCESS
}

JULY 1972 - NUMBER 22

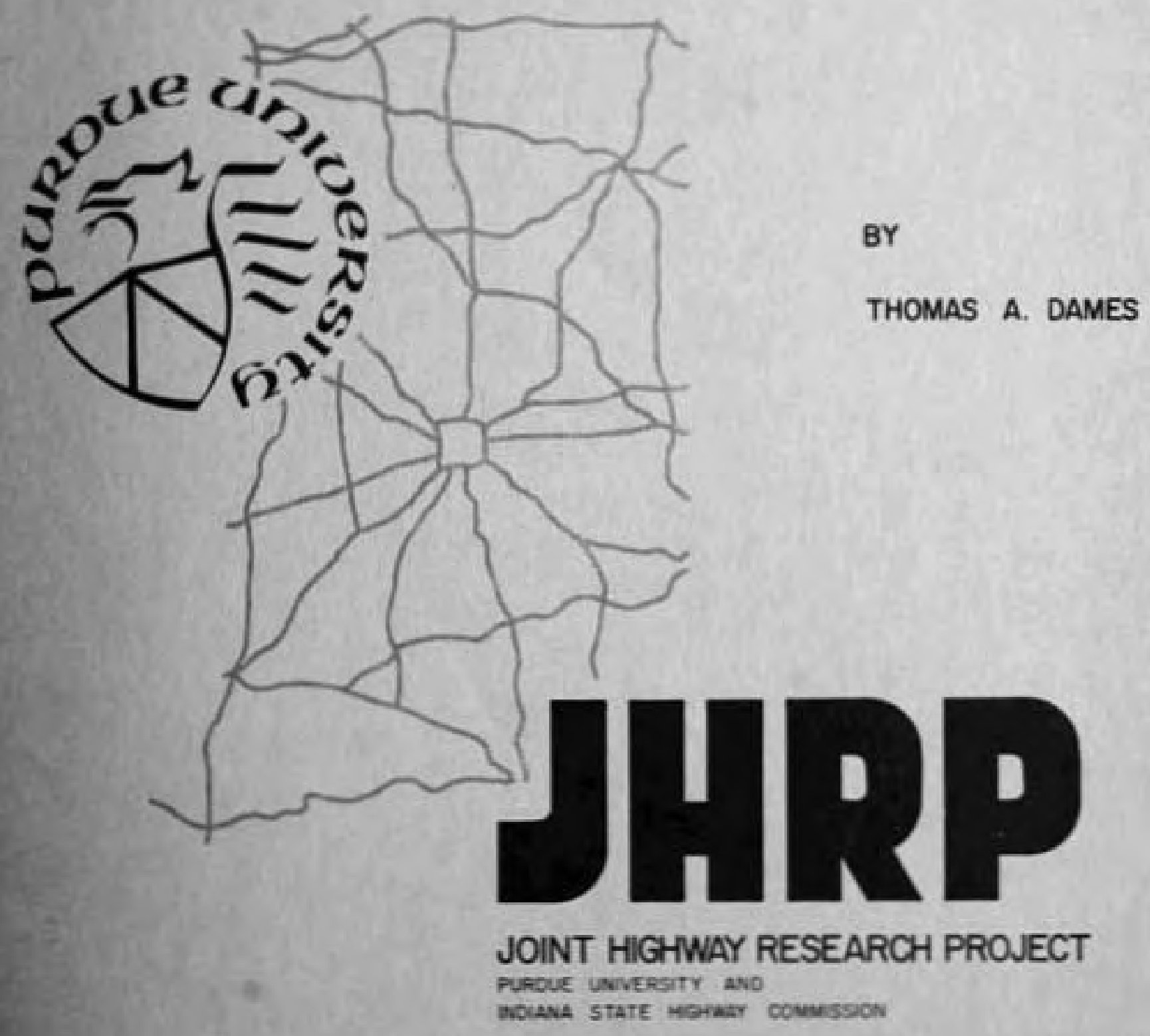


TO: J. F. MeLaughlin, Director Joint Ilighway Research Project

July 26, 1972

FROM: H. L. Michae1, Associate Director Joint Highway Research Project

File: $\quad 3-7$

The attached Report titled "The Urban Planning Process" has been authored by Thomas Allan Dames under the guidance of Professor W. L. Grecco. Mr. Dames used this Report as his thesis in partial fulfillment of the requirements for the Ph.D. degree.

The report is a presentation of the methodology connon to urban planning over the entire ranges of such planning from the most comprehensive to the most 1 imited and from the greatest in areal extent to the smallest. The process, from a definable beginning, through many intermediate steps to a definable end is developed and conceptually modeled. Planning procedures are outlined and discussed and examples are presented.

This research was conducted by $\mathrm{Mr}$. Dames under a U. 5 . Navy educational assignment and is presented to the Board as information.

IILM:ns

Respectfully subnitted,

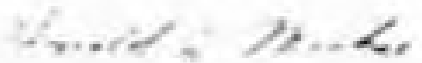

Harold L. Michael Associate Director cc: W. L. Dolch

R. L. Eskew

W. H. Goetz

W. L. Grecco

M. J. Gutzwiller

G. K. Hallock
R. H. Harre11

M. L. Hayes

C. W. Love11

G. W.Marks

R. D. Miles

J. W. Miller
C. F. Scholer

M. B. Scott

J. A. Spooner

N. W. Steinkamp

II. R. J. Walsh

L. J. Yoder 
THE URBAN PLANNING PROCESS

by

Thomas A11an Dames

Joint Highway Research Project

File: $\quad 3-7$

Purdue University

Lafayette, Indiana

July 26, 1972 
Digitized by the Internet Archive in 2011 with funding from

LYRASIS members and Sloan Foundation; Indiana Department of Transportation

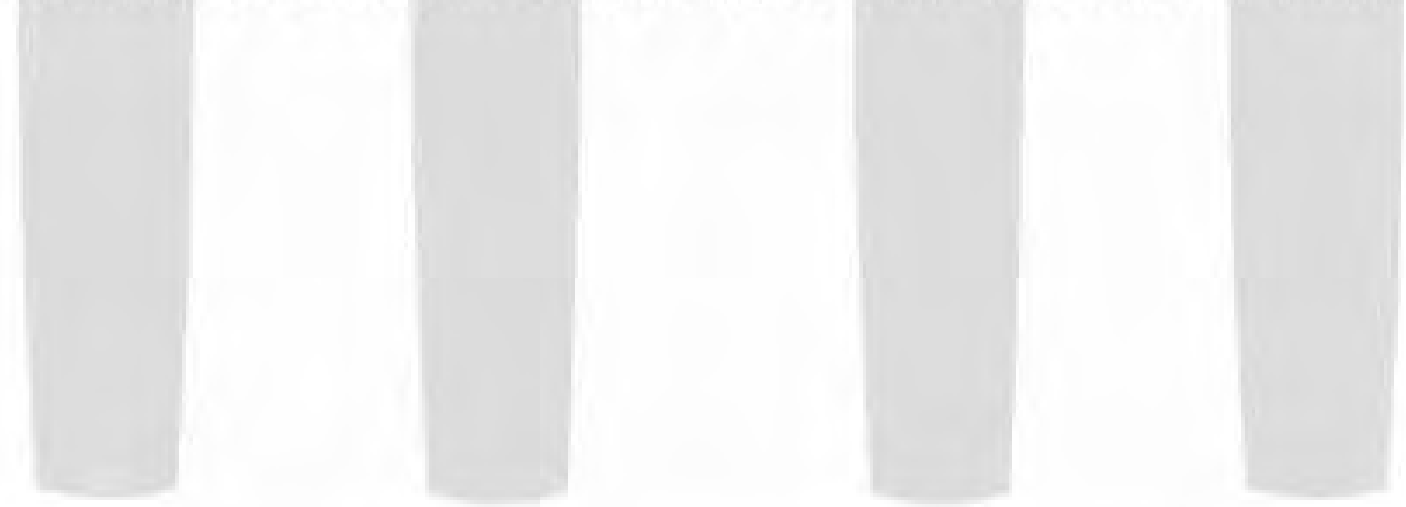




\section{ACKNOWLEDGMENTS}

With a deep sense of gratitude, the author wishes to personally thank Dr. William L. Grecco, Professor of Urban Planning and Engineering at Purdue University, for his enlightened leadership and counsel, not only during the conduct of this research, but throughout our warm and professional association. All that is worthwhile in this work was born of this association. To receive such counsel from Dr. Grecco is an unforgettable intellectual pleasure.

For their interest, guidance, and reasoned criticism of this research, the author wishes to sincerely thank Professor Harold L. Michael, Head of Urban Planning and Engineering at Purdue, Professor Robert D. Miles of the School of Civil Engineering, and Dr. Colin L. Moodie of the School of Industrial Engineering. Their participation was most welcome and they constituted a most sympathetic audience for the early drafts of this material.

I must also acknowledge a strong debt to my fellow officers in the Civil Engineer Corps, United States Navy, for altogether demonstrating a standard of professional excellence not exceeded elsewhere in my experience. With a sincere concern for the inequity of singling out one such officer, I must nonetheless note that Rear Admiral Spencer R. Smith afforded me the opportunity to observe this excellence at first hand, and never failed to encourage me to emulate it.

To Dr. John F. McLaughlin, Head of the School of Civil Engineering at Purdue, and his staff, I owe a debt of thanks for the ease of reentry to the Academe. 
To my fellow students, past and present, I offer a warm thank you for a vibrant and stimulating environment of intellectual endeavor.

I acknowledge the professional and personal counsel of Dr. Charles C. Schimpeler of Schimpeler - Corradino Associates, Louisville, Kentucky. Dr. Schimpeler's unfailing enthusiasm and competence is a joy to experience.

We are all, of course, the products of our experience and I must finally acknowledge the unrepayable debt to my parents and my family for providing environments conducive to intellectual persuit, often at considerable sacrifice. 
TABLE OF CONTENTS

LIST OF TABLES

Page

LIST OF FIGURES

ABSTRACT

INTRODUCTION

CHAPTER I. GOALS AND OBJECTIVES

ix

$\mathrm{x}$

xii

Identifying the Community Influentials

The Development of Community Goals and

objectives .............. 13

The Ordering of Community Goals and objectives . 26

Notes

CHAPTER II. ORGANIZATION . . . . . . . . . . 38

A Conceptual Model of Planning Activity . . . . 38

The Use of the Model in Planning Organization . 44

The Use of the Model in Study Design . . . . . . 50

The Study Design Methodology . . . . . . . . . 57

Notes . . . . . . . . . . . . 66

CHAPTER III. INVENTORY . . . . . . . . . . 67

A Data-Use Matrix . . . . . . . . . . 72

Land Data . . . . . . . . . . . . . 83

Land Use . . . . . . . . . . . . 83

Ownership . . . . . . . . . . 84

Frontage and Area . . . . . . . . . . 84

Easements . . . . . . . . . . 84

Landmark . . . . . . . . . . . . . . 84

Number of Parking Spaces . . . . . . 84

Assessed Value of Land and Improve-

ments .......... 84

Real Estate Tax Revenue . . . . . . . 84

Sale Price and Sale Data . . . . . . 85

Summary . . . . . . . . . . . 85

Street Data . . . . . . . . . . . 85

Intersection ......... . . 85

Length of Segment, Right-of-way

Width and Pavement Width . . . . . 85

Functional class .......... . 85

Structural Composition and Percent

Grade . . . . . 86

Average Traffic and Peak Hour Traffic. 86

Number of Accidents . . . . . . . . . 86

Curb Parking . . . . . . . . . 86 
TABLE OF CONTENTS (cont.)

Page

Sidewalks and Street Lights . . . . . 86

Number of Lanes and Loading Zone . . . 86

Transit Route and School Route . . . . 86

Access Control . . . . . . . . . . . . 87

Condition . . . . . . . . . 87

Utilities Sharing Right-of-way . . . 87

Summary . . . . . . . . . . 87

Structura1 Data . . . . . . . . . 87

Year Built and Type of Construction . 87

Building Condition . ....... 87

Number of Floors, Total Floor Area

and First Floor Area ....... . 88

Number and Type of Building Code

Violations . . . . . . . . 88

Rehabilitation Cost . . . . . . 88

Police Calls and Fire Calls . . . . . 88

Utility Service ............ . . 88

Summary . . . . . . . . . . . . . 88

Dwelling Unit Data $: \ldots 9 . \quad 89$

Percent Vacant . . . . . . . . 89

Residents by Sex and Age Groups . . . 89

Family Income . . . . . . . . . . 89

Family Education and Occupation . . . 89

Vehicles Owned, Place of Work and

Means of Transportation to Work . . 90

Number and Types of Communicable

Rent .

Diseases............ . 90

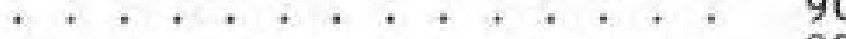

Non-Dwelling Unit Data . . . . . . . . 91

Peak Shift Employees, Number of

Employees and Optimum Total

Employment ........... 91

Major Product Groups . . . . . . . . 91

Percent Sales Outside the Area . . . . 91

Summary . . . . . . . . . . . 91

Some Concepts of Sampling . . . . . . . . . . . 92

Sample Size . . . . . . . . . . . . . 94

Sample Selection . . . . . . . . . . 95

Simple Random Sample ... . . . . . . . 95

Stratified Random Sample . . . . . . . 96

Systematic Sample and Stratified
Systematic Sample

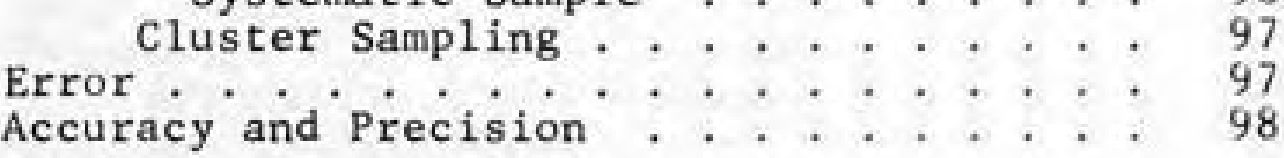


TABLE OF CONTENTS (cont.)

Notes

Urban Information Systems

Page

Information Hierarchy ........... 102

Levels of System Sophistication . . . . . . 102

System Development . . . . . . . . . 102

Summary ................ . . 105

105

CHAPTER IV. ANALYSIS . . . . . . . . . . . 106

The Use of Models . . . . . . . . . . . . . 109

The Strategy and Tactics of Modeling . . . 110

An Example ............. . . 113

The Use of Systems Analysis . . . . . . . . . . 117

General Systems Theory . . . . . . . 117

Urban Systems Analysis . . . . . . . 121

CHAPTER V. FORECASTING . . . . . . . . . . 125

The Forecasting Mode1 . . . . . . . . . . 126

Substance . . . . . . . . . . . . . 126

Area . . . . . . . . . . . . . . . 134

Procedure . . . . . . . . . . . . 135

Forecasting Techniques . . . . . . . . . . 136

Economic Activity Forecasts . . . . . . . . 136

Population Estimates and Forecasts . . . . 145

Land Use Forecasts . . . . . . . . . . . 147

Summary

Transportation Forecasts . . . . . . . 149

158

CHAPTER VI. DESIGN . . . . . . . . . . . . . 159

Considerations of Form . . . . . . . . . . . . 161

Considerations of Quality . . . . . . . . . 169

Operational Considerations ........... . 176

An Example . . . . . . . . . . . . 179

Summary .................. . . 183

Notes . . . . . . . . . . . 183

CHAPTER VII. EVALUATION . . . . . . . . . . . . . 184

The Conceptual Model of the Evaluation Phase . . 186

Substantive Scope........... 186

Areal Scope ............... . . . 188

Procedural Scope . . . . . . . . . . . . . 190

Evaluation Steps . . . . . . . . . . 190

Evaluation Roles............ . 190

Summary

Evaluation Strategies. . . . . . . . 191 
TABLE OF CONTENTS (cont.)

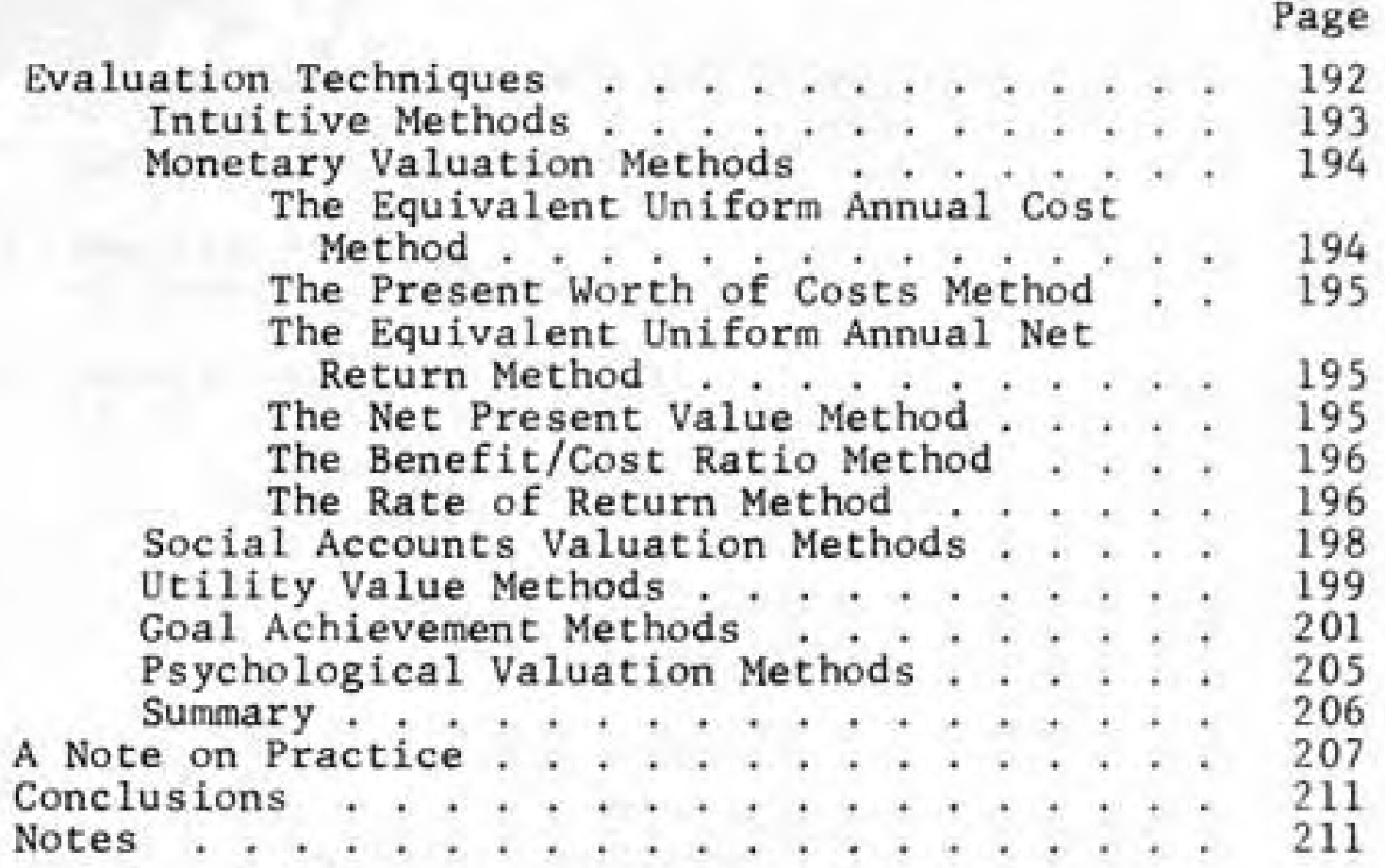

CHAPTER VIII. IMPLEMENTATION . . . . . . . . 213

The Conceptual Model of the Implementation

Phase ............ 215

Substantive Scope . . . . . . . . . . 215

Areal Scope . . . . . . . . . . . . . 219

Procedural Scope ............. . 221

Operational Considerations . . . . . . . . . 223

A Note on Federal Assistance . . . . . . . . 233
Summary . . . . . . . . 234

Notes . . . . . . . . . . . 235

CONCLUDING REMARKS . . . . . . . . . . . . 236

BIBLIOGRAPHY . . . . . . . . . . . . 238

General References . . . . . . . . . . 247

VITA . . . . . . . . . . . . 258 


\section{LIST OF TABLES}

Table

Page

Sample Community Goals and Objectives . . .

II-1 Sample Work Item Resource Assignment . . . . .

II-1 Descriptive Data Showing a University Level of Service................. . . . 70

II -2 Sample Land Use Plan Objectives and Data Items ............. . . 73

V-1 Cents Worth of Input per Dollar Output . . . . 138

V-2 Input Requirements in Dollars . . . . . . . 139

V-3 Allocation of Sales by Percent . . . . . . . . 140

V-4 Allocation of Sales by Percent Direct and Indirect. . . . . . . . . . . . . . 141

VI-1 Site Features/Design Considerations: Steeply Sloped Site . . . . . . . . . . . 171

VII-1 Conceptual Payoff Matrix . . . . . . . . . . . 199

VII-2 The Goals-Achievement Matrix . . . . . . . . . 202

VII-3 Historical Evaluation Technique Emphases . . . 210

VIII-1 Methods of Implementing Environmental Policies, by Land Form . . . . . . . . . . . . . . . 
LIST OF FIGURES

Figure

Page

1-1 A Conceptual Visualization of the Client Constituency ............ 10

11-1 A Conceptual Model of Planning Activity . . . 39

II-2 A Conceptual Elemental Event in the Planning Model

II -3 The Community Land Use Forecast in the Model.

II -4 The Organization Phase in the Conceptual Model of Planning Activity . . . . . . 45

II-5 Conceptual Demand Curves .......... 47

II-6 The Use of the Conceptual Model in Planning Organization............ 52

II-7 Four Conceptual Staffing Schemes . . . . . . 54

II-8 Sample Parking Study Flow Diagram ...... 58

II -9 Sample School Study Flow Diagram . . . . . . 59

II-10 Sample Organization Phase Flow Diagram.... 61

III-1 The Inventory Phase in the Conceptual Model of Planning Activity........... . 68

III-2 A Sample Data-Use Matrix . . . . . . . . . 78

III-3 The Relationship Between Sampling and Nonsampling Error..............

III-4 The Relationship Between Accuracy and Precision ............. 100

III-5 Logic Diagram for Coding Information to Land Parcel ............. 104

IV-1 The Conceptual Model of Statewide Recreational Travel to State Parks

$V-1$ The Forecasting Phase in the Conceptual Model

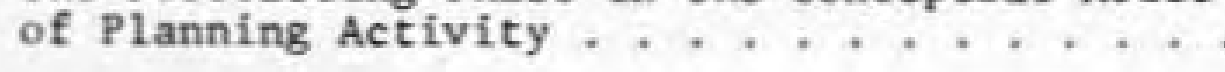

v -2 A Conceptual Forecasting Model ........ 128 
$x i$

LIST OF FIGURES (cont.)

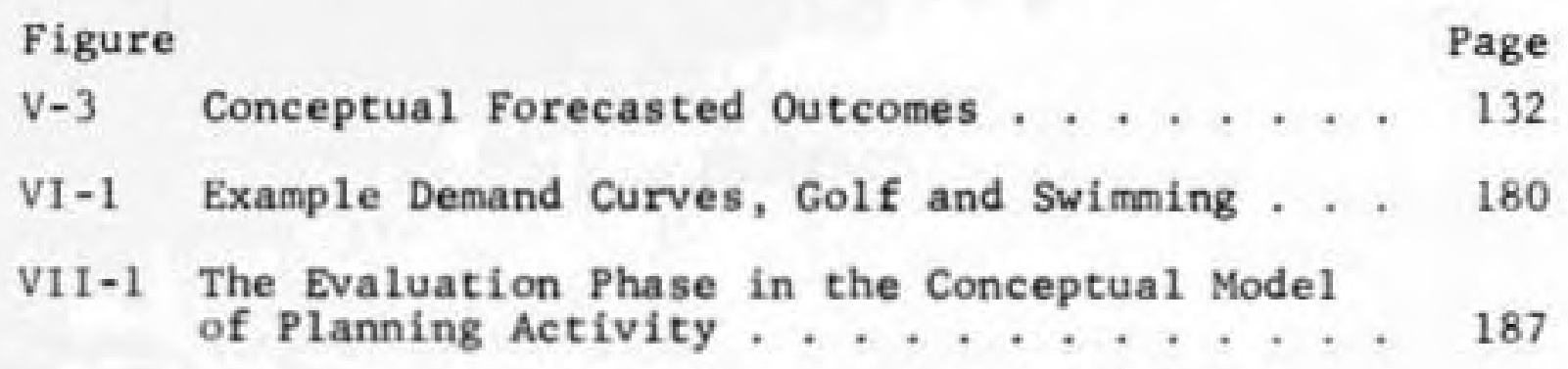

VIII -1 The Implementation Phase in the Conceptual Model of Planning Activity........ 216 


\section{ABSTRACT}

Dames, Thomas Allan. Ph.D., Purdue University, August, 1972. The Urban Planning Process. Major Professor: William L. Grecco.

The precept central to this work is that there is a methodology common to urban planning over the entire ranges of such planning from the most comprehensive to the most limited and from the greatest in areal extent to the smallest. This common methodology is considered as a process with a definable beginning, a definable end and requisite intermediate steps.

The beginning occurs with a need to plan perceived by the client constituency of the planner and refined through the formulation of a set of goals and objectives of this constituency. This procedure, as well as necessary administrative requirements, occurs in the organization phase of the planning process. The planning process continues sequentially through a series of steps or phases to investigate and institute proposals deemed desireable and feasible based upon the enunciated goals and objectives. The phases have been designated as that of organization, inventory, analysis, forecasting, design, evaluation, and implementation. The distinctions among the phases are both conceptual and operational, not withstanding due regard given to feedback and feedforeward elements.

A conceptual model of the planning process is introduced and examined throughout this research. It is hypothesized that this model adequately demonstrates the sequential nature of the planning process. It further demonstrates that procedural considerations can be used to conceptually examine the substantive scope of planning, from the most 
general to the most specific, and the areal scope of planning, from the greatest to the smallest. The interaction of substance, area, and process defines planning in both a conceptual and operational sense.

Specific examples of planning procedures are introduced in the research with a twofold purpose: to demonstrate the mechanics of a specific technique; and, more importantly, to bridge the gap between the themes of concept and operationality.

The research is addressed to specific audiences. These include the engineer who finds himself in a planning situation, representatives of other professions similarly situated, executives in both the public and private sectors and, generally, that individual with little planning education or experience who is faced with the need to participate in urban planning.

A second audience is the Academe. A work of this type will constitute a sound basis for a graduate or undergraduate introduction to urban planning irrespective of the student's main area of interest.

A third audience is the planning profession itself. The body of literature on the planning process is disjointed and fragmented. Typically it consists of four types of documents: detailed technical treatises on a particular technique; somewhat more general works albiet about a specific type of planning; histories about the planning process in a specific situation participated in or observed by the author; and philosophical works about the need to plan. This is an impressive and valuable body of knowledge but, perhaps owing to its generally recent vintage, it has not been brought together in a format such as this. 


\section{INTRODUCTION}

The precept central to this work is that there is a methodology common to urban planning over the entire ranges of such planning from the most comprehensive to the most 1 imited and from the greatest in areal extent to the smallest. This common methodology is considered as a process with a definable beginning, a definable end and requisite intermediate steps.

The beginning occurs with a perceived need to plan. This perception has as its basis the difference between the style of 1 ife currently held by the perceptor and that style defined as "better" based upon his set of values. In a macro sense, the exploration, definition and development of the various sets of values held by the public defines the public purpose. The public is made up of those people directly affected by the plan and is termed the client constituency of the planner so as not to 1 imit this discussion to the more restrictive sense of public; i.e., governmental, planning. The formulized and measured sets of values are called the goals and objectives of the client constituency and serve as the conceptual basis for specific planning endeavors .

The planning process then runs sequentially through a series of steps or phases to investigate the institute proposals deemed desirable and feasible based upon the enunciated goals and objectives. The phases have been designated as that of organization, inventory, analysis, forecasting, design, evaluation, and implementation. The distinctions among the phases are both conceptual and operational, not withstanding due regard given to feedback and feedforeward elements. 
A conceptual model of the planning process is introduced and examined throughout this work. It is hypothesized that this model adequately demonstrates the sequential nature of the planning process. It further demonstrates that procedural considerations can be used to conceptually examine the substantive scope of planning, from the most general to the most specific, and the areal scope of planning, from the greatest to the smallest. The interaction of substance, area, and process defines planning in both a conceptual and operational sense.

These themes of concept and operationality run throughout the work. In maintaining the two, some information at the extremes is necessarily omitted. As a result, this work is neither a theoretical development of the planning process nor a procedural manual. It rather is conducted on a level of discussion intermediate between the two. A further theme is one of commonality. Only where absolutely necessary were distinctions made between planning in the public sector and planning in the private sector. Institutional considerations were also minimized, so little reference is made to planning in a large, complex and highly structured environment or one less so in any of these qualities. It is thought that such considerations have impacts which will not detract significantly from the information presented. Balancing this commonality, specific examples have been included with a twofold purpose: to demonstrate the mechanics of a specific technique; and, more important1y to bridge the gap between the themes of concept and operationality.

The examples were purposely chosen so as not to fall within one type of planning from chapter to chapter. It was felt that this would lend too much credence to the mechanics of the examples, to the detriment of the concepts underlying those mechanics. There is a commonality of concept from one type of planning to another, quite apart from whatever 
the substance of the chosen examples happens to be. It is up to the reader to make the necessary transfer as appropriate.

In this same vein, the applications of the conceptual model of planning activity are suggested, but not exhausted.

The themes of concept, operationality and commonality were nonetheless addressed to specific audiences. These include the engineer who finds himself in a planning situation, representatives of other professions similarly situated, executives in both the public and private sectors and, generally, that individual with little planning education or experience who is faced with the need to participate in urban planning.

A second audience is the Academe. It is thought that a work of this type will constitute a sound basis for a graduate or undergraduate introduction to urban planning irrespective of the student's main area of interest.

A third audience is the planning profession itself. The body of literature on the planning process is disjointed and fragmented. Typically it consists of four types of documents: detailed technical treatises on a particular technique; somewhat more general works albiet about a specific type of planning; histories about the planning process in a specific situation participated in or observed by the author; and philosophical works about the need to plan. This is an impressive and valuable body of knowledge but, perhaps owing to its generally recent vintage, it has never been brought together in a format such as this. Chapter I opens with a discussion of the concept of the client constituency and methods of its identification. The discussion then turns to methods of identifying the goals and objectives of this constituency and measuring their relative importance.

Chapter II, Organization, introduces the conceptual model of planning activity. This model, together with the 
goals and objectives of the client constituency developed in Chapter I, is then used to delimit the planning area and nest the substance of the plan into a hierarchy of planning, from the most general to the most specific. The adninistration of the planning effort is discussed and the refinement of the goals and objectives into an operational scheme is traced through the preparation of a prospectus, a study design, and procedural manuals.

Chapter III discusses the inventory of information deemed necessary to plan, based upon the operational and administrative refinements executed in Chapter II. A data-use matrix is presented showing the conceptual end use of various data for typical plans. Discussions of sampling and the use and development of urban information systems close the chapter.

Chapter IV investigates the analysis of inventoried data. Typically this analysis follows the classical scientific method of induction, generalization, deduction and testing. The use of models is defined and explored and some suggestions are of fered regarding the strategy and tactics of modeling. Two examples illustrate these concepts. General systems theory is outlined and a discussion on urban systems analysis demonstrates that the use of the conceptual model of planning activity developed in this work is itself a systematic analysis.

Chapter $V$ contains an investigation of the problem that urban planners face in dealing with future events and the attendant risk of forecasting. A conceptual forecasting model is examined and a relatively detailed discussion follows on the techniques of forecasting key measures of economic activity, population characteristics, land use characteristics, and transportation characteristics.

Chapter VI on urban design discusses the preparation of a plan, or a set of alternative plans, designed to meet these forecasted characteristics in a manner arising from 
and consistant with the goals and objectives of the client constituency. It is necessarily the most philosophical phase of the planning process. An exploration of general and specific considerations of form and considerations of quality is followed by a discussion of the modi operendi of urban design. One such mode is developed as an example at the end of the chapter.

Chapter VII investigates the evaluation phase of the conceptual model of planning activity. As with other phases, the benchmarks continue to be the goals and objectives of the client constituency. A relatively detailed treatment is offered of the range of evaluative methods including those that are intuitive, monetary, social, utile, goal-achieving, and psychological. Examples of current practice are included.

Chapter VIII investigates the natural and operational cunclusion of urban planning, implementation. The role of the planner is explored within the context of the conceptual model of planning activity. A discussion of implementation strategies, tactics, techniques and aids closes the chapter. 
CHAPTER I

GOALS AND OBJECTIVES

It seems logical to begin the study of planning methodology with a short note about the planner himself and the milieus in which he must act. A planner is one who plans. An urban planner plans aspects of urban life and a professional urban planner does so or teaches so for a living with a further connotation of working under an ethic.

It is not purpose of this research to elaborate on this theme except to note that it is not surprising that numerous longer established professions lay some claim to professional urban planning (Pollard, 1969). Under the above definitions, such claims are justified.

A client is someone for whom another person acts, again with an ethical connotation. It is difficult, but necessary, for an urban planner to correctly identify his client, because the professional relationship established subsequent to this is as delicate as any repeatedly referred to in law or medicine.

The client of the professional urban planner is a constituency made up of the people affected by the plan and the employer of the urban planner. Carried to its extreme, we are each a constituent client of any urban plan ever conceived. The dilemma presented by this situation is, of course, avoided by limiting consideration of this constituency to those persons most likely to be materially affected by the plan.

Two examples will suffice to illustrate this. In the case of a single private entrepreneur who wishes to develop his vacant property for residential use and annexation by 
an existing community, the client constituency is:

the entrepreneur,

the future residents of the property,

the current and future residents of the conmunity, and, in some respects, the current and future

residents of the region encompassing the community.

In the case of the city manager who wishes a land use plan for his community, the client constituency is:

the city manager,

the current and future residents of the city, and probably the current and future residents of the region encompassing the city.

Some investigation of this client constituency has been carried out by Kaplan (1969) and he notes that the client/planner relationship becomes complexed by individual constituents who want to participate in the planning process, hy individual constituents who view the employer/planner relationship as working counter to their best interests, and by the self doubt of the planner himself as to who exactly is his client.

Add to this the fact that decision making in urban aftairs has been often justifiably characterized as incremental, remedial, serial, exploratory, fragmented and disjointed (Braybrooke, 1963) and one is left with the question "Why plan at all?"

The reason is that the study of urbanization leaves little doubt that past plans have had an impact on urban development. This impact has sometimes been generally good, sometimes generally bad. The later instances are often thought of as a failure to plan but it is the contention of this work that they were the failure to plan adequately. Indeed, many of the serious problems of American cities today have been traced by sociologists, politicians, and urbanologists to the failures of past planning. The natural 
forward extension of this contention is that today's plans must be adequate to deal with problems that not only face cities today but also those that will face our cities some years from now. A logical correlary to this is that everything should be planned.

Three constraints serve to keep the urban planning profession away from this normative state of perfection. We cannot be sure of those aspects of past planning that contribute to urban malaise today; we cannot be sure of the consequences tomorrow of today's planning; and we do not have the resources to plan everything even if the causative relationships were known. Since none of these constraint:i seens likely to be overcome, urban planning will probalbly never reach a normative state of perfection. But it is contended here that the profession can advance toward this state of perfection by an easing of the three constraints. This easing can be accomplished by an investigation of the goals and objectives of the client constituency to establish the direction of remedial planning (the first constraint), the direction of prescriptive planning (the second constraint), and the allocation of scarce resources to this effort (the third constraint).

An investigation of the goals and objectives of the client requires citizen participation in the planning process, actual or vicarious. It is important to consider citizen participation as a process rather than as a product of this process (Chisholm, 1970) or an administrative necessity to gain funding. This process infuses and permeates the planning process to such a degree that both the planning and the goals and objectives of the client constituency change over time as a result of their interaction.

In discussing planning in a Swedish suburb Anton (1969) notes:

The goals of the various actors were developed in the process of bargaining itself, rather than existing as 
predetermined ideas in the minds of the actors. Since goal modification in exchange for political support was the essence of the bargaining process and since political support of a sufficient number of actors to produce agreement was essential for resolution of the issue, the outcome represented the final stage in a series of successive approximations to what was least objectionable rather than to what was most desirable. $1 *$

Two themes are emphasized in this comment. First, the foals and objectives of the client constituency change over time and the course of the planning process, and second, these same goals and objectives are used tr evaluate proposals and decide from among alternatives. A sample methodology for establishing the goals and objectives of the client constituency at the outset of the planning process follows in this chapter. Later in the work, and particularly in Chapter VII, several methods of evaluation are explored to decide from among alternatives.

The set of individuals comprising the client constituency can be analyzed in a manner similar to that depicted in Figure $1-1$. This set is actually a system of overlapping interests, some organizational and some issue oriented. At the apex rests the decision maker who will most probably play many roles. A single private developer way be the dispenser of monies, the arbiter of conflict, the representative of future occupants, etc. Similarly, at the apex might be a city planning commission, a private foundation, a federal agency, a city manager or any such conceivable employer of a professional urban planner. This is the usual point of entry for the planner into the system.

At the base rests the public at large characterized by a very limited knowledge of their city or cities in general, a very limited knowledge of the time and expense

* Superscript numbers refer to Notes at the end of the Chapter. 
of the planning process, and a very limited awareness of the interdependence of the elements that make up their city (Branch, 1968).

In between these extremes and at the apexes of various smaller figures are individuals with personal or altruistic interests in the plan. These individuals are the community leaders or responsibles of subsets of individuals within the community, and as such, they are influential in community affairs. These subsets are often called publics and almost everyone in the community can be said to participate in many publics; one say arising from his job, another from his ethnic origin, another from his religion, another from his Harital status, etc.

The methodology exampled here suggests the use of these community influentials to establish the goals and objectives of the client constituency. The arguments for this are threefold. First, the goals and objectives of the employer or even the employer/planner team are most probably not congruent with those of the client constituency. Second, the cost of establishing the goals and objectives of the client constituency as a whole, even by sampling methods, is prohibitive. There are many reasons for this, among them might be the need for a massive public education progran to enlighten the public at large. It cannot be denied that this would be a worthwhile endeavor of itself but it is probably outside the budgetary and professional scope of urban planning. Further, such an education and subsequent investigation of community values would take so long a period of time that the data might perish. Bolan (1967) writes that,

. values are continually changing, goals are shifting, priorities are varying - the public agenda never really stands still for one to mount a concentrated attack on it. Moreover the decision environment itself changes over time. Elections are won and lost, faces and personalities change, new laws are passed, and marginal adjustment of institutional structure continually occurs. 2 
The third argument for using community influentials to establish goals and objectives is that the community influentials themselves are in a position to aid in implementation of the plan, and thus tender their judgments not only upon hypothetical considerations, but also upon specific future conditions that they will work to see effected. Their prophecies tend toward self fulfillment. Further, to plan without taking the goals and objectives of the community influentials into account leaves the plan vulnerable to challenge by them.

The goals and objectives of the client constituency are estahlished and measured by the following three step process:

1. Identify the community influentials;

2. Have the community influentials develop the goals and objectives of the community;

3. Have the community influentials develop an order of precedence of these goals and objectives.

Much of what follows here regarding these steps was first elucidated in a work by Schimpeler (1967) in louisville.

\section{Identifying the Community Influentials}

There are several methods for identifying comminity influentials. The first consists of identifying those individuals who have the potential of being influential by virtue of their position in the client constituency. The employer of the planner would be identified here, if not elsewhere. other examples are elected or appointed officials, bank presidents, industrial magnates, leaders of civic organizations, major businessmen, prominent professionals, media directors, educators, and leaders of political parties.

Another method involves issue examination. For each issue area in the recent client constituency history, an attempt is made to establish who supported proposals that were adopted, or who successfully countered the proposals of others (Dah1, 1961). 
A third method begins with a panel of knowledgable citizens who are asked to select from the set of individuals in the client constituency (perhaps provided by methods one and two) those who are community influentials (Hunter, 1953). This process can be iterative and converging by then going to the selected influentials and asking them in turn to select from the list of selectees.

A fourth method recognizes the correlation between influence and participation in social and civic organizations such as the Chamber of Commerce, the Rotary club, etc. Persons who participate in many if these are probable influentials (01mstead, 1954).

A fifth method is to identify the relatively small number of individuals who hold, or have held policy making positions in a number of organizations. These interorganizational influentials then comprise a highly distilled and possibly closed network of influence that can be brought to bear on a given issue (Perrucci, 1970).

There appears to be no unanimous agreement among sociologists and political scientists as to the best method. Further, there is dissent on the degree that the methods -ffect the results (Perrucci, 1970) and whether the methods converge on the same set of influentials (Preston, 1969 and Fix, 1969).

Schimpeler noted that the Hunter Reputational Technique and the Position Potential Techniques can result in the broadest identification of community influentials.

The Development of Community Goals and Objectives

The community influentials are gathered together at what will most probably be a series of meetings extending over several weeks. They are given the charter by the planner or the planner/employer team to develop a set of goals and objectives for the community. Here the planner provides an extremely important function by providing seed ideas to 
insure that, over the course of these meetings, each facet of community development that he knows as a professional t.) lie important is considered by the committee. The planner wust be manifestly objective in this process and most careful not to inject his own values into the process. Further, his audience will be affected not only by what he says but by how he says it, in the same manner that the public may be affected not only by the physical characteristics of a presented plan, but also by its manner of presentation (Creighton, 1969). These seed ideas may take the form of tectures or discussions about prior studies or may even be an exarnination of the goals and objectives developed in conjunction with other plans. It is recommended that the planner provide this committee with an initial set of goals and wbjectives as a starting point from which the final set will evolve. Convergence on a single set will be much faster with some initial input, yet this will not preclude the formulation of goals and objectives in words meaningful to the committee. A sample set of goals and two levels of objectives is here provided in Table I-1 for the planner's consideration. It would be highly improbable that any connittee would completely accept the given set without substantial change.

Free discussion of the meaning of goals and objectives should ensue so that each participant and the planner are aware of the connotations of sometimes abstract terms. The goals and objectives should be well ordered in so far as their generality is concerned and there must be some aggregation of concept from the specific to the general. One suggested order is that goals be defined by several levels of objectives which are further defined by work items. If one participant feels very strongly about "providing pedestrian foot paths between residential areas", for instance, that can be a second order objective under "develop a balanced, effective, integrated transportation 


\section{Table I -1}

Sample Community Goals and Objectives ${ }^{3}$

A. Public Safety Program Development

1. Insure Safe Publicly Owned Facilities (excludes legislative action)

a. Insure the maintenance of public buildings (transit terminals, 1 ibraries, public offices, theaters, etc.)

b. Provide for safety through design, construction, maintenance, and operation of the transportation system (streets, highways, transit and sidewalks.)

c. Provide maintenance for the grounds and equipment of open space areas.

d. Insure well 1 ighted public areas.

e. Provide efficient emergency forces and facilities (civil defense, fire fighting, police, etc.)

2. Provide for adequate public and semi public facilities through safety regulations and their enforcement.

a. Insure the safe operation of transportation system.

b. Insure the control of dangerous goods and installations (explosives, chemicals, etc.)

c. Insure the safe installation and operation of public utilities.

d. Promotion of industrial safety.

B. Public Utility and Transportation Development .

1. Insure maximum effectiveness of public utilities, by design and locational considerations (electricity, telephone, water, sewers, and gas).

a. Location of various utilities should be coordinated.

b. Insure that all public utilities are provided in an area as necessary to assist the desired stage of development. 
Table 1-1, cont.

c. Extension of utilities must be done in an efficient and econonical manner.

2. Take measures and develop programs to minimize maintenance costs of public facilities.

a. Develop program of preventive maintenance and reduced maintenance costs.

b. Evaluate maintenance costs as a basis for selecting design.

3. Develop a balanced, effective and integrated transportation system which provides for the accessihility requirements of each land use.

it, Provide pedestrian footpaths between residential areas, schools, shopping centers and recreational areas.

b. Provide adequate arterial roads to insure rapid and safe movement to and from the area and also within the area.

c. Reduce the pedestrian-vehicular conflict in the CBD.

d. Provide alternative modes of travel to serve the various needs of people and activities as and where necessary.

e. Provide for the safe and convenient interchange between mode.

f. Leconomic Development Programs

1. Develop public improvement programs within available financial resources.

a. Provide capital works improvements which will provide for economic growth.

b. Provide improvements to maintain value inherent in existing facilities.

c. Establish priorities of capital works improvements on the basis of community's value system. 
Table 1-1, cont.

2. Insure effective utilization of mineral, vegetation, air and water resources.

a. Provide priorities for immediate and future water use.

b. Provide for flood control improvements.

c. Utilize available water resources for generating electric power.

d. Utilize fertile lands for the production of foodstuffs.

3. Establish a strong economic base through conumerce that will bring money into the community.

a. Achieve an external-internal favorahle balance of trade.

h. Diversify the community's economic base.

c. Promote the advantages of the community's recreational or tourist facilities.

d. Require or reserve sites for possible new thanufacturing or industrial facilities.

e. Provide utilities, streets, zoning changes, etc. for industrial or commercial use.

4. Insure the optimal utilization of all land.

a. Provide a comprehensive land use plan.

b. Provide proper and adequate zoning for the various land use forms.

c. Provide guidelines as to the proper location of buildings and utilities within the zones.

d. Establish a proper planning and control unit to advise on the proper use of available 1 and.

e. Establish desirable standards to be used for the setting up of the various land units. 
Table $\mathrm{I}-1$, cont.

5. Achieve increased disposable income for all people.

a. Training to provide skills for unskilled people and increase skill level of skilled people.

b. Increase number of available jobs, workers per family and/or number of hours worked per week.

c. Tie all salaries, wages and pensions to the Consumer Price Index.

d. Provide guaranteed minimum annual wage.

D. Cultural Development

1. Preserve historic sites and areas of natural beauty.

a. Promote formation of local citizens groups to identify sites and work for preservation.

b. Encourage private enterprise to purchase and preserve sites through tax incentives.

c. Establish a trust fund from federal taxes to be used for purchasing and preserving sites.

d. Encourage individuals to convert suitable private sites to public land through tax incentives.

e. Make awards for good design of housing developments, highways, etc., which preserves natural sites.

2. Promote adequate public 1ibraries, museums and cultural activities.

a. Provide neighborhood libraries as well as central 1ibraries.

b. Provide mobile libraries.

c. Provide or promote facilities for meeting places for neighborhood cultural and service groups.

d. Provide portable displays from museums and cultural centers for use in neighborhood school and social centers. 
Table I -1 , cont.

3. Protect meaningful focal tradition and encourage civic pride.

a. Promote civic committees and groups to observe important local traditions and historical dates and anniversaries.

b. Promote funds for operation of civic leagues.

k. Health Program Development

1. Regulate the provision and design of health facilities for the prevention and cure of disease.

a. Establish minimum standards for health facilities (hospitals, nursing homes, clinics).

b. Enforcement of the abofe standards .

2. Regulate the numbers and training required of personnel in health.

a. Establish minimum standards for personnel in health areas.

b. Enforcement of the above standards .

3. Provide for the removal of contaminants through community programs and regulations.

a. Provide sanitary sewers and treatment plant.

b. Provide storm sewers.

c. Provide for refuse collection and disposal.

d. Provide for street cleaning, snow and ice removal from publicly owned facilities.

e. Establishment and enforcement of air pollution control measures.

4. Provide for adequate public health facilities, personnel and programs for the prevention and cure of disease.

a. Provide training and education programs to enlighten the population to common nuisances or health hazards. 
Table $I-1$, cont.

b. Provide preventive medicine services.

c. Promote community programs and planning to eliminate mental and physical health sources.

d. Educate the population to health welfare services available and coordinate the programs.

F. Education program Development

Provide adequate personnel and facilities to insure

- basic (12 Year) education for all.

a. Improve coordination between schools in both the public and private sectors for economic utilization of resources and a unified effort.

b. Provide adequate primary education personnel and facilities.

c. Provide adequate high school education personnel and facilities.

d. Improve and update the curriculum on all above leve1s.

2. Provide adequate facilities and personnel for other educational programs.

a. Provide adequate pre-school facilities and personnel. (Headstart, nurseries, kindergarten, etc.)

b. Provide adequate colleges and personnel.

c. Provide adequate technical schools and staff. (vocational studies, job retraining, etc.)

d. Promote non-formal adult education.

G. Welfare Program Development

1. Eliminate injustice based on discrimination

a. Provide information to all communication media.

b. Provide a police force supervised by the people. 
Table I-1, cont.

c. Provide for correction of injustice through proper legal channels.

d. Promte media which encourage understanding be ween atl groups.

2. ocvelup needed public welfare programs.

a. Provide aid to the elderly.

b. Provide aid to unmarried nothers.

c. Provide special education and aid to handicapped people.

d. Provide a Day Care Center for families where both parents must work.

e. Provide medical assistance to needy people.

f. Provide informational centers for instructing eligible people of the services available.

3. Encourage development of religious opportunities.

a. Provide suitable building sites.

b. Provide for adequate parking facilities.

4. Develop an aesthetically pleasing environment.

a. Provide attractive structures.

b. Provide attractive landscaping .

c. Screen or remove objectionable land uses.

d. Eliminate objectionable advertising displays.

H. Recreation Program Development

1. Establish open space programs.

a. Provide sufficient space to meet the existing and future needs of the community.

b. Establish and design the open space in a pattern so that it provides a maximum of emenity and convenience. 
Table I -1 , cont.

2. Provide adequate recreational facilities utilizing places of natural resources and beauty and at places of greatest need.

a. Make all facilities flexible so that they insure economy and efficiency.

b. Provide standards and recreation programs that are compatible with cultural, social, and economic characteristics of the community.

c. Use recreational facilities as a developmental tool to reinforce patterns of land use consistent with community goals.

d. Make proper use of buffer zones.

1. Political Framework

1. Improve the framework for citizen participation in governmental functions.

a. Keep the public fully informed of governmental affairs to ensure an awareness of issues, objectives and decisions (using the various mass news media, public meetings, exhibitions, etc.)

b. Develop in people a sense of personal participation and responsibility (using citizen meetings and/or committees).

c. Encourage people to voice opinions and to discuss issues so that those making decisions will be better able to judge what is in the best interests of the community as a whole.

2. Establish equitable taxation policies (bases, mix, rates).

a. Policies to provide the needed revenue, compatible with the community's ability to pay the taxes.

b. Make policies completely rational and equitable, free from any form of discrimination or favoritism. 
Table I-1, cont.

c. Ensure that tax assessors are adequately trained and skilled to prevent taxation injustices.

d. Select tax bases that are easily understood and accurately and easily collected.

3. Develop an effective governmental administration.

a. Ensure an efficient management structure within the administration.

b. All staff appointments to be made on the basis of capability and special skills (not on seniority or political affiliations).

c. Fix salary levels and conditions for staff so that the best available people are attracted.

d. Ensure that decision making at all levels is free from any political considerations.

e. Ensure full co-ordination and 1 iason between governmental agencies and also with private enterprise (to enable a ready exchange of aid, ideas and information).

4. Establish sound governmental fiscal programs.

a. Examine all existing and possible new sources of revenue to ensure that all possible revenue is channeled into the fiscal programs.

b. Ensure that programs achieve the optimum balance between the community's goals and the finance available.

c. Ensure that programs are realistic (i.e. within the economic capability of the community).

d. Coordinate expenditures necessary for the initial plan implementation.

5. Develop an effective area-wide planning process.

a. Establish a permanent planning organization for the area. 
Table I-1, cont.

b. Ensure that planning is a continuing process by up-dating and review.

c. Set up regional committees to provide for representation of each local government unit in the area in the planning process.

d. Promote funds for research and development in fields concerning urban development.

e. Promrte funds for research and development (in the planning sphere) necessary to continually improve the plan as conditions and technology change.

6. Establish effective regulations and control mechanisms.

a. Thoroughly review all existing legislation within the city (establishing any that are missing, removing any anomalies, etc.)

b. Legislate for effective land use zoning controls.

c. Legislate for effective land access controls (to enable more efficient arterial usage).

d. Legislate for effective controls on all nuisances impairing the uroar. anvironment.

1. Housing Developmient

1. Encourage rehabilitation and conservation of neighborhood programs.

a. Provide incentives for owner's improving by conservation or rehabilitation.

b. Provide public work improvements to encourage conservation and rehabilitation.

2. Provide adequate low cost housing.

a. Provide for low cost rental housing.

b. Provide for increased ownership of low cost housing unit. 
Table I-1, cont.

3. Develop neighborhood Programs.

a. Provide delimiting boundaries.

b. Provide a central social and cultural institution.

c. Provide for recreational and open space facilities.

d. Provide for convenient shopping.

e. Provide for a safe circulation program.

f. Provide for the esthetics of the neighborhood.

g. Provide for adequate land use in the neighborhood.

h. Provide for auxillary activity facilities.

4. Promote a wide variety of housing types as required within the community.

a. Provide for various choice of housing types.

b. Provide for adequate design and esthetics of units.

c. Provide for densities of structures.

d. Provide for various area densities. 
system which provides for the accessibility requirements of each land use" which is itself a first order objective under the goal "public utility and transportation developnent". Some such ordering of generality is necessary for the purposes of comparison and evaluation. The assignment ot work items to define specific objectives in specific commity situations is a matter for the goal formulation conmitlee.

1t is important for the planner to be prepared for an iterative and painstaking analysis. The planner inject: iveas, the participants respond, the planner injects, the participants respond, etc.

After the fourth or fifth trip around the cycle the elements which pass through the screen of democratic approval accord more and more closely with the value system of the people in the community. In the process, the idea formulator himself has been tempered with the heat of his confrontation with his peers, and he himself, perhaps unwittingly, has become a inore sensitive instrument more closely atuned to cotnmunity values. 4

The Ordering of Comnunity Goals and Objectives

The placing of the formulated goals and objectives into an order is relatively easy using any of the three netluds described below. These methods can he used to oruer the goals and then to order the objectives within. each goal. The term "criterion" is used to mean cither a goal or an objective as applicable.

In a ranking method, each of the participant community influentials gives to the most important criterion the value 1 , the second most important criterion, the value 2 , etc.

If there are $n$ criteria and m participants, the plimner converts each rank by subtracting it from $n$. Thus - cunverted rank of $\mathrm{n}-1$ is assigned the criterion receiving Lhe raw rank of $1, n-2$ for the criterion receiving the riw rank of 2 , etc. The composite rank $\left(R_{j}\right)$ for a given 
criterion ( $j$ ) is the sum of the converted ranks of all the in judges.

$$
R_{j}=\sum_{i=1}^{m} R_{i j}, j=1,2, \ldots . n-1, n .
$$

A normalized utility value $\left(u_{j}\right)$ associated with each eriterion $j$ over all the participants is then:

$$
u_{j}=\frac{R_{j}}{\sum_{j=1}^{n} R_{j}}, j=1,2, \ldots . .
$$

\begin{tabular}{|c|c|c|c|c|}
\hline & a & b & c & d \\
\hline$C \quad A$ & 1 & 2 & 2 & 3 \\
\hline B & 2 & 4 & 1 & 2 \\
\hline C & 3 & 3 & 4 & 1 \\
\hline D & 4 & 1 & 3 & 4 \\
\hline
\end{tabular}

An example follows.

Participants

\begin{tabular}{|c|c|c|c|c|}
\hline & a & b & c & $d$ \\
\hline A & 3 & 2 & 2 & 1 \\
\hline$B$ & 2 & 0 & 3 & 2 \\
\hline C & 1 & 1 & 0 & 3 \\
\hline D & 0 & 3 & 1 & 0 \\
\hline
\end{tabular}

Raw Ranks
Participants

Converted Ranks 




Composite Ranks

$$
\begin{array}{llll}
\text { C } & \text { A } & 8 / 24=.333 \\
r & & & \\
\text { i } & \text { B } & 7 / 24 & =.292 \\
\text { t } & & \\
\text { e } & \text { C } & 5 / 24 & =.208 \\
\text { r } & \text { i } & \\
\text { a } & \text { D } & 4 / 74 & =\frac{.167}{1.000}
\end{array}
$$

Utility Values

A rating technique may also be employed with essentially the same mathematics. In this case, a list of criteria is placed adjacent to a scale marked in units continuously from, say, 10 to 0 . A rating of 0 indicates no value and a rating of 10 , the highest possible value. Any value (including duplicates) along the continuum may be assigned to any criterion. This avoids the conversion step in the previous method and, as hefore,

$$
R_{j}=\sum_{i=1}^{m} R_{i j}, j=1,2, \ldots n-1, n
$$

and,

$$
u_{j}=\frac{R_{j}}{n}, j=1,2, \ldots . .
$$


Yet anothez way of ordering the criteria was developed 4 Schimpeler, (1967) modifying a method developed by Churchman and Ackoff (1954). Let the symbol $\}$ be read "is preferred to". If criterion $\mathrm{f}$ is preferred to atiterion $\left.k, G_{j}\right\} \quad G_{k}$, then $u_{j}>u_{k}$. Let this symbol $\sim$ be read "is indifferent to". If $G_{j} \sim G_{k}$, then $u_{j}=u_{k}$.

Step 1. Rank the criteria according to preference (perhaps according to methods one and two);

$$
\begin{aligned}
& \left.\mathrm{G}_{1} \underset{\sim}{\mathcal{\sim}} \mathrm{G}_{2} \mathrm{G}_{3}\right\} \\
& \left.\left.G_{n-1}\right\}_{n} G_{n} \text {, where } G_{1}\right\} \quad G_{n} \text {. }
\end{aligned}
$$

Step 2. Tentatively assign the value $u_{1}^{\prime}=1$ to $G_{1}$. Assign tentative utility values to the remaining criteria according to their approximate preference.

\section{$\mathrm{n}$}

Step 3. If $\left.G_{1}\right\} \bigwedge \quad G_{j}$ (the remaining criteria $\mathrm{j}=2$

taken together), adjust $u_{i}^{\prime}$ so that $\left.u_{i}^{\prime}\right\rangle \sum_{j=2}^{n} u_{j}$

and proceed to step 4. If $G_{1} \sim \bigwedge_{j}$,

$$
j=2
$$

adjust $u_{i}^{\prime}$ so that $u_{i}=\sum_{j=2}^{n} u_{j}^{\prime}$ and 
proceed to step 4.



n

$u_{i}<\sum_{j=2} u_{j}^{j}$. Then drop the least

preferred criterion, $G_{n}$, from consideration and repeat step 3 . Continue this process

until $G_{1} \prod_{j=2}^{P} G_{j}$ where $G_{p}$ is the least

perferred criterion of all the remainder

taken together when $G_{1}$ first hecomes preferred or indifferent to this combination.

Step 4. Drop the most preferred criterion $G_{1}$ from consideration and repeat the entire proceedure for $\mathrm{G}_{2}$, and $\mathrm{G}_{3}$, etc., until the last comparison; i.e., $G_{n-2}$ versus $G_{n-1} \bigwedge G_{n}$ is completed.

Step 5. The tentativeutility values are then normalized before




To carry foreward the previous example, assune that a participant judge maintains the following relationships among criteria:

$$
\begin{aligned}
& \mathrm{G}_{\mathrm{a}}\left\{\mathrm{G}_{\mathrm{b}} \wedge \mathrm{G}_{\mathrm{c}} \wedge \mathrm{G}_{\mathrm{d}^{\prime}}\right. \\
& \left.\mathrm{c}_{\mathrm{a}}\right\} \mathrm{G}_{\mathrm{b}} \wedge \mathrm{G}_{\mathrm{c}^{\prime}} \\
& \mathrm{G}_{\mathrm{h}}\left\{\mathrm{G}_{\mathrm{c}} \wedge \mathrm{G}_{\mathrm{d}^{\prime}}\right. \\
& \left.\mathrm{G}_{\mathrm{b}}\right\} \mathrm{G}_{\mathrm{c}^{\prime}} \text { and } \\
& \mathrm{G}_{\mathrm{c}} \sim \mathrm{G}_{\mathrm{d}^{*}}
\end{aligned}
$$

Then for $u_{a}^{\prime}, u_{a}^{\prime}=1, u_{b}^{\prime}=.8, u_{c}^{\prime}=.6, u_{d}^{\prime}=.5$ and

$$
u_{a}^{\prime}=1<\sum_{j=b}^{d} u_{j}^{c}=1.9 \text { is in consonance with the }
$$

judge's preferences.

Dropping $G_{d}$ from consideration, we find that

$$
u_{j}^{\prime}=1<\sum_{j=b}^{c} u_{j}^{\prime}=1.4 \text {, which is counter to the }
$$

judge's preferences. Therefore $u_{a}^{\prime}$ must be adjusted upward to, say, 1.5 , and $G_{a}$ is dropped from consideration.

$$
\text { Then for } u_{b}^{\prime}, u_{b}^{\prime}=.8<\sum_{j=c} u_{j}^{\prime}=.9 \text { is in }
$$

consonance with the judge's preferences.

Dropping $G_{d}$ from cousideration, we find that $\mathrm{u}_{\mathrm{b}}^{\prime}-.8>\mathrm{u}_{\mathrm{c}}^{\prime}=.6$ which is in consonance with the judge's preferences. $G_{b}$ is dropped from consideration. 
Then for $u_{c}^{\prime}, u_{c}^{\prime}=.6>u_{d}^{\prime}=.5$ and this is counter to the judge's preferences which reflect that this pair is indifferent. $u_{c}^{\prime}$ is then adjusted to .5 to reflect this indifference and the iterations end.

The new relationships are thus:

$$
\begin{aligned}
& u_{a}^{\prime}=1.5, \\
& u_{b}^{\prime}=.8, \\
& u_{c}^{\prime}=u_{d}^{\prime}=.5, \text { and the associated normalized utility } \\
& \text { values are, } \\
& u_{a}^{\prime}=1.5 / 3.3=.454 \\
& u_{b}^{\prime}=.8 / 3.3=.242 \\
& u_{c}^{\prime}=.5 / 3.3=.152 \\
& u_{d}^{\prime}=.5 / 3.3=\frac{.152}{1.000} .
\end{aligned}
$$

In this manner, each goal is compared to all the ther goals, each first order objective defining a goal $i+$ compared to the other first order objectives defining that same goal, and each second order objective defining a Eirst order objective is compared to the other second urder objectives defining that same first order objective.

What results then, are utility values for each subset of criteria which then must be normalized over the entire set of criteria. The normalizing is easily done by multiplying the appropriate utility values.

Suppose that the previous example was a comparison of goals, there being only four in this case.

$$
\begin{aligned}
& \mathrm{u}_{\mathrm{A}}=.454 \\
& \mathrm{u}_{\mathrm{B}}=.242 \\
& \mathrm{u}_{\mathrm{C}}=.152 \\
& \mathrm{u}_{\mathrm{D}}=\frac{.152}{1.000}
\end{aligned}
$$


Suppose that goal A was defined by five first order objectives with the following utility values;

$$
\begin{aligned}
& u_{A 1}^{\prime}=.222 \\
& u_{A 2}^{\prime}=.306 \\
& u_{A 3}^{\prime}=.150 \\
& u_{A 4}^{\prime}=.176 \\
& u_{A 5}^{\prime}=\frac{.146}{1.000},
\end{aligned}
$$

and that first order objective Al was defined by seven second order objectives with the following utility values;

$$
\begin{aligned}
& u_{A 1 a}^{\prime}=.102 \\
& u_{A 1 b}^{\prime}=.130 \\
& u_{A 1 c}^{\prime}=.176 \\
& u_{A 1 d}^{\prime}=.170 \\
& u_{A 1 e}^{\prime}=.200 \\
& u_{A 1 f}^{\prime}=.050 \\
& u_{A 1 g}^{\prime}=\frac{.172}{1.000} .
\end{aligned}
$$

Let $v_{i}$ equal the utility of goal $i, v_{i j}^{j}$, equal the non-normalized utility of first order objective i defining goal $i$, and $v_{i j}$ equal the normalized utility of first order objective $j$ defining goal $i$.

Then $v_{i j}$ equals $v_{i} \times v_{i j}^{\prime}$

and

$$
\sum_{j=1}^{n} v_{i j}=v_{i}, \begin{aligned}
& \text { for n first order objectives } \\
& \text { defining goal } i \text {. }
\end{aligned}
$$

Similarly, let $\mathrm{v}_{i j k}^{\prime}$ equal the non-normalized utility of second order objective $k$ defining first order objective $i$, and $v_{i j k}$ the normalized utility of second order objective $k$ defining first order objective $j$. 
Then $U_{i j k}=U_{i j} \times U_{i j k}^{\prime}$

and



$$
U_{i j k}=U_{i j}, \begin{aligned}
& \text { for m second order objectives } \\
& \text { defining first order objective } \\
& \text { gowich, in turn, defines } \\
& \text { goal } i \text {. }
\end{aligned}
$$

It follows then that, for $p$ goals,
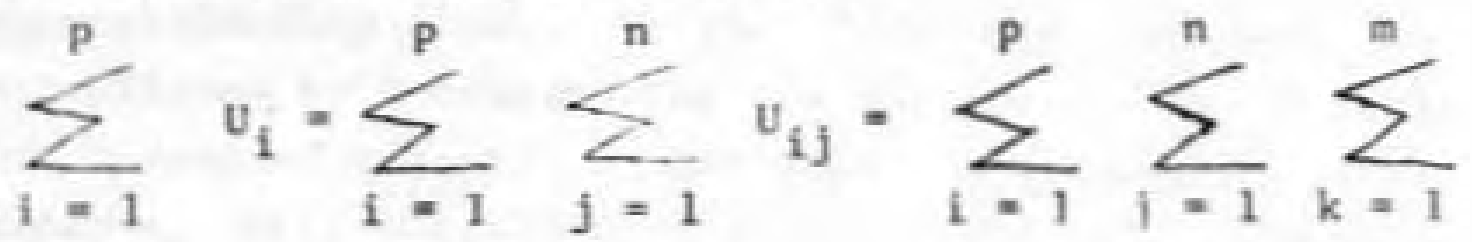

$v_{i j k}=1$.

In the example,

$$
\begin{aligned}
& U_{A 1}=U_{A} \times U_{A 1}^{\prime}=.454 \times .222=.101 \\
& U_{A 2}=U_{A} \times U_{A 2}^{\prime}=.454 \times .306=.139 \\
& U_{A 3}=U_{A} \times U_{A 3}^{\prime}=.454 \times .150=.068 \\
& U_{A 4}=U_{A} \times U_{A 4}^{\prime}=.454 \times .176=.080 \\
& U_{A 5}=U_{A} \times U_{A 5}^{\prime}=.454 \times .146=\frac{.066}{.454},
\end{aligned}
$$

and

$$
\begin{aligned}
& U_{A 1 a}=U_{A 1} \times U_{A 1 a}^{\prime}=.101 \times .102=.0103 \\
& U_{A 1 b}=U_{A 1} \times U_{A 1 b}^{\prime}=.101 \times .130=.0131 \\
& U_{A 1 c}=U_{A 1} \times U_{A 1 c}^{\prime}=.101 \times .176=.0178 \\
& U_{A 1 d}=U_{A 1} \times U_{A 1 d}^{\prime}=.101 \times .170=.0172 \\
& U_{A 1 e}=U_{A 1} \times U_{A 1 e}^{\prime}=.101 \times .200=.0202 \\
& U_{A 1 f}=U_{A 1} \times U_{A 1 f}^{\prime}=.101 \times .050=.0050 \\
& U_{A 1 g}=U_{A 1} \times U_{A 1 g}^{\prime}=.101 \times .172=.0174
\end{aligned}
$$


This chapter closes with a discussion of some of the pitfalls that await the unwary planner. The concept of using community influentials as advocates of the client constituency is obviously a middle road. On one hand, it is proposed that the value system so established more accurately reflects that of the client constituency than if this value system were established or assumed by the planner working alone. On the other hand, the value system established by investigating the full set of individuals (or a sampled subset) is considered to be an unnecessary expense. Many social scientists and planners will find fault with this, and with good reason. But it must be remembered that real life situations are constrained by time and money and the process described here bends rigor to gain feasibility. An obvious matter of further research would be to measure just how closely such a process approximates the values of the community as a whole, taking into account the aforementioned problem of public education in planning, the great area of indifference to specific proposals, the transient nature of some residents and the apathy of others. A11 these and other factors mitigate against consensus.

The time dependency of community influence has been discussed. The planner should be sure that the process described herein is brought to an expeditious conclusion and that the values can survive the time span required to use them in planning and execution. The process described here bends rigor to gain speed.

Community leaders themselves are biased. Participants should be instructed to seek some measure of selflessness in considering goals and objectives. Some residual bias is not necessarily a fatal defect however, as this bias is presumably apparent to and supported by the power base of each position of community influence. 
Some leaders may not want to disclose their position of influence and some may not have the time to participate in the moderately lengthy negotiations. These factors should be considered in the selection of the goal formulation participants. There is the further danger that some genuine leaders may not be identified in the process and thereby made opponents of.

Some of the publics identified in Figure I-1 may have no leaders, or may constitute such minorities that they might be ignored by the mechanics of the identification process. The planner may have to devise safeguards to protect their best interests.

Finally, the goals and objectives developed by the client constituency influentials may run counter to the professional opinion of the planner.

As in the legal profession, client's defined objectives, priorities, and ultimate strategies take precedence over those of the professional as 1 ng as the professional-client relationship exists, but the professional can always opt out if selected value systems and defined courses of action cause moral or professional anguish. 5

The goals and objectives developed, weighed and measured by the community influentials become, in the last analysis, a kind of counsel to the planner and to the decision maker. The latter takes this counsel, adds his cwn political, economic, and managerial intelligence, and decides how to allocate resources to the planning effort. He decides what, if anything, needs planning most. If this decision specifies some planning, then the planner takes that direction, adds the counsel of the community influentials, and plans.

\section{$\underline{\text { Notes }}$}

1. Thomas J. Anton, "Politics and Planning in a Swedish Suburb," p. 262 . 
2. Richard S. Bolan, "Emerging Views of Planning," p. 243.

3. William L. Grecco, "Planning Methodology and Techniques," Course C.E. 613, Purdue University, West Lafayette, Indiana. These goals and objectives were developed by Dr. Grecco and his students over several years during the conduct of this course. The set given is as of 1971 .

4. Ednund N. Bacon, "Urban Process," The Conscience of the City, p. 1169.

5. Marsha11 Kaplan, "Advocacy and the Urban Poor," p. 97. 


\section{CHAPTER II}

ORGANIZATION

In 1968, the American Institute of Planners committed itself to consider social and economic development planning in addition to physical planning in future professional endeavors. Wetmore (1970) relates how the Committee on Restatement of Institute Purposes found a cube diagrain to be particularly helpful in visualizing the extent of comprehensive planning.

This Chapter introduces a modified and refined version of that cube, the investigation of which forms the basis for the organization of any planning effort. Subsequent chapters will again refer to this cube from time to time. This cube is hypothesized to be an adequate conceptual model of planning activity.

\section{A Conceptual Model of Planning Activity}

Consider the cube illustrated in Figure II-I. One axis defines the areal scope of planning activity. This axis is bounded at one extreme by the largest physical area that can be considered in planning, the universe. At the other extreme is the smallest area, perhaps a single room in a dwelling. In reality, of course, these limits are only approached and in between them lie the more commonly investigated areas of nation, state, region, urban area, city, community, neighborhood, parcel, etc.

Another axis defines the substantive scope of planning, from the most comprehensive to the most limited. At the comprehensive limit of this axis, planning escalates into policy making and at the limited extreme, planning 


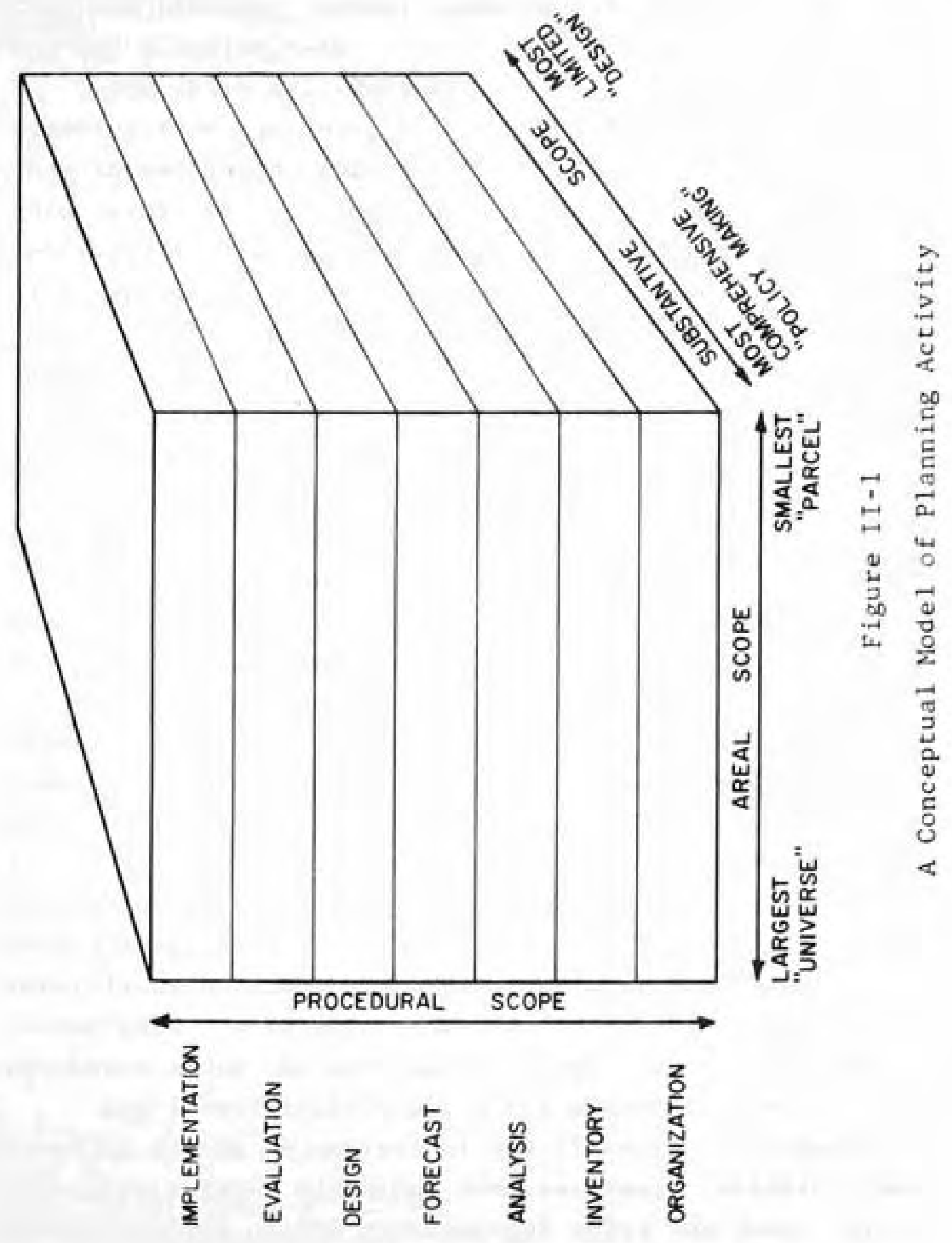


becomes, in fact, design. The limits of this axis are also only approached in applied planning and in between lic the familiar "comprehensive" planning, economic planning, land use planning, school planning, recreation planning, tot lot planning, etc.

The third axis defines the procedural scope of plinning from beginning to end. The basic framework of this investigation reflects the contention that, of the three axes, this is the most clearly bounded, the most analytically discrete and the most easily understood. This axis maps the planning process through its seven rational phises; organization, inventory, analysis, forecasting, design, evaluation, and implementation. This axis is generic to any planning irrespective of its substantive or areal scope.

Consider a single element in this model as illustrated in Figure II-2. Let this single element represent an event in the planning process. Disregarding model boundary conditions, this event is procedurally preceeded by another event and followed by a third event. Even if this one event runs concurrent with many others, it and the others each have a precedent and an ensuing event in real time. The inescapable passage of time forces this relationship and thereby provides the methodological basis for an investigation of the planning process. An ordering of this event with respect to its precedents and its ensuing events identifies it along one axis of the cube. This identification enables the planner to systematically investigate the relationships of this event with its neighbors along the substantive scope and areal scope axes.

Any identification along the areal scope axis is a function of the objectives of the client constituancy, the prior related planning, the resources available, and the boundaries of the governmental units involved. Any identification along the substantive scope axis is a 





function of the first three factors above, as well as being a function of the necessary precursors in planning, is a population study and an economic base study are necessary precursor: to land use planning.

Consider, by way of example, that event defined by the intersection of "comunity", "land use", and "forecast" alung the areal, substantive and procedural scope axes respectively. This is illustrated in Figure IT -3 .

occurring at a point in time before the comnunity land use forecast must be a community land use analysis; that is, the structuring of the base data to accurately portray the state of community land use at a point in time and from which forecasting will be made. Occurring at a point in time after the community land use forecast will be one or more community land use designs based upon the forecasted data. These relationships are procedural and cccur along the procedural scope axis.

Along the areal scope axis there are two problems. First, the area of the element itself nust be defined in space. Second, the relationships of that elemental area to that that includes it, possibly here called the region, and to those that make up it, possibly here called neighborhoods, must be explored. The use of this conceptual model forces the planner to make these explicit considerations, generally called delimiting the study area .

Along the substantive scope axis of the mode1, the planner is forced to fit the plan in question into a hierarchy of planning, recognizing that some plans are so general as to be policy statements which generally recommend further planning. Further, as plans become more limited in substantive scope, they tend toward specific design measures and action programs which have more apparent impact on the community. As plans tend toward specific designs they draw upon explicit or assumed or intuitive prior 


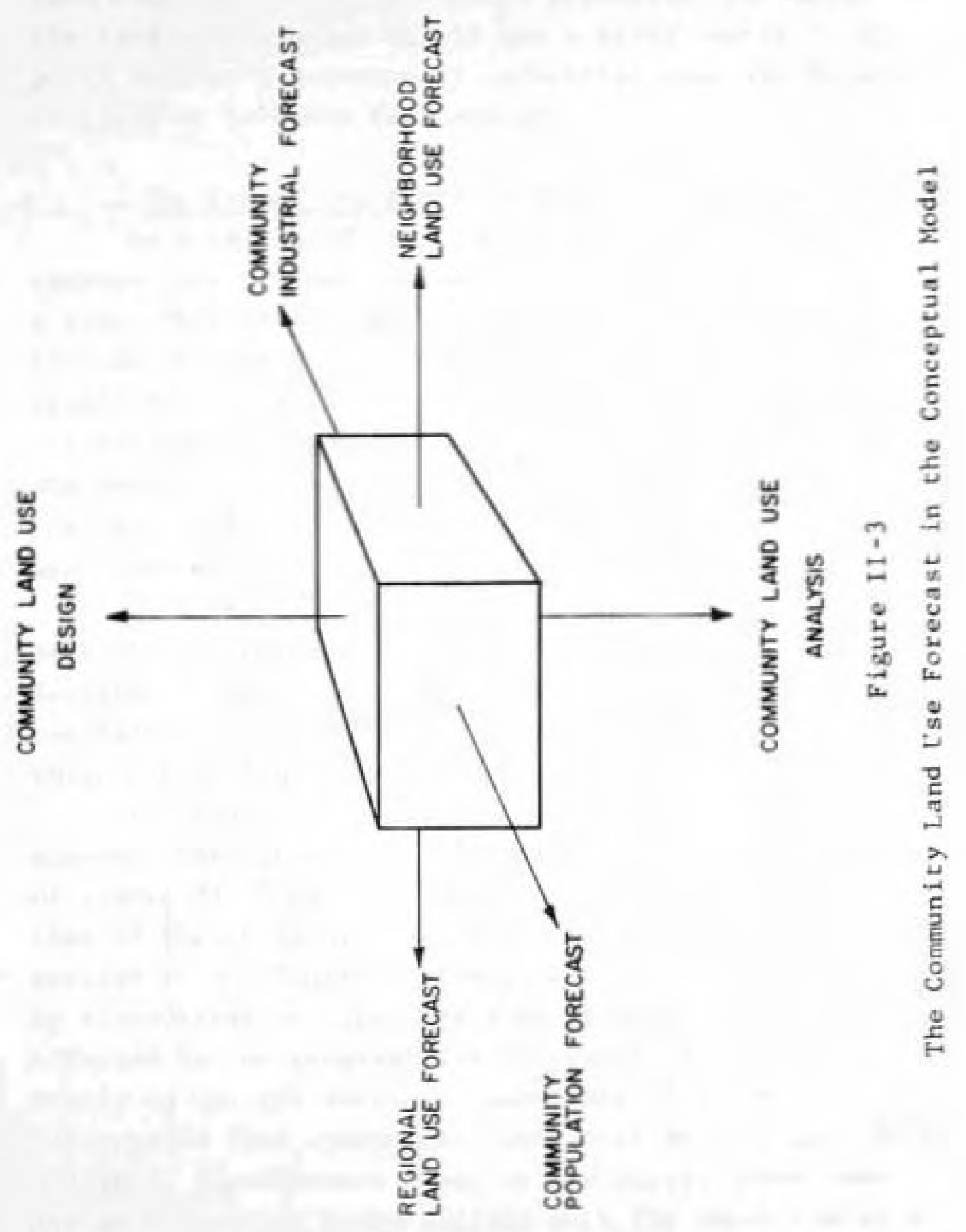


planning as necessary precursors. Thus the community land use forecast must be based on some higher order information contained in the community population forecast, and the land use forecast itself has a relationship to its parts such as the community industrial land use forecast, residential land use forecast, etc.

The Use of the Model in Planning Organization

As a result of the process described in the last chapter, the planner has been given a charter to develop a plan. This development logically begins with an investigation of the plane of the model cube defined by the substantive scope axis and the areal scope axis. This is illustrated in Figure II 4 and the planner must now set the boundary conditions of his effort and design a study that will fulfill the goals of his client constituency as near optimally as possible.

Considering first an investigation of the areal scope axis, it is apparent that any chosen houndary must be a function of the type of study to be done. Given this, the factors to be considered can be thought of as comprising three catagories, socio-economic, physical and political.

It is difficult to cite some examples of socioeconomic influences on areal scope outside of the context of a specific kind of study. Nonetheless it seems apparent that if the study deals with a service such as those available in a Central Business District, or those provided by transportation, that the area studied will be markedly affected by the geographical distribution of those people likely to use the service. Sometimes this can be interpreted from symptomatic data such as the agricultural milkshed, the commuter shed, or the retail trade shed. Any such planning study dealing with the provision of a service and thereby satisfying a demand can probably best be delimited by setting thresholds of maximum and minimum 


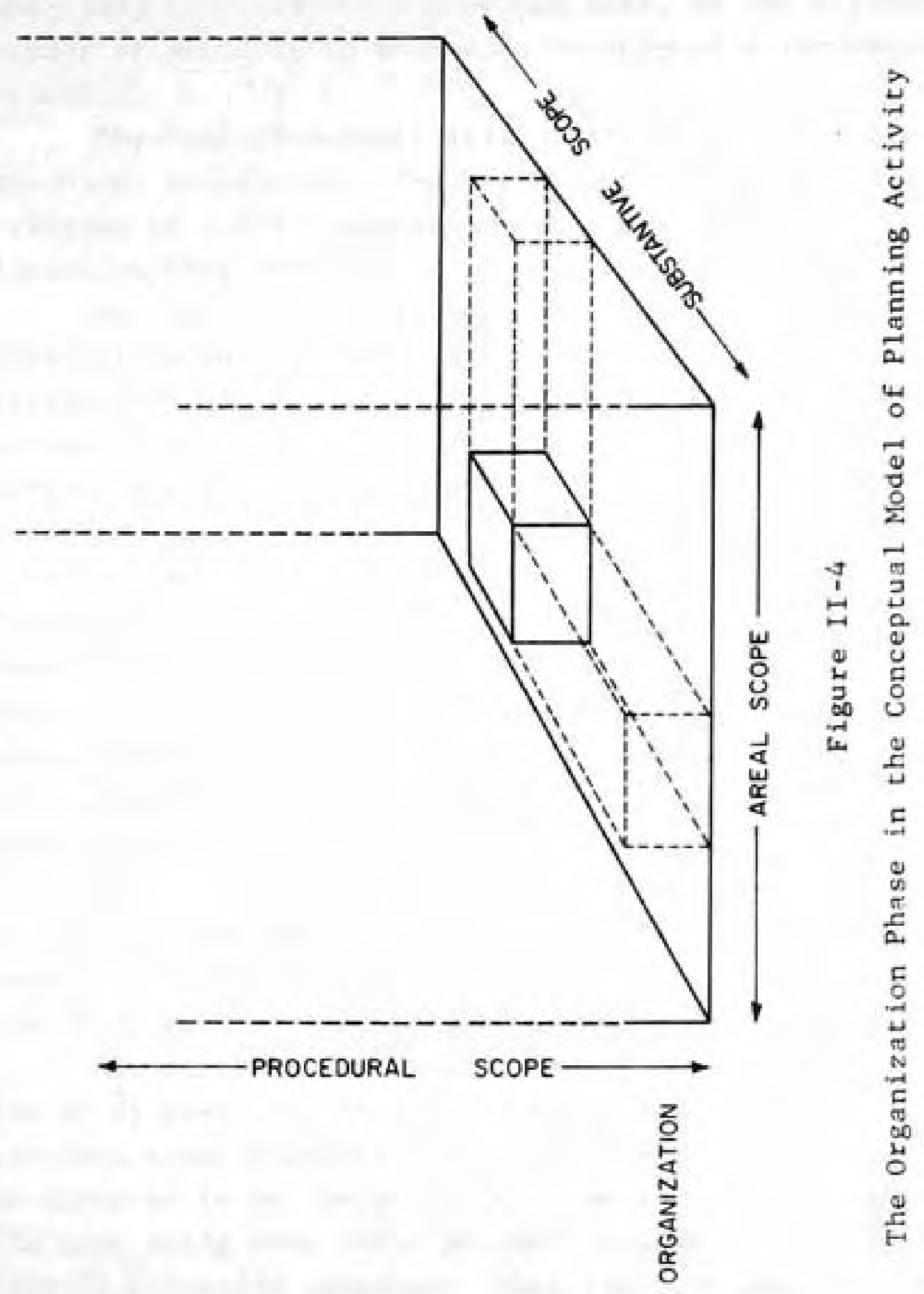


areal size. The minimum areal size may be also a functional consideration of the facility such as the minimum number and types of stores in a shopping area, or the minimum number of students to economically support a secondary school.

Physical characteristics of the area set some geographical boundaries. The building of a highway or the bridging of a river may extend the study area more in one direction than another.

Much of the analysis of both socio-economic and physical factors lends itself to graphical interpretation. Figure II -5 displays the often encountered shapes of demand curves of the plots of distance (or time as a measure of distance) versus the cumulative percentage of people whose needs are satisfied at this distance. The factors plotted could be "secondary school students walking to school" or "metropolitan newspaper deliveries" or "patrons of a amusement park" or any such factor bearing on the study at hand. The abscissa measures the "friction of space". The slope changes indicated could be interpreted as occuring at that point of distance, the threshold, where a marginal increase of the factor loses significance.

Those factors deemed to be important and representative by the planner could then be plotted on a map of suitable scale and some approximation made of a 1 imit to the study area suitable for them all.

One of the most important influences in delimiting the study area is political. If a governmental agency provides some or all of the funds, the study boundary could be directed to be the political boundary of that agency. The same holds true for a private employer. If outside factors are still important, they can sometimes be simulated as "influence sources" or "influence sinks" at the appropriate edges of the study area. 


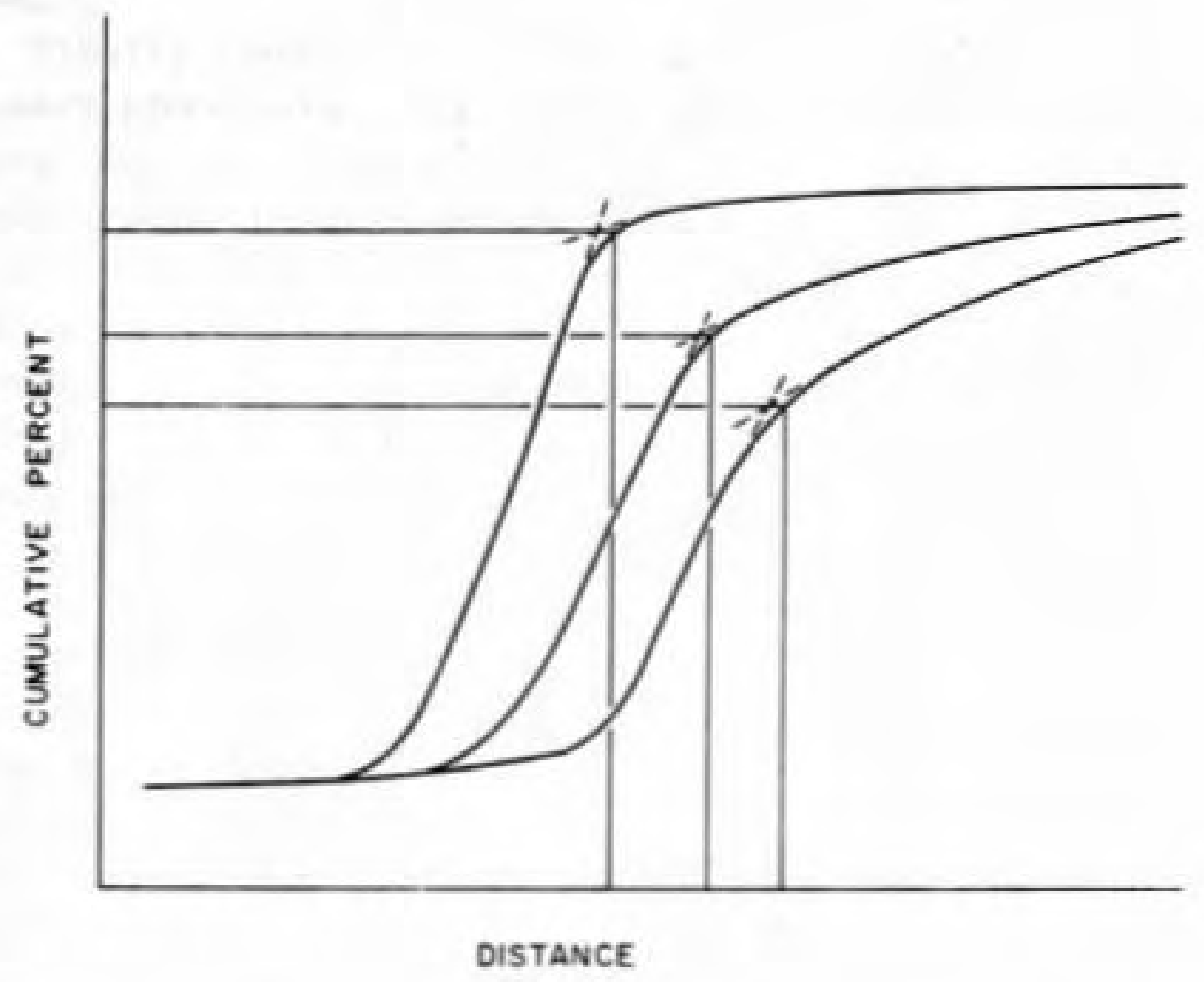

Figure II -5

Conceptual Demand Curves 
There are two remaining decisions to be made regarding delimiting the study area. One must always consider the extent of the resources available for planning. Nearly every resource can be reduced to dollars and for any effort the dollars available must at least equal the dollars needed.

Finally there remains the concept of prior work and necessary precursors. If, for instance, the planner is directed to study housing in an area, and there exists accurate recent population data for a somewhat larger or smaller or overlapping area, he must consider the cost of adapting these data to his proposed area versus changing his area to fit the existing data base. This leads directly to the investigation of the other axis defining the organizational plane in Figure II -4 , and the concept of a hierarchy of planning.

This other axis is used to measure the substantive scope of planning and reflects the existence of a hierarchy of planning. By hierarchy of planning, it is recognized that different plans may address the same subject in different detail. One would not logically find a timing order for sequential traffic signals on Main Street in a comprehensive plan, although that plan will offer the general scheme for a desired transportation system. A next lower order plan, the transportation plan, will probably continue to refine this subject but the timing order would probably be designed in a still lower order plan, the major thoroughfare plan. In the same nanner, a comprehensive plan may speak of school locations by comunity, a land use plan may designate a large parcel for school development, a school plan may site the school, and finally an architect/engineer designs the building. One would not logically find the siting considerations or the building design in the comprehensive plan. 
These examples demonstrate that there is an order of generality and comprehensiveness in planning, from the management of gross data over comprehensive consideration to the management of specific data over limited consideration. This same axis measures the orderly development of planning from policy making to design, from the general to the specific.

Unfortunately for the reputation of planning as a profession, this means that the results of some plans are mandates for further planning. So to counteract Ihis, one sometimes finds the most amazingly discrete recomendations in otherwise broadly comprehensive plans. This is a forced consideration, however, and one that does not immediately follow from the scope of data considered. In general though, the order of planning measured along the substantive scope axis is relative, with higher order plans dealing with gross data, many disparate factors for consideration, and being policy oriented. Lower order plans are concerned with specific data, allied factors for consideration, and action programs and specific designs.

Ideally, a planner should be directed to plan in this natural progression from the general to the specific. Various factors, some political and some arising from competition for scarce resources, sometimes force the planner to "start in the iniddle". If, for instance, a client constituency wants a land use plan and has no comprehensive plan, population or economic base studies, the planner must compensate for this by designing that land use planning process if not to overcome, at least to ease the impact of the absence of this higher order policy and data. He may design the study to incorporate some of the major elements of population and economic base studies and term the resultant land use plan as "interim" pending the results of recommended further study. In this case, the population and economic base studies are necessary 
precursors to 1 and use planning and, if they do not exist, the planner must compensate for this in the study design.

\section{The Use of the Model in Study Design}

The design of an urban planning process is called a study design. A study design often is comprised of three types of documents, a prospectus, the study design itself, and one or more procedural or operational manuals,

A prospectus is a highly distilled general statement of the objectives of a particular study, the role of various agencies and participants in the study, the general process to be followed, some gross estimate of the time involved and a gross estimate of the cost. The objectives stated are those of a particular study which follow from, and should not be confused with, the goals and objectives of the client constituency in the meaning of Chapter I. This is a most sensitive document to author as it is used to justify funding of the study design. Many times the prospectus is prepared with very limited funds in the hope that the ensuing justification will provide funds to cuver its costs. Great care should be taken in the wording of the study objectives so that if subsequent investigation reveals that these objectives are for some reason not suitable, they may be amended without threatening the funding. Even more care should be taken to insure that any cost figures given are sufficient to complete the study design. The prospectus is the document prepared to make an initial estimate of the study feasibility and to fund the study design, and these funds should not be confused with those generated by and justified by the study design to do the actual planning. The finished prospectus presents decision makers with a basis to judge whether or not to proceed with the study design. As such it is a decision point for the sometimes many sponsoring agencies involved. In the case where the single private developer is the 
decision-maker, this process of evolving a prospectus could well be carried out orally, Given the decision and the funds to proceed, the next step is to design the study.

The study design itself is a work program formalation of the steps necessary to do the planning. It is somewhat similar to this discussion in that it is not the planning but instead the planning methodology. It should define what is to be done, who is to do it, when it will be done and how much it will cost.

Here the conceptual model of planning activity is most valuable. Figure II-6(a) shows the ideal structuring of the planning process. Here all necessary higher order planning has been accomplished, there is no major interaction with greater or smaller geographic areas, all necessary precursors are present, policy is set and the planner can proceed up the procedural axis from organization to implementation in designing the study.

It is much more likely however that the elemental interface considerations forced by the conceptual use of the model will disclose vacancies in higher order planning, elemental interaction with greater or lesser geographic areas that cannot be ignored, the absence of necessary precursors or policy or a combination of all these.

Figure II-6(b) represents the case where an element of a necessary higher order plan is missing and must be addressed in the lower order plan, and therefore in the lower order plan study design.

An example might be a land use plan study design where it was found necessary to complete or amend a prior economic base study forecasting.

Figure II-6(c) represents the case where elemental interaction with both lesser and greater geographic areas forces that interaction to be explicitly addressed in the plan, and therefore in the plan study design. An example might be a community major thoroughfare plan where the 

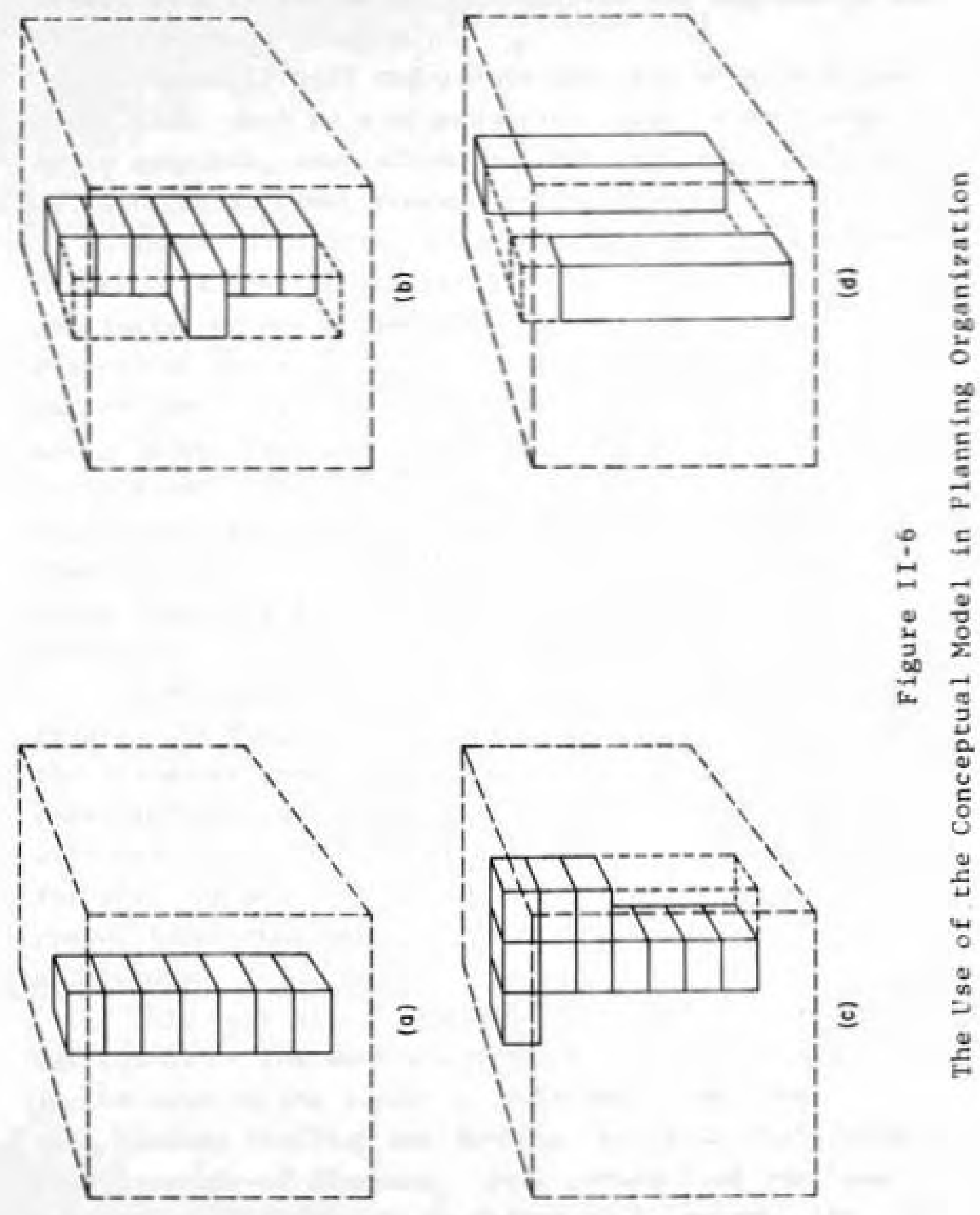
regional major thoroughfare a1ready implemented forces some aspects of the community plan, and the community plan itself affects the design, evaluation and implementation of neighborhood feeders.

Figure II-6(d) represents the case where a higher order plan, such as a comprehensive plan, even though not quite complete, can influence a plan several levels below it, such as an urban renewal plan.

These, of course, are merely examples of the great number of elemental interactions that could exist for a particular proposed plan under particular conditions in a specific situation. The important concept is that the use of the conceptual model of planning activity in the study design forces the planner to consider these interactions and allow for them where necessary in the study design and thereby avoid mistakes of omission. Further discussion of the relationships of each successive element along the procedural scope axis follows in Chapters III through VIII.

A study design must address the questions of procedure, staffing and cost nearly simultaneously. Normally, the framework used for analysis beginning with the inventory phase and ending with implementation is that of procedure, with the study then broken down and reassembled to check for staffing and cost feasibility. In the organization phase, first consideration is more often given to staffing and funding.

This work will not examine the staffing of consultant operations or the moot question of single source funding as in the case of the single private developer. Rather it will examine staffing and funding in the multiple sponsor public sector of planning. Four generalized staffing schemes are illustrated in Figure II-7 (Hensen, 1968).

The policy committee is typically composed of elected or appointed officials of the participating public 




(a)



(c)

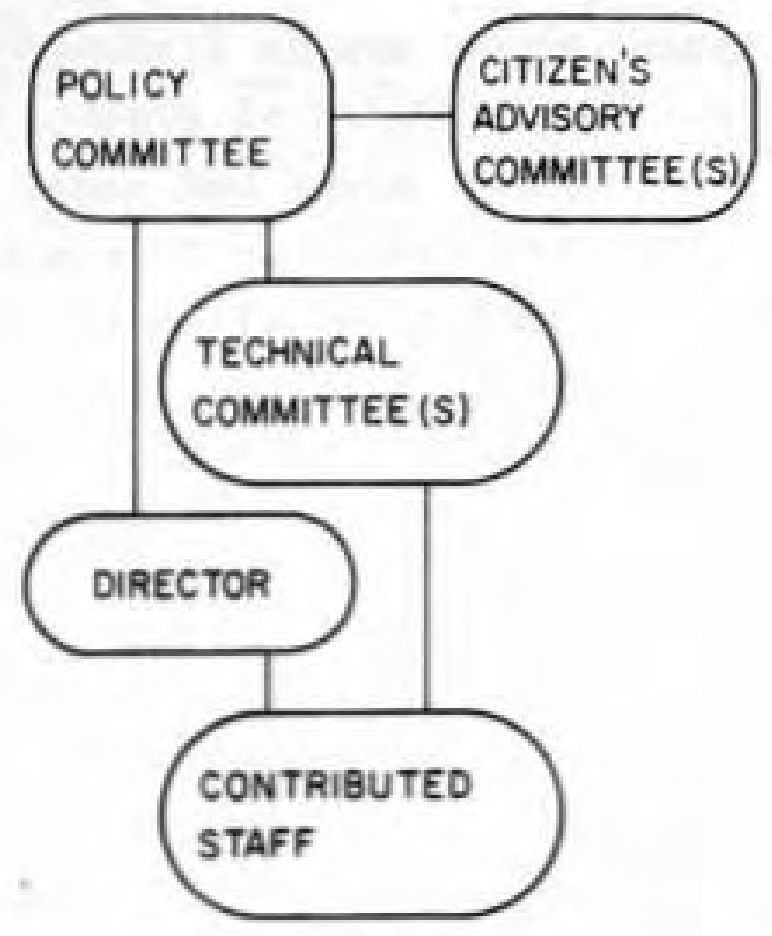

(b)

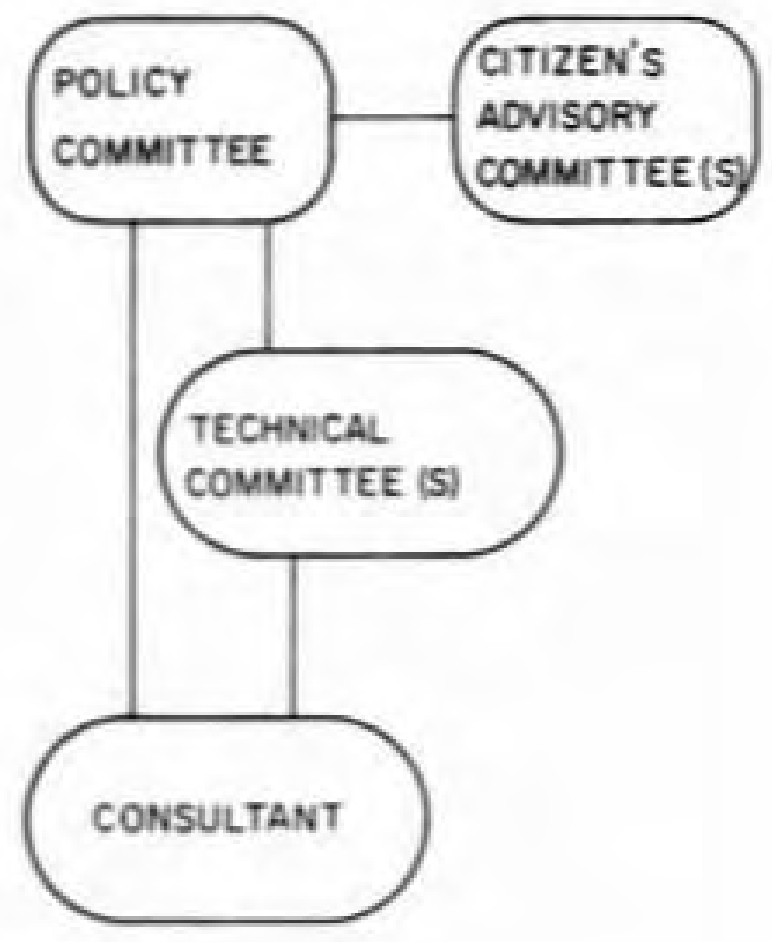

(d)

\section{Figure II-7}

Four Conceptual Staffing Schemes ${ }^{1}$ 
agencies. It establishes the framework of the study, sets policy and finance, makes appointments to other committees, employs key personnel, reviews plans and makes the ultimate decisions as to selection of alternatives. They are the decision makers. In the Rhode Island Statewide Comprehensive Transportation and Land Use Planning Program (1965) for example, this policy committee was composed of:

the State Director of Public Works,

the Executive Director of the Rhode Island Development Council,

the Program Director,

the Director of the State Department of Business Regulation,

the Chairman of the Rhode Island Public Transit Authority,

the Mayor, City of Cranston,

the Mayor, City of Pawtucket,

the Mayor, City of Providence,

the Director, Eastern Region, Federal Aviation Agency,

the Division Engineer, Rhode Island Division, United States Bureau of Public Roads,

and the Regional Administrator, New York Regional office, United States Housing and Home Finance Agency.

The Citizens' Advisory Committee(s) is composed of key business, labor, civic leaders and public officials who advise the policy committee on matters of public concern. They in turn aid in the general public's understanding of the key concepts of the resultant plans. Such a committee could be identically the same as, or a subcommittee of, that described in Chapter I.

The Technical Committee is typically composed of planners, engineers and other professionals who are called upon to both advise the policy committee and advise and possibly direct the staff or consultant. Since there is this dual purpose, there are often two such committees, one composed of those professionals who are direct participants in the etudy and the other made up to tap professional resources not so directly involved. In the Joint Program for the Twin Cities Metropolitan Area (1963), the directly 
participating technical committee was made up of:

representatives of the Minnesota Highway Department, representatives of the Twin Cities Metropolitan

Planning Commission,

representatives of the Minneapolis City Planning

Commission,

representatives of the St. Paul Planning Board,

the Minneapolis Engineer,

the St. Paul Engineer,

the Washington County Engineer,

the Scott County Engineer,

the Ramsey County Engineer

the Hennepin County Engineer,

the Dakota County Engineer,

the Carver County Engineer,

and the Anoka County Engineer.

The use of permanent staffs, staffs contributed from participating agencies, and the degree of use of consultants is a matter for the judgment of the policy committee based upon the need and availability of resources. In analyzing the generalized staffing forms shown in Figure II-7, Hensen notes that II-7(a) is characteristic of large urban areas in a position to pay the continuing salaries and expenses of such a staff. Form II-7(b) may be more economical but with a degradation of service by contributing agencies commensurate with their contribution to the study staff. Often this degradation is not acceptable if the contributing agency is a small one and such a structure has the tendency to be dominated by the larger contributors who can more easily minimize this degradation. Form $1 \mathrm{l}-7$ (c) is characterized by the use of a 1ocal, sma11, but permanent staff to direct the work of the consultant. This is quite expeditious in that it can get the study moving without taking the time to fill many staff positions or negotiate with contributing agencies for staff support. Form II-7(d) is the most expeditious of all in that it eliminates entirely the difficult problems associated with staffing.

Generally, as consideration of staffing alternatives moves from $1 \mathrm{I}-7$ (a) to $[\mathrm{I}-7$ (d) there is an increase in cost. 
an increase in speed of accomplishment, a decrease in personnel associated problems and a decrease in the level of effort assigned to a continual planning process as opposed to a single plan. These are important questions for the decision maker, answered only by an examination of the resources available in a specific situation.

\section{The Study Design Methodology}

Given that participating agencies feel a need to plan, and that a prospectus has been authored defining the substantive scope and the areal scope of the effort (what to plan), and that based upon this prospectus the participating agencies have funded a study design and formed a policy coumittee, and this policy committee has appointed coordinating committees and established an organizational structure (who will plan;, there remain two unanswered questions before a decision can be made to proceed; namely how to plan and what wi1l it cost. Both of these questions are answered in the study design.

What follows here is an examination of study design methodology. This is inextricably tied with planning methodology, addressed phase by phase in this work, beginning, of course, with this chapter on organization. Much of the detail of planning methodology must then necessarily be deferred to later chapters and one cannot design a study without reference to the information contained therein. But because study design is necessarily accomplished in the organization phase, the methodology therefore must be examined at this juncture.

This first step in study design is to construct a precedence diagram or flow chart of the major activities to be performed. The ordering of activities in this precedence is one of work, which is similar to but not necessarily the same as ne of time. Two examples are given in Figures II -8 and II -9 . 




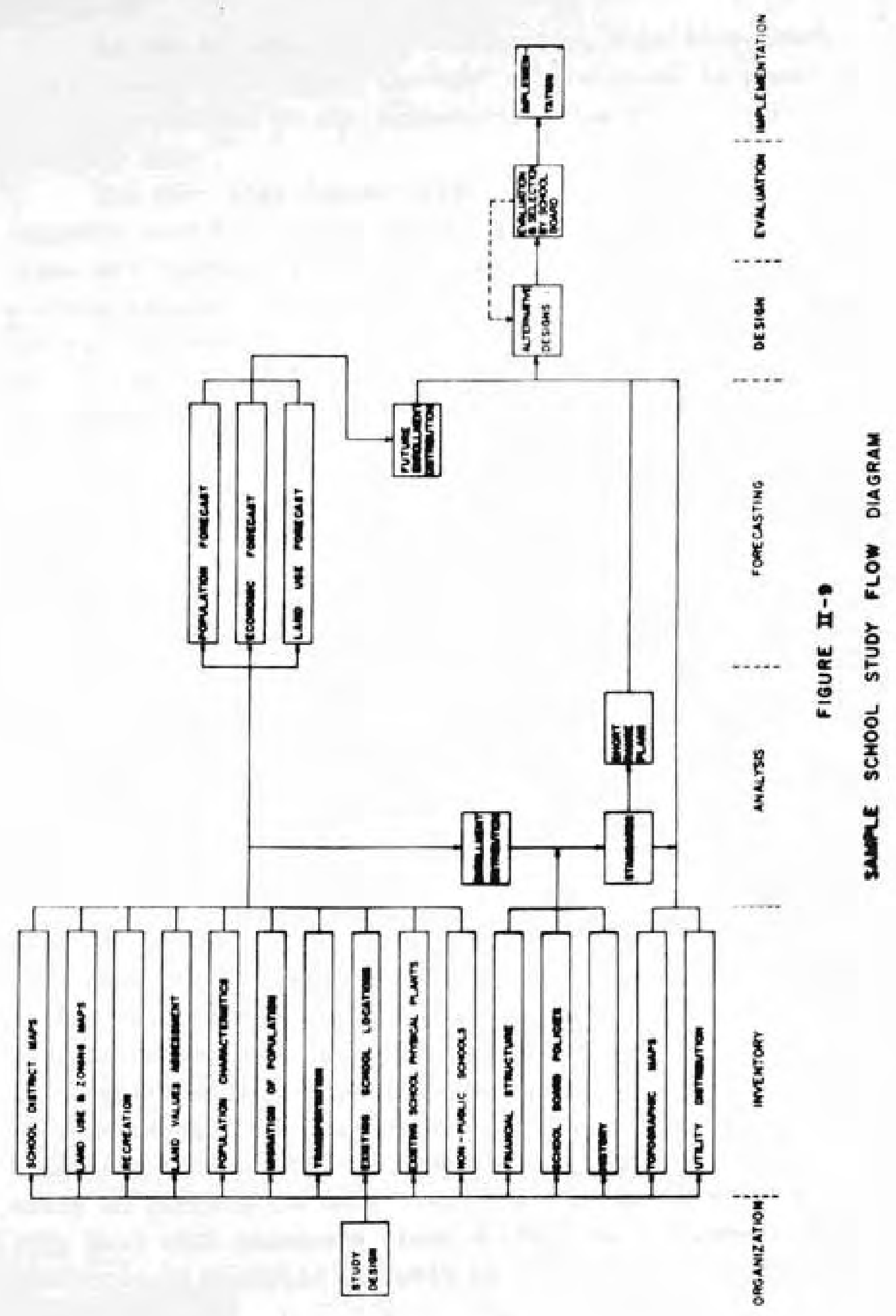


As can be seen for these examples, this flow chart is a schematic "thinking through" of the study by examining it with reference to the procedural scope axis of the planning model.

The next step further refines the flow chart by breaking each flow chart element into its appropriate work items and continuing the assignment of precedence. An example is given in Figure II-10, from the Cleveland Seven County Transportation/Land Use Study, (1966). Note that this example deals substantively with the subject matter of this chapter and its illustrative purpose here is thus twofold.

Because of the great number of work items that are likely to be considered, it becomes helpful to code the work items. This coding should be so devised that a single unique number will identify a work item for budgeting, work scheduling, progress reporting, cost accounting and filing. Rhode Island (1965), for example, used a six digit number with the first digit defining the substantive scope, the second digit the procedural scope, and the renaining digits in sequential order. Thus if " 5 " were land use and " 3 " were analysis, the 530000 series of work items all deal with land use analysis.

This process of breakdown is repeated as many times as necessary until the planner feels he has a sufficient uniqueness of each work item to enable him to tentatively assign resources for its accomplishment. The planner then assigns resources based upon their expected availability as established by the policy committee of decision makers. In some cases, there may be only a single cost figure necessary to describe the case where a consultant will be asked to perform the work item. At the opposite extreme of a full time permanent study staff, the assignment of resources is exampled in Table II-1. 

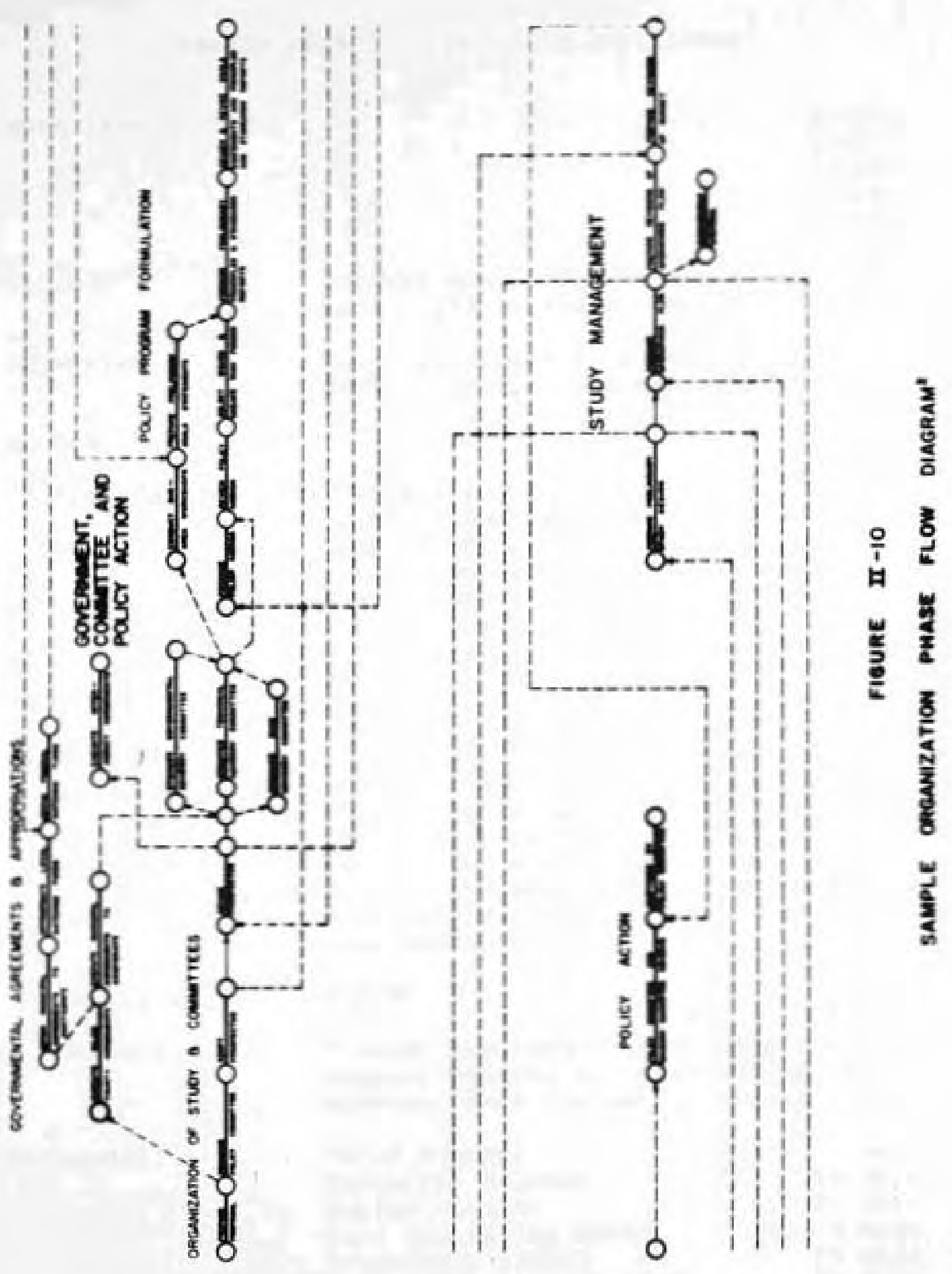
Table II-1

Sample Work Item Resource Assignment ${ }^{3}$

Work Item Number:

570002

570003

570004

570005

570006

Title:

Objective:

Method:

Procedure:

Input :

Output :

Personnel:
Compute and distribute socio-econonic data: $1990,1970,1975,1980,1985$.

To obtain input data for generation of trip productions and attractions.

The selected land use plan will be based on forecasts to 1990. Accomplishment of the recommended pattern of development must be "staged" at five year intervals from 1970 to 1990 in order to determine transportation and other facility requirements for each period.

Forecasts prepared in five year increments provide the basis for staging the land use plan. The analysis of development potential will help guide the staging process. Policy decisions, such as those involved in extension of utility services or construction of community facilities, will also be considered.

570000

A staff memorandum describing the staging process and quantifying socioeconomic data for each forecast year.

Chief Planner

Principal Planner

Senior Planner

Data Processing Chief

Programmer (1401)

Senior Engineering Aide

Junior Planner

Typist
5 days

10 days

25 days

5 days

25 days

25 days

25 days

15 days 
Table II -1 , cont.

Equipment :

Cost :

Allocation :
Desk Calculator

Planimeter

IBM 1401 Computer

Personnel

Computer

Other

Tota 1

R I D C
10 hours

$\$ 3,552$

500

0

$\$ 4,050$ 
When the tentative assignment of resources is complete for every work item, the planner aggregates these resources by catagory over all the work items. He may discover, for instance, that he has assigned 393 senior planner man-days and at 218 man-days per man-year, the policy committee nust hire a senior planner for 1.8 years. Al1 resources are so aggregated and then a final distribution of resources is made taking into consideration feasibility, (hire a senior planner for two years and assign .2 man-years of non-senior planner work); resource availability, (is a senior planner available); and procedural constraints illuminated in the flow chart, (perhaps two senior planners can be hired for a year each and work concurrently).

This is the point in study design where the planner must actually schedule the work within the resource constraints. These are management decisions and the PERI/CPM methodologies are highly recommended as tools to aid this managerial effort. O'Brien (1969) is an excellent reference for these methodologies. Upon completion, the planner reports to the policy committee/decision maker the answers to the questions posed by them; namely, how will we plan and what will it cost.

of course it is recognized that this detailed managerial eftort is costly. It is clearly wasteful if the scope of the planning or the experience of the planning staff is such that good management would deem it unnecessary. Should these or other circumstances allow it, the complexity of the planning study design as outlined here can be reduced.

The conclusion of the study design is the next decision point for the policy committee/decision maker. Should they feel that the study methodology is within their resources and that all prior decisions are still germane, they can decide to proceed with the plan itself. For small or relatively straightforeward plans, the planner can proceed directly to his designed inventory phase. 
More often, however, there exists a need for one further elaboration and refinement of the study design to educate the staff in procedure. This refinement is usually satisfied by the preparation of procedural manuals for selected elements in the study design. A procedural manual gives step by step direction to a practitioner. Very commonly, procedural manuals are written for home interviewers to set standards of appearance, insure that the information is entered correctly on the form, to provide the interviewer with the answers to probable interviewee questions, to set work standards and generally to try to set a uniformity of procedure from interview to interview. Procedural manuals are also often prepared for key punch coders to ease the strain of interpretation. If the answer in box 33 is "yes", enter " 1 " in line 64 on the card, etc.

Occasionally the policy committee decision makers will funcl the preparation of procedural manuals separately from and before the study itself. If so, the completion of the procedural manuals then represents yet another decision point for the policy comittee. As before, if all still augurs we11, the decision may be made to proceed and the planncr enters the inventory phase of the plan.

In summary, there are four decisions in this organization phase. The first is the decision to plan and this results in a formal structuring of the decision makers (policy committee, advisory committees) and the preparation of a prospectus. The second is the decision to design a study and this results in resource allocations. The third decision results in procedural or operational manuals as deemed necessary. The fourth decision examines the feasibility of the study as a whole and results in a decision whether or not to proceed to the inventory phase of planning. In practice, some of these decisions may run together but they are always nonetheless implicitly or explicitly made. 
In closing, it should be pointed out that if there is one phase of the planning process that is subject to criticism, it is this of organization. There is probably no phase more consistantly underfunded in practice, owing the failure of the policy committee to realize that to plan once they must actually plan twice. The planning process must be examined from beginning to end via the study design and then the planning itself executed. The reluctance of the policy committee to expend considerable resources before even "starting" is understandable and therein lies a dilemma which can only be mitigated through a wider understanding of the planning process. It is obvious that if the study design will not yield the results sought after, the study itself can hardly be expected to make up this deficiency.

\section{Notes}

1. R. J. Hensen, "Development of an Informational Manual on the Urban Transportation Planning Process for Technical Committees in Smaller Urban Areas," p. 68.

2. After Cleveland Seven County Transportation/Land Use Study, "Operations Plan," CPM/PERT Network.

3. Rhode Island Statewide Comprehensive Transportation and Land Use Planning Program, "Program Design Report," p. 239 . 


\section{CHAPTER III}

\section{INVENTORY}

Figure III-1 presents the inventory plane of the conceptual nodel of planning activity. On this plane lie all the pieces of infornation or data necessary to plan over the entire substantive and areal scopes of urhan planing.

The information all exists. It may be not collected, or collected in an unusable form, or collected by an agency which is unknown or unavailable to the planner. It may be collected and at hand but too old or too biased. But it all exists and the seeking out, sorting and using of this information usually constitutes by far the most expensive phase of the planning process. This seeking out and sorting of information for eventual use is termed the inventory phase of planning and procedurally follows organization and preceeds analysis.

One way to approach the problem of taking inventory is to recognize that there are, in general, two major end ases of data. Data may be used to describe a situation or to analyze a situation. Although in practice this distinction sometimes is blurred, its importance is such as to warrent continued consideration here.

Consider descriptive data. Information such as this is used to describe a situation and compare that situation to others by comparing the equivalent descriptive data sets. From a methodological standpoint, there exists a marked tendency to use those descriptive data items already available rather than to initiate a new collection. This follows frum the intuitive or explicit knowledge that most situations can lee deseribed in many ways, even by symptonat ie data in 


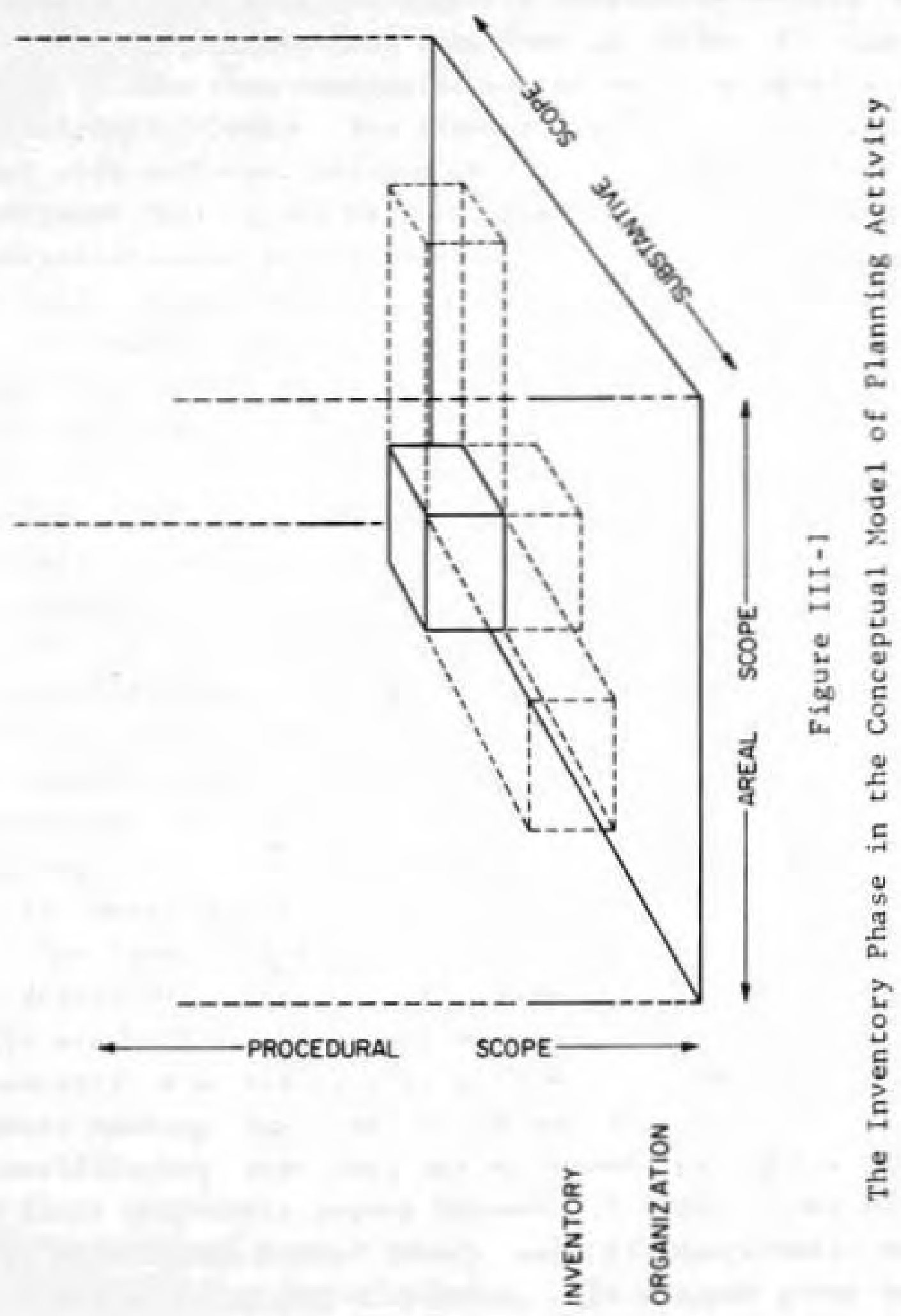


place of causal data. Thus, the data needs are not rigorous $1 y$ constrained and available data are easily substituted for what were originally considered desired data.

Descriptive data must sometimes be differently aggregated to make them meaningful to the decision maker and client constituency. The planner may find it helpful to deal with parts-per-million of an air contaminant, for instance. But it may be more meaningful to describe that concentration as pounds swallowed per year - that being enough to kill a horse etc.

So descriptive data can be characterized as substitutable, possibly symptomatic, comparative, readily available and meaningful to the general recipient. Taken together, sets of descriptive data are said to describe a level of service. This level of service then represents the balance struck between the demand for that service and the resources allocated to fulfilling that demand.

"Level of service" is something of an elusive term and is only defined within the context of a problem. The level of service of a transportation facility, for instance, may be expressed in terms of travel time, safety, comfort, convenience, cost or any combination of these and other factors. The choice of expression is strongly influenced by its meaningfulness to the client constituency.

The level of service of a university, for instance, may be described by the data sets shown in Table III-1. Some data are both available and meaningful in the academic community, some are equally available but have acquired a lesser meaning, and some, of course, are unknown. In cross classification, some data may be termed descriptive because of their inherently strong theoretical basis. Some data rest on somewhat weaker theory, some are symptomatic and some may be false and misleading. The example given here can be argued against but, taken as a whole, it does describe a level of service and becomes particularly meaningful when 
Table III-1

Descriptive Data Showing a University level of Service

\begin{tabular}{llll}
\hline & $\begin{array}{l}\text { Known and } \\
\text { Meaningful }\end{array}$ & $\begin{array}{l}\text { Known and Less } \\
\text { Meaningful }\end{array}$ & Unknown \\
\hline $\begin{array}{l}\text { Strong Theoretical } \\
\text { Basis for } \\
\text { Description }\end{array}$ & $\begin{array}{l}\text { Admission } \\
\text { Standards }\end{array}$ & $\begin{array}{l}\text { Undergraduate } \\
\text { hours taught } \\
\text { by instructors }\end{array}$ \\
$\begin{array}{l}\text { Weaker Theoretical } \\
\text { Basis for } \\
\text { Description }\end{array}$ & $\begin{array}{l}\text { Dollar } \\
\text { value Staff } \\
\text { Research }\end{array}$ & $\begin{array}{l}\text { Staff counseling } \\
\text { time/student }\end{array}$ \\
$\begin{array}{l}\text { Symptomatic } \\
\text { Descriptors }\end{array}$ & $\begin{array}{l}\text { Number and } \\
\text { Kind of } \\
\text { Academic } \\
\text { Awards }\end{array}$ & $\begin{array}{l}\text { Alumi Dollar } \\
\text { Support }\end{array}$ \\
False & $\begin{array}{l}\text { Footbal1 } \\
\text { Record }\end{array}$ & -2 & \\
Descriptors & & & \\
\hline
\end{tabular}

the status of one university are compared to some "standard" or yet another university.

The second and other general type of data are analytic in nature. This type of data probably has associated with it very strong elements of causality. Failing that, it at least has been proven to be, or is strongly suspected of being, highly correlated with as yet undiscovered elements of causality. Data of this type is measured with a stated degree of precision and is used in calibrating analytic models of growth and behavior. Because these data are used in model building they are, or should be, forecastable on a sound theoretical basis. They are generally not substitutable as were the descriptive data and therefore must be collected regardless of expense. It is the need for these data that precipitates field work of sometimes vast proportions and this is largely what determines their expense. 
As opposed to descriptive data, analytic data are causative or highly correllated to cause, precise, forecastable, expensive and sine qua non to ensuing analysis.

Obviously then, the need for analytic data must be closely examined. The need for such data must be fully documented and justified in the most rigorous way to ensure that the cost of collection is not horne unnecessarily. Each analytic data item collected must have its use in later analysis and forecasting phases of the planning process.

of course, when the undeniable need for some analytic data item precipitates an expensive collection procedure, that procedure often makes some descriptive data margina11y beneficial when collected under the the same procedure. The archetypical case is the United States decennial census which was first organized to count people and now has been broadened considerably.

Still caution must be applied here, too. Any data must be cuded, stored, retrieved, displayed and manipulated in many ways and there are very real costs associated with al1 these activities. The collection of data, no matter how easy or difficult, must be based on the need for that data in the ensuing phases of the planning process. It is to minimize the cost of data collection and its subsequent manipulation, if for no other reason, that the organization phase described in the previous chapter is so important. Before any data are collected there must be some iterative feedback from the analysis and forecasting phases to that of inventory to ensure that there is a necessary end use for each data item and that no end uses go wanting for data.

So in selecting those data to be collected, the planner's charter is to be highly selective and discriminatory in the ad hoc situation. Nothing is gained and much is lost in collecting data for their own sake.

In Chapter II, one of the purposes of the organization phase of the planning process was to establish a highly 
distilled statement of the objectives of a particular plan. This was generally done in the study design and, more specifically, in the prospectus. In the inventory phase of the planning process, each data item collected must substantially contribute to the achievement of those objectives. The only justification for incurring the cost of collection and subsequent manipulation of data is that those data make this contribution. Al1 data not making this contribution are superfluous to the plan considered, and a mismanagement of resources.

As an example of the type of analysis needed to preclude such an occurrance, Table III-2 has been prepared showing a hypothetical set of land use plan objectives and the data items necessary to achieve them. This table has been abstracted from the areal scope axis of the conceptual model of planning activity and, accordingly, no attempt should be made to employ it quid pro quo in an actual planning process.

\section{A Data - Use Matrix}

As an example of the types of data generally collected in urban planning, Figure III-2 matches these data against end use by plan. Data items considered here are compiled from three general sources (Hearle and Mason, 1963; Maxman, 1968; and Tiebout, 1962). The fourteen planning processes 1 isted are representative of the range of urban planning activity measured along the substantive axis of the model. For each cell defined by a data item and a planning process, an " $A$ " is entered if that data item is generally used in an analytical way in the process and a " $D$ " is entered if the data item is generally used in a descriptive way in the process. No entry signifies that the data item is indifferent to that planning process.

The matrix is generalized and bears no relationship to a particular geographic area measured along the areal scope axis of the model. Accordingly, the matrix can be 
Table III -2

Sample Land Use Plan Objectives and Data Items

Broad Plan Objective:

To provide a plan for orderly and optimum use of major community resources of land, both spatially and quantitatively.

Specific Plan Objectives:

a. To determine the kinds of land use required for the community.

b. To determine (based upon standards acceptable to the community) intensity of development for each land use.

c. To establish the amount of land required in each land use.

d. To properly locate each land use, relative to each other.

e. To coordinate with other planning .

f. To establish procedures for implementation.

g. To secure citizen cooperation.

h. To research.

Data to be Collected

1. Base Maps and Charts

A. Regional Map
Purpose of Collection

For displaying or plotting data collected and to serve as a basis for studies.

To determine the community's geographic location and relation to surrounding cities and communities, indicating any specialized land uses. 
Table 1 II-2, cont.

B. Street, Road and Highway Map indicating right-of-way, width, and structural capacity

C. Topographic Map

v. Geological Map

E. Soils Map

F. Zone Map

G. Existing Land Use Maps

1. Public and semipublic facilities, such as public buildings, parks, playgrounds, schools, hospitals, churches, museums, treatment plants, libraries, etc.

2. Private facilities such as single family, two family and multi-family residences, commercial buildings, light and heavy industry.
To determine location of

circulation system and can be used in tabulating area used for streets, roads and highways to assist in classification of street system.

To determine drainage patterns and general suitability of areas for specific types of development.

To determine existance of deposits of materials of possible commercial value and thereby determine suitable 1 and use.

To determine suitability for various types of buildings, airports, and other structures requiring special foundations.

To determine existing zones in use by the city.

To determine categories of present land use and for tabulating land use by percentage of total land.

To determine location and number of community and private facilities.

To determine location and availability of lakes, forests, and other areas suitable for recreational development.

To determine adequacy of facilities by coordination with other development plans to establish areas required for future use. 
Table III-2, cont.

3. Undeveloped and vacant areas.

H. Location of navigable rivers, rail roads, RR sidings and stations, piers and wharfs, bus terminals, airports, etc.

I. Location of pollution discharges and the Sag curve for various points along rivers and streams. Also location of significant air pollution sources.

J. Easements for public utilities noting ownership, existing utility lines and their capacities.

K. Population Density Map

L. Population Changes Map

M. Land Value Map

2. Percentages employed in each occupational category.
To determine available vacant area for future development.

To determine the measure of accessibility for various land parcels.

To determine the possible uses of adjacent land.

To determine planning of future land uses on the basis of their utility needs.

To determine present population density by area and evaluate existing densities.

To determine future density and community facility requirements.

To determine population movement, increases and decreases.

To determine economic suitability of land use proposals.

Determine primary and secondary functions of community and to relate land use requirements to these functions. 
Table III-2, cont.

3. Populations and their composition by age, groups, income and sex.

4. Aerial Photographs

5. Prevailing Winds

6. Area Industrial Trends

a. Standard Industrial Classification

b. Average 1and used and number of employees for each class number.

c. Historical trends on economic activity

1. Number of labor force

2. Percent unemployed

3. Basic/non-basic ratio
To determine buflding cypes and population density.

To determine types of land use required.

To determine standards for intensity of use of land.

To determine amounts of each land use.

To determine percentage of each type of residential development.

To determine community facilities required on a neighborhood, community and regional basis.

To determine, in conjunction with other data collected, land use and geographic

features.

To determine spatial relation of industrial and other land use.

To determine tha area attractions to certain SIC classes.

To determine existing land use requirements in terms of employees.

To determine future economic potential. 
Table III-2, cont.

d. List of community attributes important to industry.

7. Area Population Forecasts

8. A11 other plans prepared for development, such as schools, recreation, etc.

9. List of civic organizations and their officers
To determine the range of industries which might be attracted.

To determine future population so it can be related to use requirements.

To coordinate with Land Use Plan.

To secure citizen cooperation and participation. 


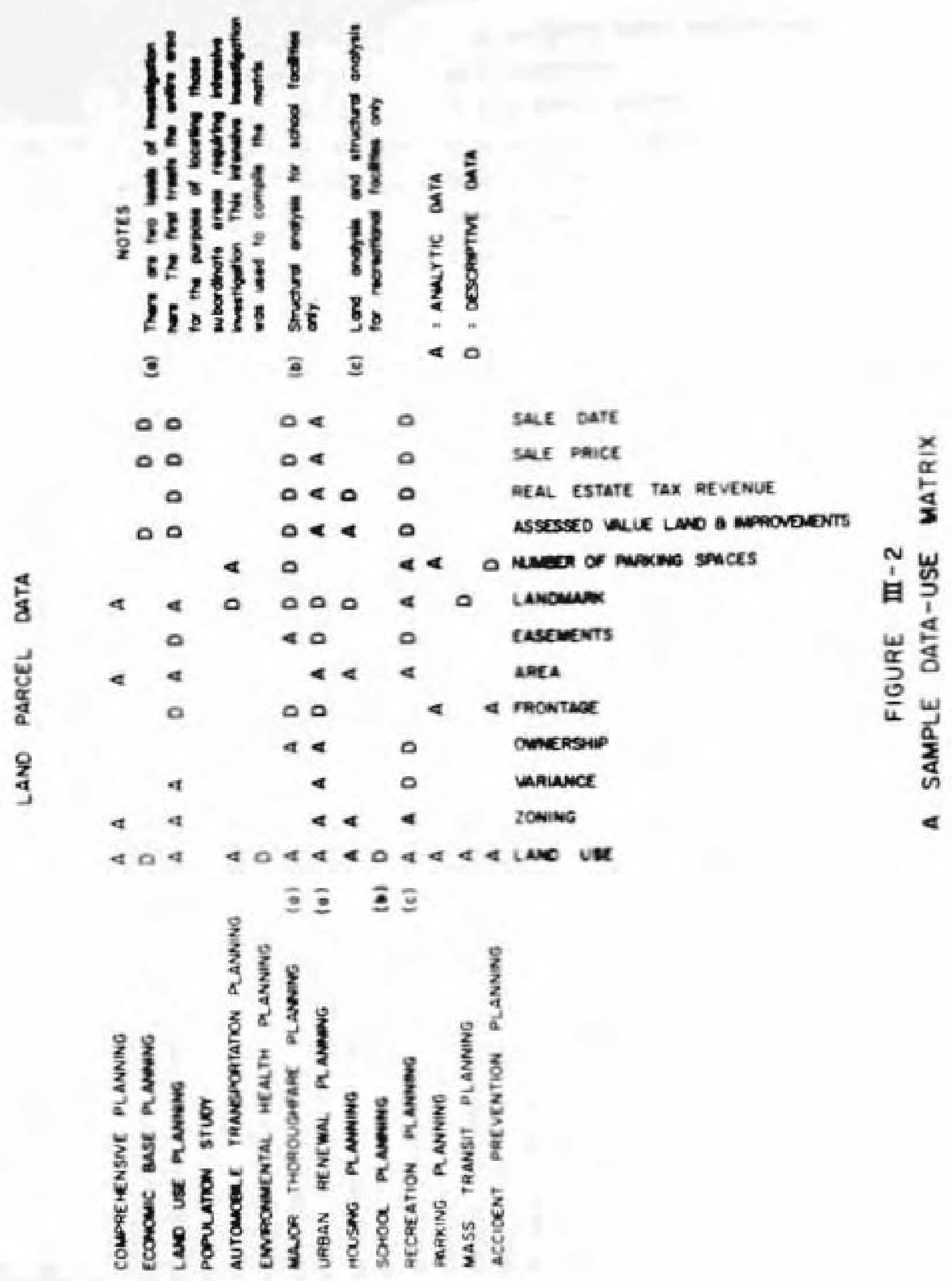




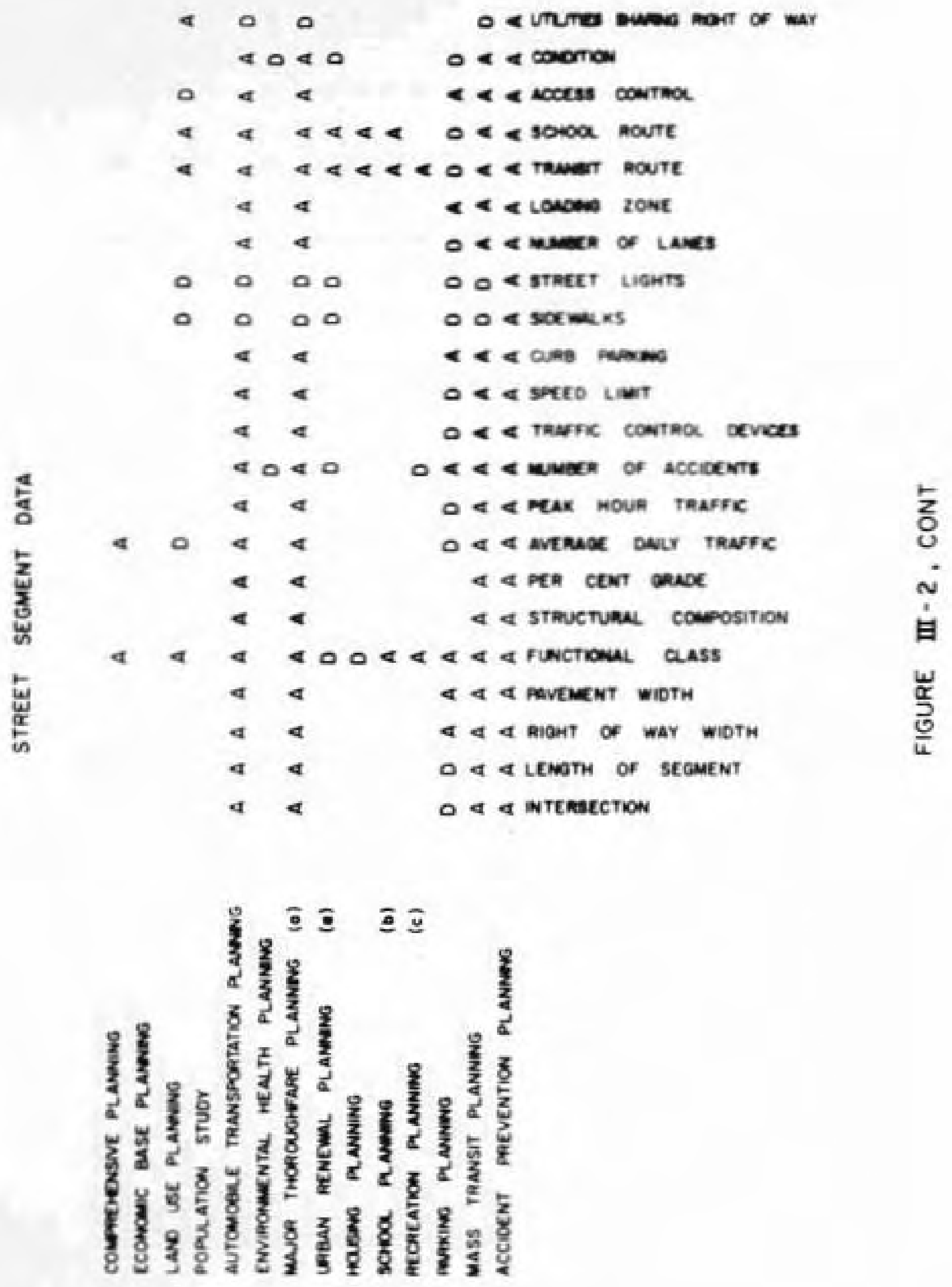




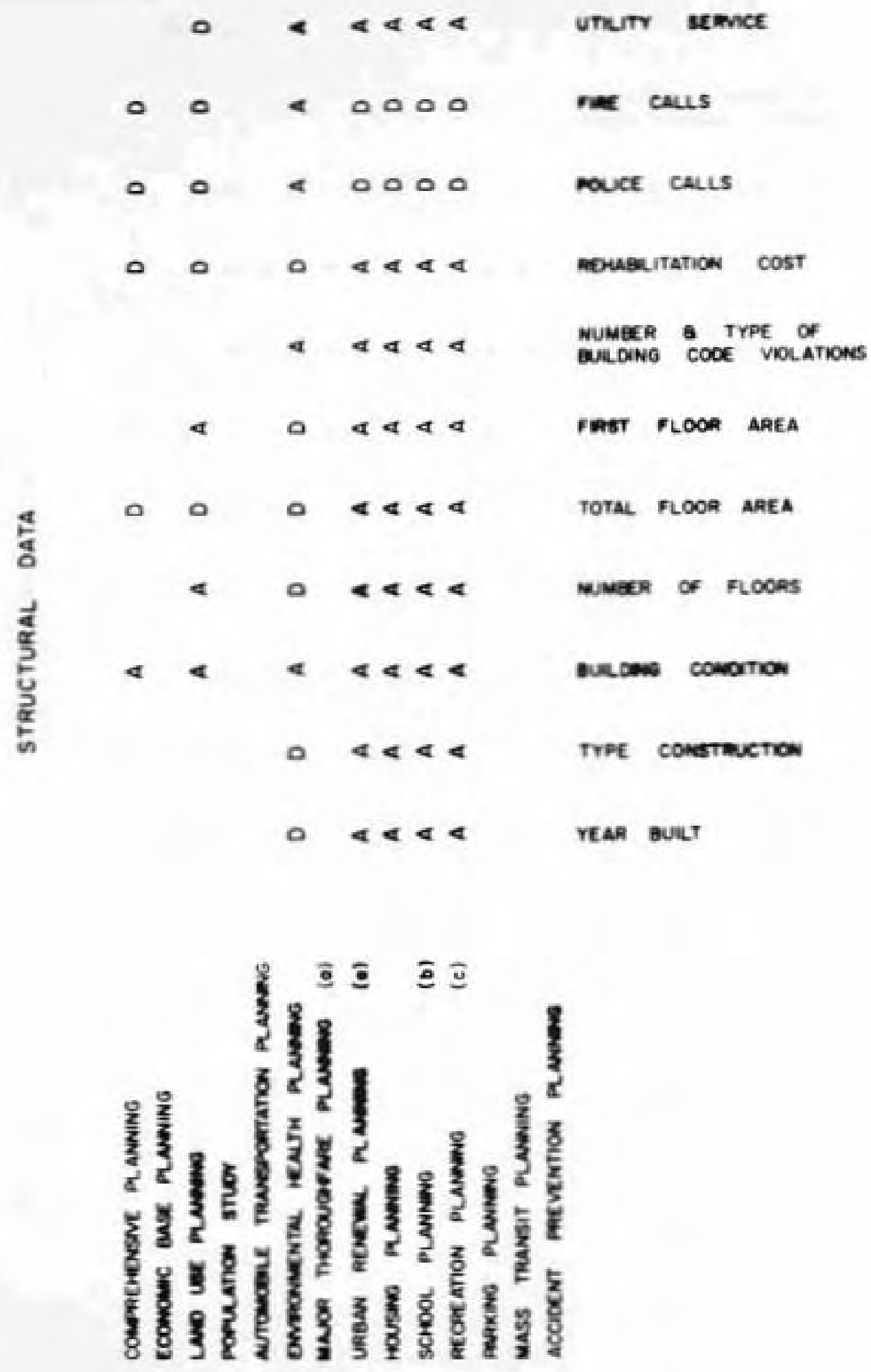

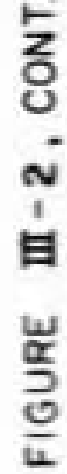




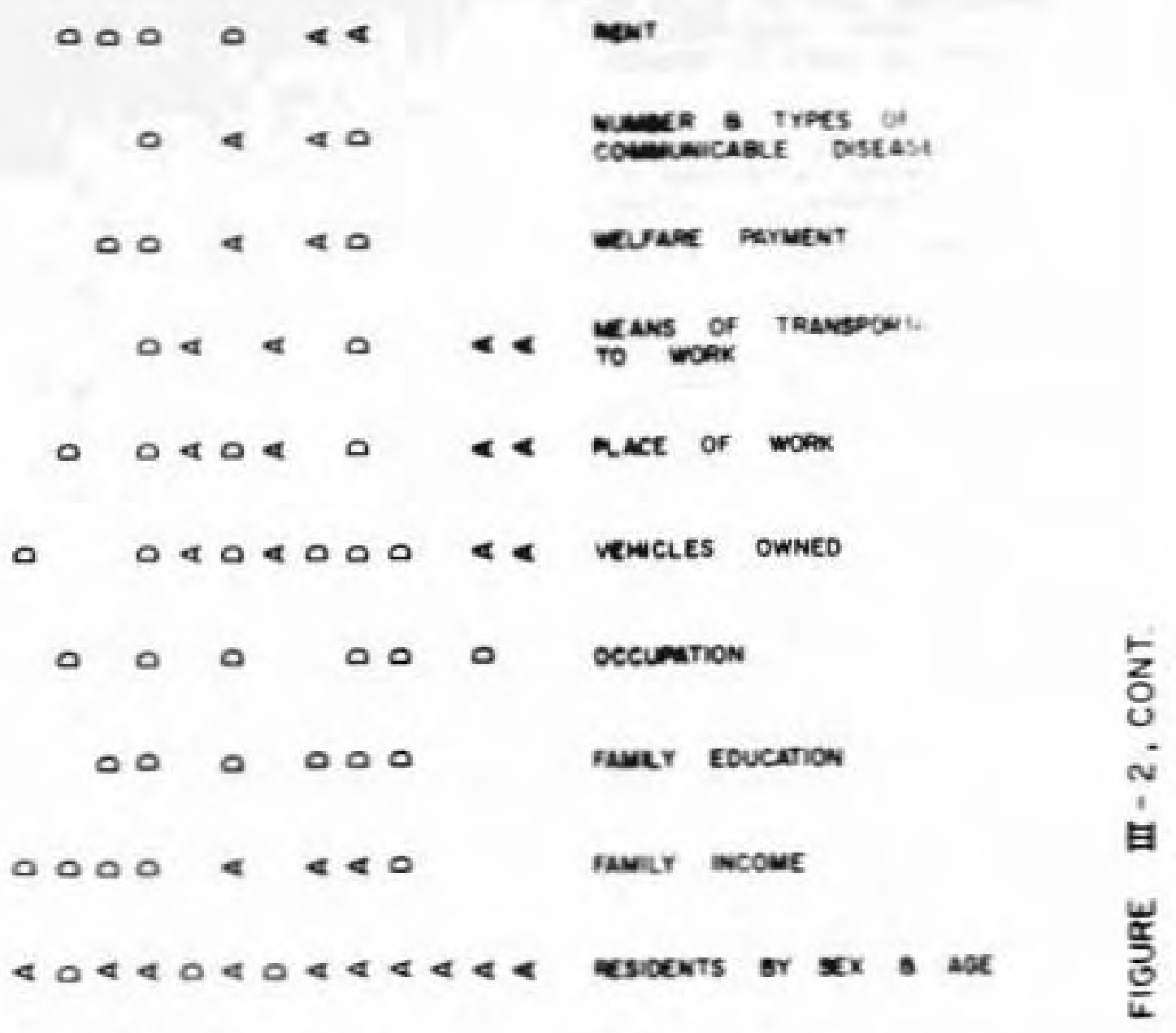

$0 \quad 0 \quad 4 \&$ nencent vacuit

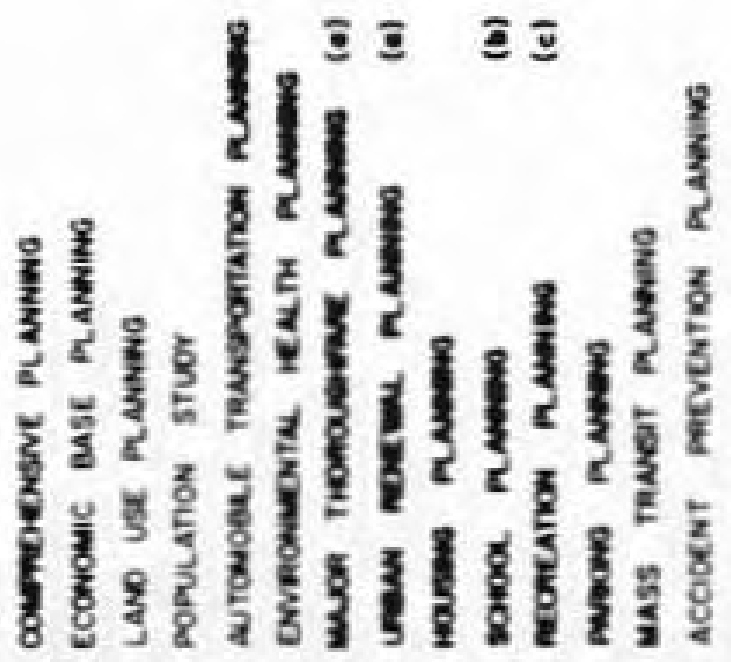


4

द

4

a

4

4

$\frac{4}{6}$

$\frac{5}{3}$ ब

$\begin{array}{ll}\frac{0}{2} & 4 \\ \frac{3}{3} & 4 \\ \frac{4}{3} & 4\end{array}$

1

을
OA SALES TO AEEA NON-CAPTAL

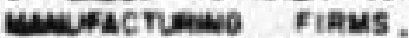
nesecewt TO rimus BY TrPES

sairs to aeca riens

a NON-CANTA OOCOS. MERENT TO MANUACTURING

or sales to meca fases of NOW-CANTL COOOS, PCACENT TO ANSRANCE, FaNANCE B AEA ESTATE

of saues to anta ranes of MON-CANTH. Co005. peracent to aetal.

of sales to alea fibus

or NON-CARTIL GOOOS,

rencent to construction

cS SALES TO AREA fines

of NON-Capral cooos,

Frecent to aceicukruer.

O6 SALES NSOE AREA, PERCENT TO

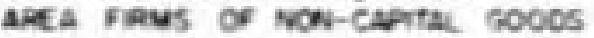

OF SALES MSCE AAE A, DERCENT

To apea FIRMS of capital cooos

$\frac{1}{2}$

Of SALES INSOC AREA, PEACENT

To LoCAL a state Goverevients

N

of saues nSOCE AREA, PERCENT

To consuncas DipeCtiLr

or sales OUTSOE AHEA, PEACENT

To recerai GovernuENi

PEACENT SALES OUTSIDE AREL

日

MAJOA PRODUCT GROUPS

\& \& OPTHEU TOTAL EMHLOYMENT

44

NLuER of EMPLOYEES

44

a ÁK SHIFT EMPLOYEES 
faulted in the context of a specific real life plan. Nonetheless most of the analytic and descriptive relationships were hypothesized to hold true from location to location.

Neither is the matrix exhaustive, but rather illustrative of the analytic/descriptive split of data end uses. It further shows how one data item may change end use from one type of plan to another. The non-dwelling unit data illustrated will provide the means for carrying out but one type of the several possible economic base studies, any one of which may be preferable to that shown. Further, some whole classes of data have been omitted, such as that data set dealing with the engineering features of the soil, water table, topography, extractive potential, etc.

The strategy in designating analytic or descriptive relationships was one of minimizing the number of analytic relationships to a level commensurate with the detail required for a particular plan. In a real life situation, this same strategy should be employed as a measure of economy. Secondly, the question of degree of aggregation of data has been deferred to later in the chapter.

The data have been organized into two main classes, land data and structural data. Street data are a special type of land data and structural data are further refined depending on whether the structure is a dwelling unit or not. All data items associated with people are linked to the dwelling unit in which they abide.

\section{Land Data}

Land Use. As can be seen from the matrix, these data are one of the singular primary inputs to analysis over much of the range of urban planning. They describe the actual land use as opposed to zoning and variance which describe the legal use and any relaxation of the law. The source of land use data is a field survey and the source of zoning and variance data is appropriate governmental records. 
Ownership. The need for owner identification occurs when particular land parcels may be considered for acquisition, as in transportation route selection or urban renewal. The source of this information is the appropriate assessor's office.

Frontage and Area. These are dimensional characteristics of the land parcel and are important in land use planning and lower order plans such as parking, accident prevention, recreation, urban renewal and housing planning. This information is available in the assessor's office.

Easements. Easement information illuminates any encumbrances on the land parcel which may restrict development. In assumes analytic importance in the case of 1 and acquisition. This information is kept by the utility companies holding the easements and is recorded in deed books.

Landmark. This information describes architecturally, historically and culturally significant items about the parcel and its use is mostly descriptive. It assumes analytic importance when its preservation is threatened. The source of this information is a field survey.

Number of parking spaces. It is a matter of indifference whether this information is coded to land data or structural data but it is an important consideration in most types of automotive transportation studies. The source of this information is a field survey.

Assessed value of 1 and and improvements. Although assessed valuation is notorious for its failure to be equitable from place to place, it may be the only readily available mechanism for a first approximation of possible purchase price. Its source is the appropriate assessor's office.

Real Estate Tax Revenue. This is a worthwhile bit of information particularly when compared to some dollar measure of municipal services consumed by the parcel, so as to determine whether a particular land parcel is a revenue 
producer or revenue consumer in a community. Its source is the local assessor's office.

Sale price and sale data. This information is probably more reliable as an indicator of worth than assessed value is, but it may be difficult to obtain. One way of estimating sale price is to count the tax stamps filed with the deed and multiply by the appropriate converted tax rate. As with all the valuations mentioned, its use is primarily descriptive except perhaps when purchase is contemplated.

Summary. The land data portion of the matrix shows some very significant trends. Land use and landmark data are important over nearly the whole range of studies listed. Zoning, dimensional and valuation characteristics are important to a somewhat lesser extent. The remainder of the data assume specialized importance depending upon the planning undertaken.

By plan, as might be expected, land use planning requires use of nearly all the land data. Recreation planning, major thoroughfare planning and urban renewal planning require like amounts of land data, but only over the parcels directly affected.

\section{Street Data}

Intersection. Whether or not a parcel is an intersection classifies the subsequently listed data bits. The source of this information is base maps and a field check. Length of segment, right-of-way width, and pavement width. These dimensional characteristics are analogous to those of a non-street land parcel and are used in a11 the listed types of transportation plans. The source of this information is base maps and a field check.

Functional class. This is a convenient division of the level of service provided by the street system - expressway, major arterial, collector, local - and is used for its descriptive characteristics over a wide range of plans. In 
that such classifications imply a wide range of controls on adjacent development regarding access, its use in analytic. The source of this information is base maps and field check.

Structural composition and percent grade. These are analytical information items used in most types of transportation planning. The source of these data is the appropriate engineering agency.

Average daily traffic and peak hour traffic. These are analytic data used in most types of transportation planning. The source of this data is a field survey.

Number of accidents. This statistic is gathered over some appropriate time interval and is used in all the 1 isted types of transportation planning to analyze the efficiency of traffic movement. It also can be used as a descriptor in other plans such as urban renewal and environmental health pianning. The source of this information is police records.

Curb parking. These are analytic data used in all types of transportation studies. Their source is a field survey.

Sidewalks and street lights. These are mainly descriptive data except in accident prevention planning. Their descriptive characteristics extend beyond the types of transportation planning to such plans as urban renewal and land use. The source of these data is the appropriate engineering agency and a field check.

Number of lanes and loading zone. These are further analytic data items used in automotive transportation studies. Their source is base maps, the appropriate engineering agency or a field survey.

Transit route and school route. These are descriptive data that become analytic because of the number of things that each implies. Their sources are field surveys and transit companies or school boards as appropriate. This information is rather widely used over the types of studies listed. 
Access control. This information is used analytically in all the transportation plans listed. Its source is a field survey.

Condition. This information is used analytically in the transportation plans and descriptively in some others such as environmental health and urban renewal. Its source is a field survey.

Utilities sharing right of way. This information is used analytically in land use planning and accident prevention planning. It can be used descriptively for other plans if the situation warrents it. Its source is the appropriate engineering agency and utility companies.

Sumnary. The street data portion of the inatrix sluws the following trends. The functional classification of a street segment is useful information over a wide range of planning studies. Transit route, school route and accident data similarly have an impact outside of pure transportation studies.

Just as the land data itens were most exhaustively used in land use planning, so too the street data items are used in the various types of automotive transportation planning. Almost all of this use is analytic in nature.

\section{Structural Data}

Year built and type of construction. These are descriptive data in environmental health planning, and analytic data for those particular structures considered in plans such as urban renewal, housing, school and recreational planning. They are generally available from the appropriate assessor's office and checked in the field.

Building condition. This information is analytic in use for all the plans enumerated above as well as higher order plans such as comprehensive and land use plans. The source of this information is the field survey. 
Number of floors, total floor area and first floor arca. These information items measure intensity of 1 and use and they are analytic in lower order plans such as urban rencwal and tend to be descriptive in higher order plans such as environmental health. This information is all gitlhered by field survey.

Number and type of building code violations. This information is all analytic and would be used in the low order small area plans, such as housing plans and etvironmental health plans. Its source is the appropriate engineering office.

Rehabilitation cost. This is an estimated cost of repairs necessary to bring the subject building up to a condition requiring only normal maintenance. It is used analytically in lower order plans and descriptively in higher order plans. It is grossly estimated during a field survey.

Police calls and fire calls. These data are used alinost always descriptively except in environmental liealth planning or when paired with the cost of other municipal services and compared to real estate tax revenue. In the latter instance some estimate can be made of the cost/income ratio generated by a particular area. Their sources are the appropriate departments.

Utility service. These data are gathered for all utilities to be used analytically in lower order pians and descriptively in higher order plans. Their sources are the appropriate utility companies and a field check.

Sumnary. The structure data portion of the matrix shows the following trends. Building condition data are used analytically over a wide range of planning processes. Intensity of use measurements, reliabilitation costs and utility service tend to be used analytically in lower order plans and descriptively in higher order plans. Police and fire call data tend to be used almost entirely in a 
descriptive sense as symptomatic of a wide range of urban i11s.

Considering the matrix by plan, low order plans deal intensively with these data in an analytic sense. The school buildings might be so investigated in a school plan, for example. Environmental health planning shows about an equal mix of descriptive and analytic use of the data. High order plans tend to deal with the data almost entirely in a descriptive sense.

Dwelling Unit Data

Per cent vacant. For each dwelling unit, data of this type is commonly used descriptively in land use planning and environmental health planning. It is used analytically in urban renewal planning and housing planning. Its source is a field survey or the United States decennial census in aggregated form.

Residents by sex and age groups. This is another primary set of information quite analogous to land use data in its universality of use. Probably the best source of these data is the U.S. decennial census, updated as necessary for intercensal years. This is particularly true after 1970 when some of these data can be disclosed by the Census Bureau at the level of the block without violating the Bureau's rules of confidentiality. For smaller areas or less aggregated information, a field survey is necessary.

Family income. This is a widely used descriptive statistic that is available from the Census Bureau in large aggregation. As a measure of socio-economic class it is used analytically in environmental health planning, urban renewal and housing planning. For small areas, the source of this information is a field survey.

Family education and occupation. These are two descriptive statistics widely used as indicators of socioeconomic status. They are available from the Census Brueau in large aggregation or from a field survey as necessary. 
Vehicles owned, place of work and means of transportation to work. These statistics are used descriptively when available and analytically in automotive transportation planning, major thoroughfare planning, parking planning and mass transit planning. They are available in large aggregation from the Census Bureau or from a field survey in more detail. The field survey would probably include a search of vehicle registration records and employer records.

Welfare payment. This information is used descriptively in land use and population studies and analytically in environmental health planning and urban renewal planning. The source of this information is the appropriate welfare agency.

Number and types of communicable diseases. This information is used descriptively in population planning and housing planning and analytically in environmental health planning and urban renewal. Its source is the appropriate board of health.

Rent. This information is used descriptively in high order plans and analytically in lower order plans such as urban renewal and housing planning. It is available from the Census Bureau in aggregated form or must be gathered in a field survey.

Summary. The dwelling unit portion of the matrix discloses the following trends. The data are very strongly descriptive overa11. This is to be expected as changes in the population are not plannable in the aggregate. The data tend to analysis in the lower order plans when they are used to establish housing classes, socio-economic status, and when the population consumes public services such as health, welfare, public housing and schools. The class of data regarding vehicle ownership and the work trip is strongly analytic in transportation plans.

Considering the matrix by plan, nearly every plan makes analytic use of the matrix entries. Population 
studies, environmental health planning and housing planning use the data most intensively.

Possible users of these types of data are strongly encouraged to investigate the information services available frow the Census Brueau (Siegelman, 1971; United States Bureau of the Census, Census Use Study, 1970-71, and 1970 Census Users' Guide, 1970).

\section{Non-Dwelling Unit Data}

Peak shift employees, number of employees, and optimum total unemployment. These measures of employment are all analytic when used. The first is an important consideration in all types of transportation planning and is a subset of the second. The third gives some measure of possible economic expansion under favorable conditions. The sources of this information include the appropriate agency administering the unemployment insurance act and a field survey of employers .

Major product groups. This information is used analytically in comprehensive, land use and economic base planning. Its source is the field survey.

Per cent sales outside the area and the remainder of the information in the table. This information is included for completeness and it is all used analytically in one type of economic base planning (Tiebout, 1962). Its source is a field survey of employers.

Summary. The non-dwelling unit portion of the matrix is entirely analytical in nature. Such descriptors of building condition, etc. that might be desirable have already been considered in the structural data portion of the matrix. There remain then just two classes of data, employment statistics and sales statistics. The former are used in transportation plans and, with the latter, in economic base plans. 


\section{Some Concepts of Sampling}

In the previous section, the source of much of the dat: used in urban planning was a field survey. This procedure is very expensive and time consuming when data must be gathered for each individual, or each structure, or each dwelling unit over a widespread area.

An alternative to gathering data for each individual, structure, dwelling unit, etc. is to sample. Some definitions are in order here.

A "population" is defined as the totality of al1 possible values (measurements or counts) or a particular characteristic. This characteristic could be a person, a structure or a dwelling unit or it could be a person's age, a structure's condition or the number of bedrooms in a dwelling unit. Thus, populations exist within populations.

Populations which may be considered for analysis: should be selected with great care and defined explicitly so that no ambiguity will arise as to the inclusion or exclusion of a given element. A "sample" is a portion of the population selected according to some rules. The sample characteristics are then used to infer the population characteristics.

In some cases, the population may be constrained in a manner such as to make sampling necessary for any measurement at al1. The population could have an infinite number of elements, as in the classic coin toss, and total enumeration of these elements is impossible. The population nember could be destroyed in measurement and thus make sampling necessary. Or the population could be inaccessible, no longer in existance or unobservable.

In urban planning, however, one is more likely to encounter populations which can be totally enumerated. Why, then, should the use of sampling be considered?

A sample in which only a portion of the entire population is examined is usually substantially less expensive 
than a total enumeration. This is true despite the added cost of sample design and analysis. Secondly, a sample will usually provide information faster than a total enumeration. This results from two considerations, the actual time required to survey the sample vis à vis the total population, as well as the lesser time of editing, coding, tabulating and analyzing sample data rather than population data. Another reason to consider sampling instead of total enumeration is that greater accuracy may be achieved. This may be surprising in view of the fact that sampling will introduce another source of error, sampling errors, about which more will be said later. But this error introduction can be more than countertended by stricter controls on interviewing, editing, coding and tabulating the data. The imposition of these stricter controls is feasible because the sampling is simply a smaller scale undertaking than a total enumeration. These stricter controls are almost all tied to personnel actions and typically arise from being able to hire a smaller but better qualified staff within available resources. The fact that qualified staffers may be in short supply and incur a premium cost simply reinforces this tendency.

Lastly, if all else remains constant, such as time, money and staff, sampling can provide more detailed and intensive information about a population than a total enumeration.

In summary, accuracy, speed and economy are the chief characteristics of data obtained by sampling if and only if the sampling procedure is carried out according to the theories of probability and statistics. These theories are applicable only with difficulty when the population size is very smal1. Also the small sized population obviates many of the problems associated with total enumeration. Accordingly, a total enumeration is more advantageous than sampling when the population is small. In urban planning, 
for instance, sampled characteristics inferred to the population of city dwelling units may illuminate general areas of substandard housing. But to decide the fate of each dwelling unit in a smaller urban renewal area would require a total enumeration of those characteristics of substandardness, particularly if each dwelling unit were a single detached house making it a population of one.

Total enumeration in urban planning also has some secondary cooptive effects which may be desirable. Public acceptance, compliance, response and support may be more readily forthcoming in the circumstance of total enumeration.

Sampling is not the unguided substitution of a portion of the population for the whole. Rather, the size of the sample required, the manner of drawing it, the measurement of sample characteristics and the inferences which can be made about equivalent population characteristics, and the errors and confidence limits on this information are all based on the rigorous application of the laws of probability and statistics.

From a conceptual standpoint, sample design is based on two considerations, size and selection.

\section{Sample Size}

Sample size is based upon the variance of the sample (and, by inference, the variance of the population) and not upon the size of the population. If the population were completely homogeneous, then the characteristics of that population could be measured with a sample of one. If the population were completely heterogeneous, then the characteristics of that population could only be determined by a total enumeration.

In reality, of course, most populations are a mix of homogeneity and heterogeneity over different characteristics. In practice, the sample size is usually determined by entering the appropriate equations with a desired variance. 
If, for a desired variance, the sample size derived is feasible in terms of time, economy, and personnel and equipment necessary to execute $1 \mathrm{t}$, it is utilized. The sensitivity of variance to size changes is examined and some judgement applied to the results.

The variance necessary to achieve the measurement objectives of the sample is estimated. It is estimated based upon the results of prior similar studies, or in some cases, the results of a pilot survey. Another common procedure is to collect a sample of some stated size, analyze the data, and if the objectives of the survey are not met, to increase the size of the sample by adding to it. This assumes that the sampling procedure is replicable and that the characteristics measured are not time dependent over the course of the procedure.

\section{Sample Selection}

Sample selection is a term describing the method of choosing the sampled elements from the total population. It takes various forms.

Simple Random Sample. This is the most basic and least complicated selection procedure. It requires three conditions; that the population to be sampled be clearly defined, that each element in this population be uniquely identified, and that the population elements are statistically independent. Given these three conditions, a necessary variance can be estimated, a sample size determined, that sample be randomly drawn from the total of the uniquely identified population elements, the characteristics of the sample measured, and these measurements inferred to the population as a whole.

The procedure of random drawing is accomplished by numbering each of the uniquely identified population elements and then drawing the sample, by number, using a table of random numbers. 
Stratified Simple Random Sample. Sometimes the population considered is already classified according to some principle significant to the projected analysis. Examples may be sex and age of human beings, buildings by age, neighborhoods by size, families by automobile ownership, etc. If the uniquely identified population elements can be assembled into strata homogeneous with respect to some known characteristic, simple random samples can be drawn from within the stratum and the resulting variance can be then considered in two parts - that resulting from sampling within the stratum and that between strata. If the stratification is indeed significant to the analysis, moderate variance reductions can be expected.

There are several types of stratified simple random sampling. It may be desirable to vary the simple random sample size from stratum to stratum, or, conversely, to hold the simple random sample size constant. It may also be desirable to allocate parts of the sample size to various strata in proportion to the anticipated variance in each stratum. This is called optimum allocation.

Systematic Sample and Stratified Systematic Sample. A more practical selection method may be substituted for the random selection described in the two methods above. This is called systematic sampling or stratified systematic sampling as appropriate and is obtained by determining the overal1 sampling fraction or the various strata sampling fractions. If this fraction is $1 / 100$ then 100 is the selection interval. A random start is established, say 37 and the sample selected is then elements 37, 137, 237, 337, etc. This method obviates the administrative complications that arise from using a table of random numbers to select every element, except, of course, the first element.

Systematic selection is a replacement for random selection, and, assuming no periodicity or linear trends in the population characteristics, may be freely used in either simple sampling or stratified sampling. 
Cluster Sampling. Homogeneity within strata has been described as a tool to reduce variance. Heterogeneity can be used also in the design of a sample. If it is suspected that, for the purposes of a particular survey, groups of population elements can be formed having the population characteristics essentially the same as those identified in random or systematic sampling, then the physical or analytical availability of these groups may make them economically preferrable to a random or systematic sample. This is called cluster sampling. The cluster basis can be analytic but is most often physical such as school rooms or city blocks. Clusters can be nested within clusters which are, in turn, within clusters. This is called multistage cluster sampling. Area sampling is a special form of multistage cluster sampling where the clusters are successive geographic units. Cluster sampling can be used with simple random or systematic sampling and stratefied sampling to create complex sample designs.

\section{Error}

The many types of error that enter a survey can be broadly classified into sampling errors and non-sampling errors. Non-sampling errors are those which would occur whether a sample is collected or a total enumeration made. An example would be trying to evaluate some characteristic of the population as a whole via a telephone interview. Obviously people who do not subscribe to telephone service would be ommitted. Further, this ommission would occur regardless of the method of survey; i.e., sample or total enumeration.

Sampling errors arise out of the general failure of the sample design or a lack of randomness where necessary.

Deming (1950) provides a classic list of sampling and non-sampling errors. He terms the latter procedural biases. Some of these include the failure of the 
questionnaire, the failure of the method of canvass, bias arising from non-response or late returns, bias arising from the interviewer, careless field procedure, and careless editing, coding and interpretation of the results.

Deming's illustration of the triangular relationship between non-sampling errors and sampling errors is shown in Figure III-3. The conceptual use of this figure is most helpful in determining the proper allocation of resources to the sampling technique.

In some types of simple industrial inspection, nonsampling errors may be relatively small and resources should be dedicated to the reduction of sampling error. In much of the survey work associated with urban planning, the converse is probably true.

According $1 y$, it is not uncommon for urban planning sampling procedure to incorporate a preliminary test of the survey, usually called a pilot study. This will serve to check the design parameters such as sample size, sample selection, procedural bias, interviewer effects and variance.

\section{Accuracy and Precision}

Precision measures sampling error. Accuracy measures total error, i.e., both sampling and non-sampling error. A precise design has a small sampling error and an accurate design has a small non-sampling error as well. In Figure III-4, design A is typical of say, a poorly designed mail questionnaire of a sample too small to measure a characteristic of the population. In design $B$, the sample size may have been expanded and stratified and the questionnaire left unchanged. In design $\mathrm{C}$, the original sample design remained the same, but the questionnaire was redesigned to remove bias, nonresponses were pursued, and editing and coding procedures were strengthened. Design D, of course, reduces both the sampling and non-sampling errors. 




$A B C$ represents some given error representation with $R M S E=A B$ RMSE = AD (a decrease in root mean squore error) can be achieved by :

1. an Increase in sampling error if the concurrent decrease in non-sompling error is great enough (AEF),

2. an increose in non-sampling error If the concurrent decrease in sampling error is great enough $(A G H)$,

3 or, of course, a decrease in both types of error (AKJ).

Figure III-3

The Relationship Between Sampling and Non-sampling Error ${ }^{1}$ 


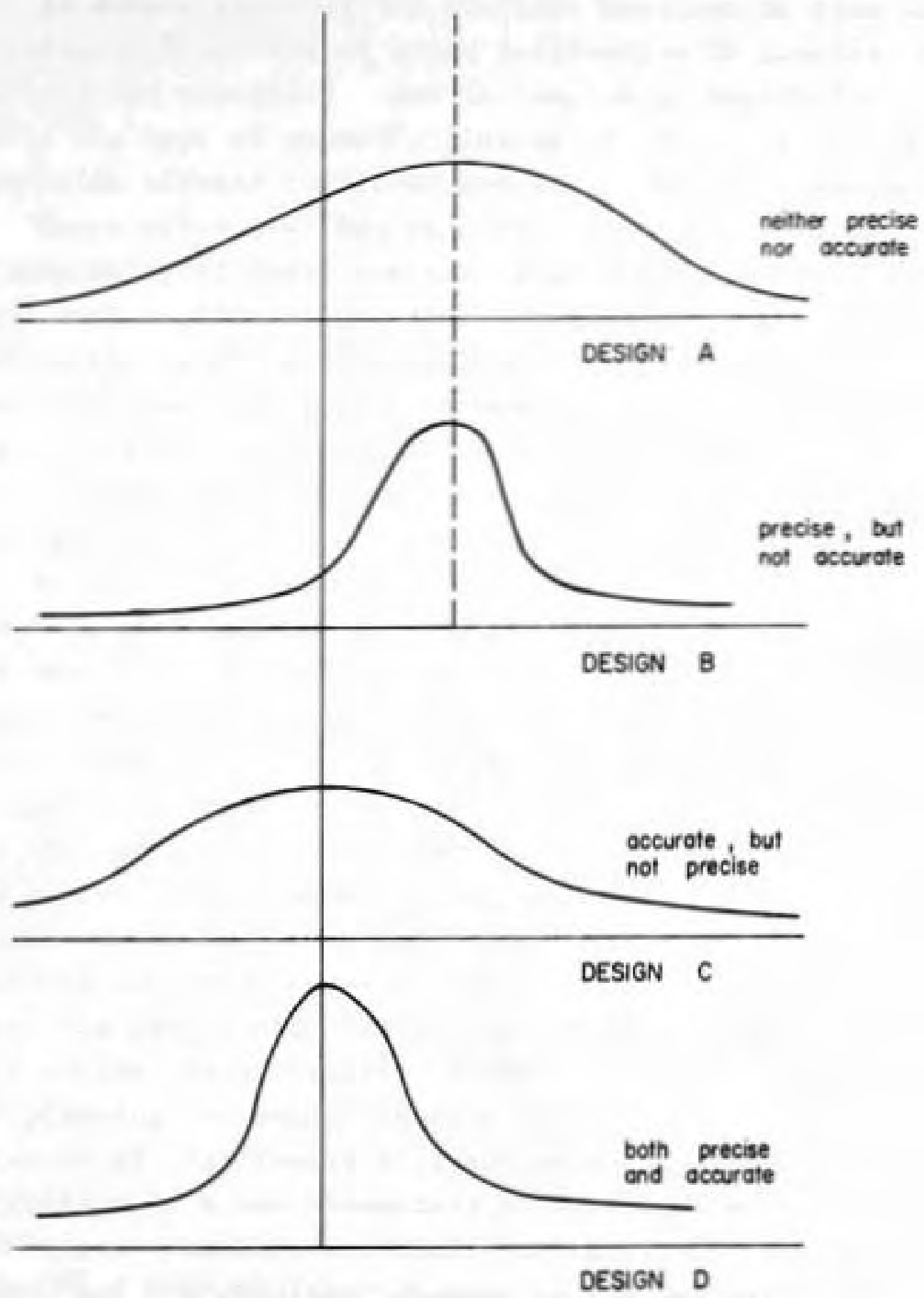

Figure III-4

The Relationship Between Accuracy and Precision 


\section{Urban Information Systems}

As demonstrated by the previous sections of this work, the collection and use of urban information is complex, time consuming and expensive. One is tempted to serach for short cuts in the hope of possibly finding the Holy Grail, the information already collected and available for planning.

Every urban area has an urban information system. The complexity of these systems ranges from the very simple to the most sophisticated. The simple systems are typically found in the files of municipal service agencies of smal1 towns. Examples are a list of dwelling units in a mail route, the fire chief's knowledge of fire main locations, a list of voters, familial information collected with school enrollment and church affiliation.

At the other extreme, urban information systems conceptually exist with complex models and data manipulations which measure real time changes in the urban area and take administrative action on these changes. An example might be the occurance of the relocating of a family in town. Here the information system might gather demographic data about the family, match the family to the new rented or owned parcel of land and dwelling unit, establish utility service and monitor consumption and bill, assign the children to schools and measure their impact on the school program, measure the new transportation service demands and their impact on the transportation system, and a whole host of other planning and administrative decisions. Perhaps the relocation of this family will automatically program the construction of a new elementary classroom, the hiring of an additional teacher, the reallocation of children to classes, and the resultant changes in the tax structure.

The planner is faced with two related problems in urban information. One is to search the already existing system, whether simple or sophisticated, for his data needs. 
The related problem is to consider the need for a system more sophisticated than that in existence. Some of the concepts which must be considered in upgrading the system's level of sophistication are addressed here to conclude this subject of the inventory phase of the urban planning process. Much of the information on this subject which follows was compiled from Maxman (1968).

\section{Information Hierarchy}

The conceptual formulation of an information theory has resulted in identifying a three step hierarchy of information (Horwood, 1964). The first stage of information is known as raw data and it consists of numbers, symbols, lists, etc., generally on paper and not yet organized into a machine record. When this information is machine processable, it is known as banked data, the second stage of the hierarchy. When this banked data is able to be manipulated such as in updating, searching and retrieval operations it is termed a data library.

Levels of System Sophistication

There are likewise three general levels of system sophistication. The first and most basic only tabulates data. The second level will contain certain specialized models which may, for instance, compare two parameters to form a ratio which may be considered valuable. The highest level of system sophistication describes that system that can both monitor and simulate the real world (Hamilton, 1964).

\section{System Development}

The choices of levels of system sophistication and hierarchy of information to be incorporated into an urban information system are based upon a number of criteria. Some of these are: the purpose of the information, the essentiality of the information, the cost of the information, 
the maintainability of the information, the ease of reduction and aggregation of the information, the applicability of the information to the users' end needs, the available hardware and software, and the political climate surrounding the establishment of the system (Hamilton, 1964).

These criteria are actually breakdowns of two essential considerations, the modules of collection and the methods of aggregation. In urban planning, the most commonly used module of collection is the land parcel. This makes good sense as urban studies are generally defined in place over the passage of time and it is the basic premise of urban planning that the physical arrangement of land uses has far reaching social and economic implications. Returning to Figure III-2, the land parcel provides information according to the logic diagrammed in Figure III-5. Thus, demographic, social and economic data are tied to the land parcel.

Since urban studies are located in space, the land parcel is also most valuable as a means of aggregation. with proper coding and programming, land parcels can be logically aggregated into blocks, tracts, zones, areas, and the political city as a whole. To maintain flexibility in this aggregation, the land parcel should be the lowest level of aggregation collected. Unfortunately, the information used in urban planning is sometimes private in nature and safeguards must be established against unauthorized disclosure of this information. Thus, the decennial census data is only published in aggregation sufficient to mask individual identification and its use is severely constrained in this respect. As a general rule, any data collected as an investment for future use would be in the least aggregated form possible. This principle differs from the highly utilitarian guidelines previously set forth for data collection for a specific planning process. For a specific process, the end use is known and it is more economical to 


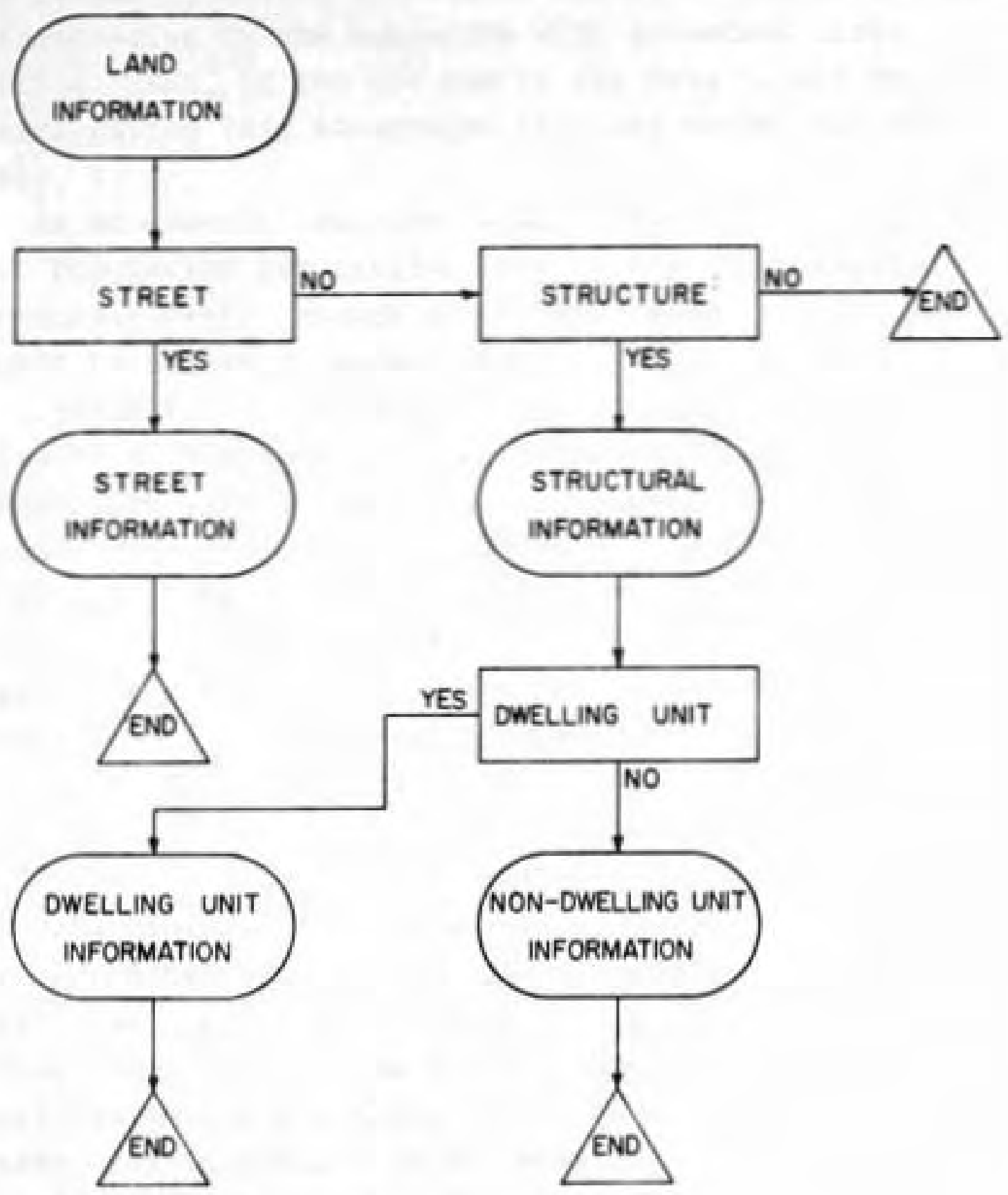

Figure III-5

Logic Diagram for Coding Information to Land Parcel 
use the highest aggregation of data feasible for two reasons; it is generally easier to obtain, and it facilitates analysis and forecasting in the aggregate with attendant error reduction. But, if the end use of the data is not known, any aggregation is a constraint that may render the data useless.

As an example, consider a data item measuring population. Population per traffic zone is highly aggregated and probably useful enough for macro transportation plans. It would be unwise, however, to collect population data in this aggregation for an urban information system. It would not disclose, for instance, the numbers and ages of children in a school district should that information be desired at a later date. Accordingly, population information should probably be collected by age and sex for each dwelling unit. Then any information necessary could be extracted from the system in any aggregation deemed appropriate. It is this need for future flexibility that makes the design of an urban information system so complex.

\section{Summary}

Urban information systems are expensive undertakings which accrue benefits only in the future. As such they comprise very real investments and must be judged as such. In these times, when so many public agencies and inunicipal authorities have great difficulty just meeting their operating expenses, the investment in an urban information system is difficult to justify. When it does occur, however, it signals a very real committment by that agency or authority to the philosophy of a continuing planning process.

\section{Notes}

1. After W. E. Deming, Some Theory of Sampling, p. $12 \%$. 
CHAPTER IV

ANALYSIS

In the ideal case of the conceptual model of planning activity, the analysis phase is something of a watershed. The goals and objectives of the client constituency have been established and endorsed by all concerned. The planning staff is organized and funded and is a viable entity. The drudgery of data collection is over and the planner now has everything at his disposal to plan. He has entered his element.

The rub is that in all too many cases, this element is unfriendly if not openly hostile. Instead of rigorous theory to guide him, he finds vague hypotheses. In the place of certainty he finds conjecture. Little seems universal, much is unique. Worse, some things claimed sure seem doubtful.

That this situation may be typical of a new discipline such as urban planning offers little consolation. The planner must face the prospect of evolving nearly ad hoc theories of urban behavior before he can begin to apply them. However he does have an arsenal of potent tools with which to work.

This chapter investigates some of those tools within the framework of the analysis phase of the planning process. Analysis is defined as the separating or breaking up of the whole into its parts with an examination of these parts to find out their nature, proportion, function and interrelationship. It implies the reverse, synthesis, as well. Analysis can and does occur with data at any point in time or over time. Historic data can be analyzed. Contemporary 
data can be analyzed and future data can be analyzed. The only distinction made in this work is that the actual forecasting of future data will be treated in the next chapter because, in practice, it follows at least the analysis of contemporary data.

Harris (1966) has correctly pointed out that urban planning analyses tend to follow the classical scientific method; induction, generalization, deduction, testing. While all these elements may not be present in a single plan, the distinction has its use.

Confronted with an array of data, the planner arranges the array into patterns. This pattern arrangement may come about as a result of intuitive feeling on the part of the planner, or as a result of his prior experience. From these patterns he generalizes their structural, spatial, temporal and functional relationships. These relationships may be based on a hypothesis of cause and effect, probability, or simply correlation. The planner analyzes from the specific conditions presented by the data to some generalities regarding their behavior. He thus induces theory. This theory is then applied to other sets of data, perhaps historical, perhaps from another planning effort, or perhaps from his own contemporary data (a subset not considered in the original induction). The behavior of the test data is deduced and then matched against actual observation. If the deduced behavior and the observed behavior are different, the theory must then be modified. If these behaviors are the same, the theory is not disproved and then used to describe the behavior of forecasted data.

As Harris notes, this distinction between induction and deduction is quite commonly blurred. Usually, induction begins with some preconception of theory. This preconception tends to identify the behavior patterns likely to occur. Also, when the deduced and observed behavior patterns differ, the planner returns to an inductive process to try to reformulate a theory. 
The fact that these preconceptions occur is not necessarily alarming. Based upon experience or insight, they may suggest theory that indeed proves to be valid. Further, these preconceptions are the only way to break the otherwise circular argument advanced in this work that one must design his analysis to see what data are needed, but one must investigate data patterns to design a proper analysis.

Implicit in analysis is a normative/substantive comparison. The analysis may demonstrate a cause for each effect, a probable cause for each effect or merely a correlation of effects or patterns. Some judgement needs to be made in any case as to the desirability of these effects. This judgement is facilitated by a comparison of that which is, with that which should be; or, for the future, that which probably will be, with that which probably should be. The philosophy and mechanics of these comparisons for design evaluation are discussed in Chapter VII, but this phase of the planning process and those following are rife with evaluative judgements and some aspects of this need be opened here.

Procedurally, the planner must take the observed contemporary data patterns, perhaps generalized into theory, and compare them to some normative data patterns or theory. This comparison of contemporary patterns to contemporary standards yields contemporary excesses, deficiencies, faults or aberrations which may then be deemed worthy to be met by short range corrective plans. The same holds true for selected times in the future. Key variables are forecasted, behavior patterns deduced, and these patterns are compared to forecasted future standards. At each temporal stage in the analysis, of course, previously injected plans have their effects. Plans are then conceived to shape and serve the deduced patterns. 
There remains the question of the source of these standards. First and forcmost they are based on the goals and objectives of the client constituency. The interpretation and refinement of these goals and objectives for a specific planning purpose has already been made in the organization phase of the process. It remains for the planner, with the advice and consent of the committees structured in the organization phase, to further refine these planning objectives into planning factors.

These planning factors are discrete, measureable criteria inferred from the objectives of the plan. As an example, suppose that "to provide for adequate housing for al1 residents" was a plan objective. It might be professionally inferred that minimum occupancy standards should include a measure of floor space per occupant. This planning factor may be then refined to mean 250 square feet today, 275 square feet five years from now, 300 square feet ten years from now, and so forth.

A collection of these planning factors describes a level of service of a particular entity. The planning design effort then centers around correcting contemporary deficient levels of service, forecasting future standard levels of service and then meeting these future levels in future plans.

The Use of Models

A11 the concepts, preconcepts, theories, patterns, and levels of service so far referred to can be generically called models. These models are the tools of planning analysis.

Lowry (1965) has noted that models can be classified as to their function. Descriptive models imitate some feature of the real world as it is observed. An urban descriptive model could possibly reduce the complex structure of a city to a set of relationships both coherent and 
rigorous. Such a model would show the interaction of the social, economic, political and physical environments of the city. But, by definition, such models will not help with information about the future or aid in the evaluation of alternatives.

If one adds to a descriptive model the notions of process and causality, the result is a predictive model. The planner generally begins with a desired output and tries to relate it to the available input. The inductiondeduction process is followed with the result that future input (plans and resources) is acted upon by future relationships (theory) yielding future output (the meeting of forecasted levels of service).

If the planner has more than one set of future inputs, as is likely to be the case, and wishes to test each set of future outputs seeking the most utile, he may devise a planning model. This is the most complex model in the Lowry scheme and the process includes the specification of alternatives, the prediction of the consequences of each alternative, and the rating/ranking of these consequences as to how well they fulfill specified goal statements.

The Strategy and Tactics of Modeling Lowry's classification suggests that there may exist a strategy of modeling. This strategy can be phrased as "employing appropriate techniques with a sense of style." There are two key concepts. Appropriateness suggests that which is right for the purpose and a proper fit. Each modeling effort must then be tied to a purpose, and fit both the specific purpose and auxiliary conditions such as quality of data and resources available. When any of these conditions is emphasized more or less than the others, dysfunction occurs. Examples of dysfunction include a modeling effort too simple by assumption for the quality of data available; the converse; too $1 \mathrm{ittle}$ or too much relative 
allocation of resources to the data collection and the modeling effort; and the generation of a predictive model based upon data which can only be poorly forecasted.

A sense of style refers to the artfullness of application. It is very closely tied to design and creativity and is the specific or characteristic manner of expression, execution and construction of the model. A sense of style, like appropriateness, only gains its meaning in application.

Contributing to this modeling strategy is a collection of tactics. One set of these tactics is that group of writings which deal with the choice between dichotomous facets of modeling. Harris (1967) offers a list of these facets which includes the distinctions between models that are: descriptive versus analytic, holistic versus partial, macro versus micro, and static versus dynamic.

The descriptive versus analytic distinction is the same as that between inductive and deductive reasoning. This has already been explored and it is only necessary to reiterate that each has its use in urban planning.

The holistic versus partial distinction is most manifest in the separation of urban planning practice and urban planning research. The practitioner is forced to take as holistic a view as possible whereas the researcher can afford the luxury of holding the balance of the urban environment constant while he investigates but one aspect of it. The distinction blurs as holistic views come to be aggregations of partial views. The substantive scope axis of the conceptual model of planning activity was devised to define the hierarchy of various types of urban plans. The distinctions along that axis came closest to mirroring the distinctions among various degrees of holistic and partial analyses.

Harris holds that the macro versus micro distinction centers around the level of aggregation concept. This was first addressed in the inventory phase of the planning 
process where it was noted that data should be collected on as disaggregated a basis as possible. The basis of this tactical distinction is, however, that most of the variables in urban planning only gain statistical meaning in aggregation. Thus we are interested in total street utilization, park space per neighborhood, sales in the CBD, school age population, etc., but these impacts are cumulative over discrete individuals, families, businesses and institutions. Micro analyses are often necessary to assess these individual impacts even though a macro analysis may show the cumulative effect of some change.

The static versus dynamic distinction is largely procedural. There is no philosophic difficulty in recognizing that urban systems are dynamic and should be so modeled. The difficulty is, of course, a computational one. For ease of conceptualization and manipulation, urban models are generally structured in static equilibrium. An approximation to dynamics is sometimes made through recursive manipulation.

Another class of tactics associated with model building deals with the relative propagation of error through possible model forms. Alonso (1968) suggests that the error propagated and amplified by "long chains of argument" may be so great as to obviate the benefit of these complex models. In this case, the aggregation or complementary use of simpler models may yield better results. As an extension of the strategy of appropriateness, poor quality data is probably best used in simple models. Further, error cumulates differently with different mathematical techniques. Alonso demonstrates that addition is the least dangerous of the mathematical operations. If one cannot add, multiplication or division are preferable to subtraction or raising variables to powers.

Yet another class of modeling tactics are largely situational in context. Bolan (1970) clearly rejects the 
notion that mode1s which are more clever, more complex, and which contain mure facts are per se necessarily superior to those with less such ingredients. He argues that the long range master planning predisposition of planners may make them too utopian in method and philosophy to model short range problems. Models must take into consideration political realities as well as technical bases. The power and capacity of the planning agency, the government as a whole, and the political process must be a part of the modeling effort. Fact should be distinguished from value judgments and further, there is a question of value to whom. Effects need be disaggregated and the diversity of value existent in society should be modeled, lest the planning decisions resulting therefrom force homogeneity where it is neither warranted nor wanted. Further, models should have relevant and real meaning to the client constituency in their planning situation. Analyses should answer questions that are utile, not questions that have not been asked.

\section{An Example}

That modeling should be at least as much art as science is apparent. Whether it be called creative technology or technologic creativity is a matter of indifference as long as both elements are present. The process occurs in the analysis phase of the conceptual model of planning activity.

Consider Figure IV -1 . Within the model this figure shows the organization, inventory and analysis of that planning effort which is defined along the substantive scupe axis as statewide (origin) to state parks (destinations). Illustrated are two analytical methods, typical of the many that could be conceived based upon the same organization and inventory.

Schulman (1964) designed a model of statewide state park recreational travel based upon the gravity model. 


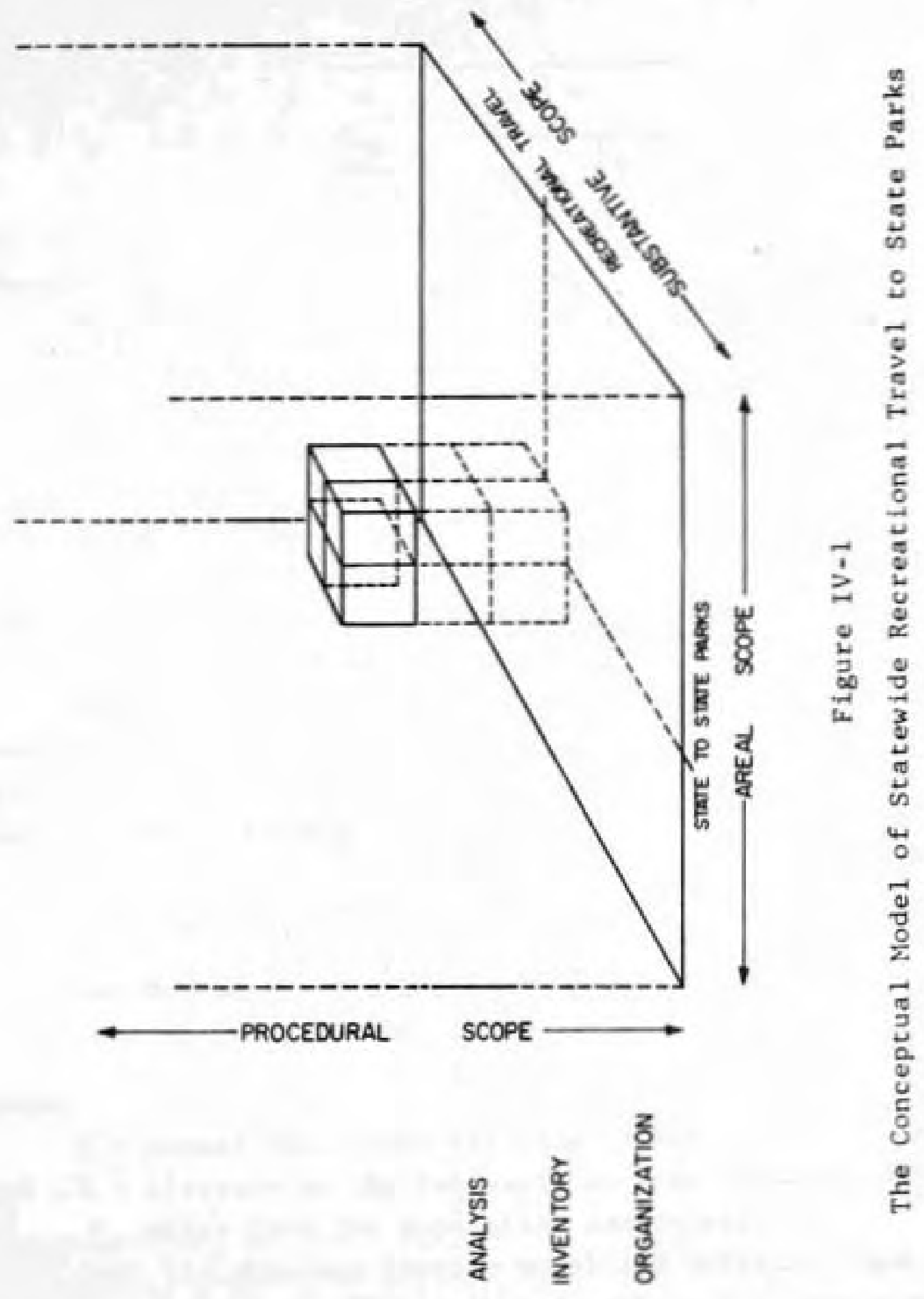




$$
T_{i j}=T_{i} \cdot \frac{\left(D_{i j}\right)^{1.64}}{\sum_{j=1}^{n} \frac{R_{j}}{\left(D_{i j}\right)^{1.64}}}
$$

where:

$$
\begin{aligned}
\mathrm{T}_{i j}= & \text { the number of automobile trips from residential } \\
& \text { area } \mathrm{j} \text { to recreational area } \mathrm{i}, \\
\mathrm{T}_{\mathrm{i}}= & \text { the total number of automobile trips attracted } \\
& \text { to recreational area } i \text { from all residential } \\
& \text { areas, } \\
\mathrm{D}_{i j}= & \text { the road distance in miles between residential } \\
& \text { area } i \text { and recreational area } j,
\end{aligned}
$$

and $\quad R_{j}=$ the number of recreational trips to all recreational areas generated from residential area $j$.

Matthias (1967), working with a similar problem, designed two models, one for travel to a state park when there was no intervening state park, and one for travel when an intervention occurred.

For the closest park,

$$
\mathrm{Y}=338 \mathrm{e}^{-0.579 x} \mathrm{x}
$$

and for an intervening park,

$$
\mathrm{Y}=129 \mathrm{e}^{-0.488 \mathrm{x}}
$$

where:

$\mathrm{Y}=$ annual trips from all origins per 1000 population, and $\mathrm{X}=$ distance to the recreational area in question in miles from the population centroids.

Both the Schulman gravity model and Matthias logarithmic model are inductive. Schulman apparently had a strong perconception that his data would fit a version of the well 
known gravity model. Matthias' work may have been more inductive in that the logarithmic form evolved from the data patterns. Both researchers then proposed using their models in a deductive way to forecast future trip generations.

Neither research was associated with an ongoing plan (such as to provide transportation service to the recreational areas) so there was no need to evolve and compare levels of service. Both Schulman and Matthias investigated the "level of service," so to speak, provided by already existent models of this type of behavior and felt that improvements could be made.

The models are both descriptive and predictive. Matthias' conceptual basis was that trips will be generated according to distance from the facility with due account for intervening opportunities. Schulman's conceptual basis was that trips will be generated in proportion to attractiveness and in inverse proportion to difficulty, resistance or "the friction of space". Both researchers assumed that historical patterns will continue which, however self-perpetuating, is hard to argue against, at least in the near future.

Both models are partial rather than holistic and both are macro rather than micro. In addition, both models are static although Schulman's has a wider conceptual use of equilibrium as it considers origins as well as destinations.

Neither researcher needed to consider the political environment. If this research were carried out in an applied situation, this environment would be very strong as has many times been demonstrated in the siting of major recreational facilities and their attendant impacts.

Outside of the contextual issue of a plan, it would be difficult to pass judgement on the adequacy of these models. It is apparant, however, that they model only a small part of something bigger. In addition, they are each composed of parts of smaller concepts which might be more meaningful if considered separately. The philosophic and procedural 
problems of "smallness", "bigness" and the feeling that everything may influence everything else leads quite naturally to the analysis of the behavior of systems.

\section{The Use of Systems Analysis}

\section{General Systems Theory}

Every systems analysis paper in the rich field of the discipline begins with a definition of a system. Definitions are elusive at times and this is perhaps no better exemplified than in the attempts made to define a system. For clarity in definition one usually 1 ists attributes or else makes some attempt to classify systems.

Generally speaking, a system is a set of related elements. Beer (1959) has noted that these elements can be simple and deterministic as in a window catch. They can be complex and deterministic as in an electronic computer. The elements can be simple and stochastic as a set of coin flips. Or they can be complex and stochastic as in a warehouse inventory system. There is usually reserved the classification of exceedingly complex stochastic for such systems as the United States Economy. The exceedingly complex deterministic system set is generally regarded as empty.

Systems analysis is an interdisciplinary endeavor. To prevent this endeavor from degenerating into undisciplined approaches, some integrating structure must be applied to the analysis. Boulding (1956) suggests that between the general constructions of pure mathematics and the highly specialized theories of specific disciplines there exists a general systems theory. There are two paths to this theory: an investigation of real world phenomena that themselves cross disciplines, and the study of the hierarchy of systems according to the complexity of their basic individuals. 
There are several real world cross disciplinary phenomena. The birth-survival-death syndrome is one which, for instance, can be applied to a living organism, an idea, a communication bit, an element in a queue and many otherwise unrelated occurrences. Other cross disciplinary phenomena include behavior, growth, and communication.

The second path to general systems theory could be the result of the following hierarchy of levels in systems analysis offered by Boulding. The first level is that of statics. Some typical systems in this level would consist of frameworks. Geography is a good example. The second level is that of simple dynamics. Implied here is regularity and a clockwork is a good example. The third level of systems is cybernetic in nature. These are those kept in a state of homeostasis by which a variable is kept between two limits and always tending to equilibrium. Blood pressure is a good example. The fourth level of systems constitutes those that are open or self-maintaining such as the cell. This level is usually the limit of theoretical systems study. The fifth level is genetic-societal in nature. An example of this is the society of ceils in a plant. The sixth level is that of self-awareness and is characterized by animals. The seventh level of systems is that of selfawareness coupled with abstraction and is typified by man. The eighth level is that of human social organization and it is the level of the nature and dimension of human value systems. An understanding of this level would benefit the discipline of urban planning. The ninth and highest level of systems is that of transcendence and the systems characterized by this level are beyond human experience.

Another hierarchy of levels of systems based on their degree of automaticity has been offered by Kossiakoff (1960). The zero order system replaces no human energy and assumes no control function. Examples are hand tools. The first order system requires energy but input and control are 
supplied by man. Examples include bench saws and pneumatic dri11s. The second order system uses mechanical power exclusively but man must start-stop the system. Examples are radial drills and pipe threading machines. The third order systems are completely self acting and first generation automatics. Examples include special manufacturing machines as for cigarettes, lamp bulbs and bottling. The fourth order system measures its own performance and corrects to a standard. Examples are oil refineries, generators and regulators. The fifth order system automatically solves problems according to pre-specified control equations. An example is a pre-programmed computer controlled machine. The sixth order system is that of system solution to complex formal $\operatorname{logic}$ conditions. Examples include telephone circuits and robots. The seventh order system learns from its mistakes, attempts different modes of operation as necessary and improves its techniques. Examples include any system that learns by experience. The eighth order system extrapolates from its experience, forms modes of operation beyond its experience and performs inductive reasoning. Examples include systems that have intuition. The ninth order of system can create beyond itself.

Because of the breadth of systems analysis and because the analysis is compounded by the fact that systems exist in systems, the search for a general systems theory is probably futile in terms of the end desired. But the ancillary effects of this search yield new techniques and perspectives, the value of which cannot be denied.

So finally we are forced to define systems analysis by listing its characteristics. Fundamental among these is the definition of the problem and the systematic examination of objectives and of the alternative ways of achieving these objectives. Systems analysis often is iterative in nature, involving formulation, testing, reformulation, re-testing, etc. Even if the conclusion of the process is that there 
is no preferred alternative, the process itself is often of educational value to the decision maker. The time frame of the analysis usually extends far into the future and as such is often fraught with uncertainty. Often there exists the possibility of catastrophic outcomes and this might preclude the use of simple expected value models. Sensitivity analysis and contingency analysis are often better tools. Systems analysis usually deals with problems within a very broad context. Straight-forward solutions are the exceptions in the welter of variables and often simulation by a black box is required, For this same reason many systems analyses are neither exhaustive nor entirely quantitative. As stressed earlier, this does not necessarily negate their value.

Despite the complexity of some systems, some useful classifications can be made of systems in terms of their analytical properties. The first distinction that is usually made is between natural and man-made systems. often clues to behavior of systems can be obtained simply by this distinction although the distinction may not be easy to make. Once made, there exists the possibility of applying such things as the Newtonian Laws or the precepts of the behavioral sciences as applicable to the system in question.

There exists an analytical distinction between an open and a closed system. Open systems exchange materials, energies or information with their environment. A closed system operates independently of environment. Some systems are characterized by their control mechanisms. An open loop system is one which once activated permits no further control. A closed loop system permits and possibly requires control. Feedback may exist in either system but when it is used for active control it "closes the loop." Yet another distinction usually made is that between adaptive and non-adaptive systems. Adaptive systems are those that possess the ability to react to their environment in such 
a way that is favorable to the continued operation of the system.

\section{Urban Systems Analys is}

Most long range planning decisions are reached through the use of the decision maker's judgment and intuition. The role of systems analysis in this process is the same as that of English, arithmetic and science. All of these taken together influence and hopeful1y sharpen the judgment and intuition of the decision maker. In almost no cases can the results of systems analysis be taken as the optimal decision because of the unquantifiable nature of some of the variables .

To more clearly define the role of systems analysis in planning, it would be helpful to define the extremes of opinion regarding it. At one end of the spectrum there are those who say that planning is entirely intuitive and based only on personal judgment and experience. At the other extreme are those who deny the role of anything not neasurable in numbers. The usual outcone of either of these two positions is either a model so simple that it no longer fairly represents the system, or an analysis so complex that it is not available until two years after the decision had to be made. Obviously the correct range of endeavor is between these two limits.

These two extremes are mirrored in the applications of systems analysis to urban problems. Moore (1966) notes that at one extreme there are people who argue that there is a wide range of problems simply begging for analysis within the urban sphere. These people maintain that there is a wealth of methodology even today available that is not being properly exploited in urbanology. Other people dispair that when analyses have been carried out they have not been used for decision making due to institutional and political constraints. 
The two positions are reconcilable. Their reconciliation involves defining the characteristics which make certain problems suitable for the application of systems analysis. This involves a consideration of such issues as welfare economics and political institutions, public goods vis-à-vis private goods, incentives in the operation of specific systems and the political feasibility of alternatives.

The provision of public goods generally requires the consideration of multiple objectives. Among these objectives are to use resources efficiently, to be equitable, to benefit special groups, and to permit scope for individual initiative. The trade-offs required in making any decision here are largely subjective in nature and perhaps best left to the political arena. The very least required of the systems analyst under these conditions is to specify alternative outcomes for different criterla. A more worthy project would be to formulate a clearly superior and universal set of criteria.

Moore notes that another problem which overlaps analysis and politics rests with the design of incentives. Too often such items as rent subsidies and tax preferences are not self adjusting to market conditions and freeze into the economy.

Surely the safest problems on which to conduct air tight analyses are those which are very limited in extent. It does not take much imagination to realize that these local optimal solutions are most probably suboptimizations in the next system and so on ad infinitum. Even with that in mind we can, and indeed must, suboptimize at higher levels than the present.

Even so, systems analysis will never reduce urban planning to an objective process. The substance of such planning is too subjective; the political process in which planning must take shape is too subjective; and decisions 
which must be made about planning are made with bounded rationality, constrained by such humanist qualities as politics and ethics, and, on a lower level, by human frailities such as ignorance and prejudice.

Nonetheless, systems analysis brings to urban planning some significant benefits. First and foremost, systems analysis is educative as to both the plan process methodology and the plan itself. It ties policy, function, process, programming and budgeting together in one analysis. It may disclose wasted resources, clarify issues, reconcile conflicting or overlapping objectives. It may possibly introduce a sense of unity to otherwise disparate features or seemingly unrelated aspects of the plan or planning process.

In conclusion, systems analysis is not merely the use of complex and holistic models. Rather, systems analysis is itself a precedural model of a method of approach to problems. It involves the specification of objectives, the systematic search for alternative methods of achieving these objectives, and a comparison of the results obtained through the use of each alternative. Models, analytical methods, and scientific procedures are used, but their assembly and application are strong functions of intuition and imagination.

The application of systems analysis to the urban planning process is direct and obvious. In fact, there is no major difference between the use of systems analysis in planning and the planning process as described in this work. As a planner moves along the procedural scope axis of the conceptual model of planning activity, he executes a systems analysis. Objectives are defined, a multidisciplinary organization is established, data are collected, analyses are made and tested, parameters are forecasted, urban designs are conceived and evaluated, the most 
optimal is selected according to some rational process, and the selected plan is implemented. The consummate planner is a systems analyst. 


\section{CHAPTER V}

\section{FORECASTING}

With this step the planner begins the second half of the planning process. Typically more than half the resurces available to him have been expended, but this should cause no great concern as it has already been recognized that the inventory phase is very expensive and time consuming and this has been taken into account in the study design.

Since plans are concerned with future activities, the analysis of contemporary data alone does not normally provide a strong rational base for any but the most remedial or short range plans. The planner is now forced to manufacture or synthesize a future inventory for the development of future planning demands. There is a very clear clement of uncertainty in this formulation. This forced, synthetic, probabilistic and assumptive "inventory" for the "analysis" of future planning conditions is called a "forecast."

Sometimes the historical inventory already taken yields data too aged to accurately portray the contempory conditions. The planner must not only then forecast into the future, he must also forecast from the past into the present. This latter process has come to be called "estimating" and this convention is maintained here.

The techniques of estimating are generally the same as those of forecasting. Usually, however, some of the inputs to the estimating procedure are presently known for certain, thus making estimating less risky than forecasting. Before considering some of these techniques it is necessary to examine the general conceptual bases for forecasting. 


\section{The Forecasting Model}

Consider Figure $\mathrm{V}-1$. It represents the forecasting phase in the conceptual model of planning activity.

\section{Substance}

Along the substantive scope axis of the conceptual model of planning activity, forecasting is used in all types of planning. However because of the risk and difficulty involved in forecasting the conditions at any point in the future, only a few key variables are forecast. All other future conditions are then inferred from these forecasts.

These key variables are characterized by two general conditions. They are forecastable with some degree of confidence by some generally accepted and rational technique; and they are so closely linked to other desired variables, either by cause or correlation, that the behavior of these other variables can be inferred from the behavior of the key variables.

Suppose that the inventory phase of the planning process yielded the data conceptually shown in Figure $\mathrm{V}-2$. Sone of the data are current and some are three years old. Suppose further that the planning process was designed to provide a plan for five, ten, and fifteen years into the future. Figure $\mathrm{V}-2$ shows the development of: first, the estimate of the present condition; second, the five year forecasts of the key variables; and third, the expansion of those variables by inference at each of the five year points of investigation.

The present or past measurement of all the variables is the inventory phase of the planning process. The establishment of the inferences for this contemporary data (estimated data if need be) is accomplished in the analysis phase. Key variables are then forecasted and inferences drawn from them as to the behavior of other variables based upon the discovered contemporary inferences. In the example 





128

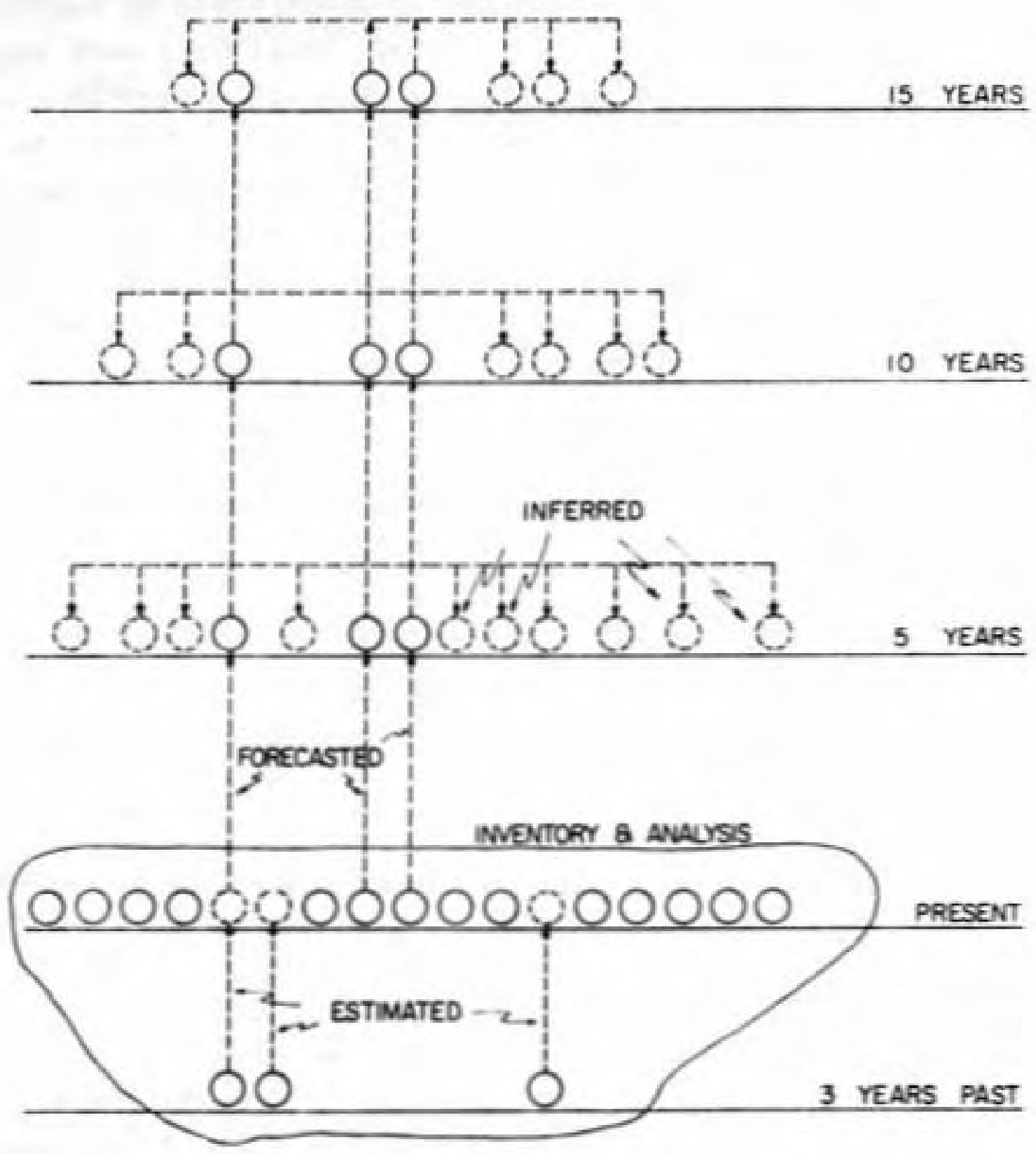

Figure $\mathbf{V}-2$

A Conceptual Forecasting Model 
shown in Figure $\mathrm{V}-2$, the forecasting is halted every five years of forecast time and the behavior of the inferred variables is deduced. Some of these inferences may be declued by the planner to be viable only in the near future and thus the figure shows a gradual reduction in the number of inferences drawn as the fifteen year forecast year is approached. Should the circumstances warrant it, no intermediate inferences need be made at a11, or, conversely, inferences could be drawn yearly or monthly into the future. The substance of the key variables for all types of urban planning is one or more of the following: measures of economic activity, population characteristics, land use characteristics, and transportation characteristics.

Each of these key variables can be further broken down into demand variables, resource variables, or standard variables. The interest of the planner is in properly satisfying the future demand for recreation, housing, community facilities, streets, or whatever the substance of the plan in question. This demand is forecasted, future standards of satisfaction are applied to the forecasted demand yielding forecasted requirements. These requirements are met by the allocation of resources forecasted to be available.

Consider, by way of example, the forecasted demand for retail food shopping in an area. This demand is generated by the resident forecasted population in the area. It also need not be forecasted as a key variable, but rather inferred from the forecasted population.

The demand is very obviously related to a resource variable which measures the supply of land likely to be available for retail food merchandising, and number and types of retail food merchandising establishments, their spatial distribution in the urban area, and the buying population hinterland necessary to support each of them. 
The specific relationships between the forecasted fermand variables and the forecasted resource variables are the forecasted standard variables. These standard variables measure levels of service. Examples in this case might include a maximum walking distance between households and convenience food shopping, the parking necessary for a supermarket, and the residential population necessary to support such a supermarket. Not only must the denand and rusturce variables be forecast, but the relationships between them, the levels of service, these standard variables tust be forecast as well. Perhaps there will be no need for convenience shopping, perhaps supermarkets will take over this function, perhaps delivery will assume a greater impurtance, perhaps people will shop less often, or more often, etc. Each of these assumptions creates a different state of nature. In the forecasting of standards, there tend to be several possible states of nature with associated probabilities that are either nearly equal or difficult to eviluate at a11. In contrast, the forecasting of demands and resources typically considers only a few states of nature and one of these usually predominates. In the example, the forecasted population is unlikely to change present eating habits.

Another complicating factor is that acceptable levels of service tend to rise. As soon as a certain level of service is met, the public expectancy grows and clamor is soon raised for the newer, the better, the faster, the less expensive and the more convenient.

Thus, the forecasting of standards is something of the bête noire of urban planning. The beast must be approached however, to help reduce the many unanswered denunds and oversupplys that plague modern urban 1 ife.

The distinction between planning in the public sector and planning in the private sector has been assiduously avoided thus far in the model because it is not until 
forecasting that it gains meaning. Consider Figure $V^{-3}$ (a). It shows four forecasts of a hypothetical variable based upon different sets of assumptions. The solid line is the forccast based upon a continuance of present governmental policies and no significant cultural changes. It is thus the most likely occurrence. This depends, of course upon how distant the forecast year may be, but is particularly likely in the near term because of cultural and governmental inertia effects.

The private sector is nearly powerless to affect the occurrence of this condition. As such, planning in the private sector seeks to meet these forecasted conditions in the best possible way. This is usually measured in terms of profit. The most likely forecast is taken as a "given", speculation on the other forecasts ends, and the process continues from this point.

The public sector, on the other hand, has some powers aviliable to $t$ thich may change the likelihood of the different forecasted outcomes. Suppose it is deemed that point $A$, in Figure $V-3$ (a), is a forecast with qualities deemed preferable to those of point $B$, resulting from a continuance of present public policies. What results then is the first major design decision faced by the planner. He must consult very closely with the client constituency and they together must determine whether they will simply plan to meet the conditions of point B, as in the private sector, or accept a higher risk course of changing public policy or public culture in the plan in an attempt to reach point A.

The degree of risk involved, in addition to the risk of forecasting itself, depends upon the substance of the forecast. If points A and B represented amounts of land zoned for high density apartment use and the local planning commission could easily change the limits on this use, then, if subsequent market pressure could be withstood, therc crold 


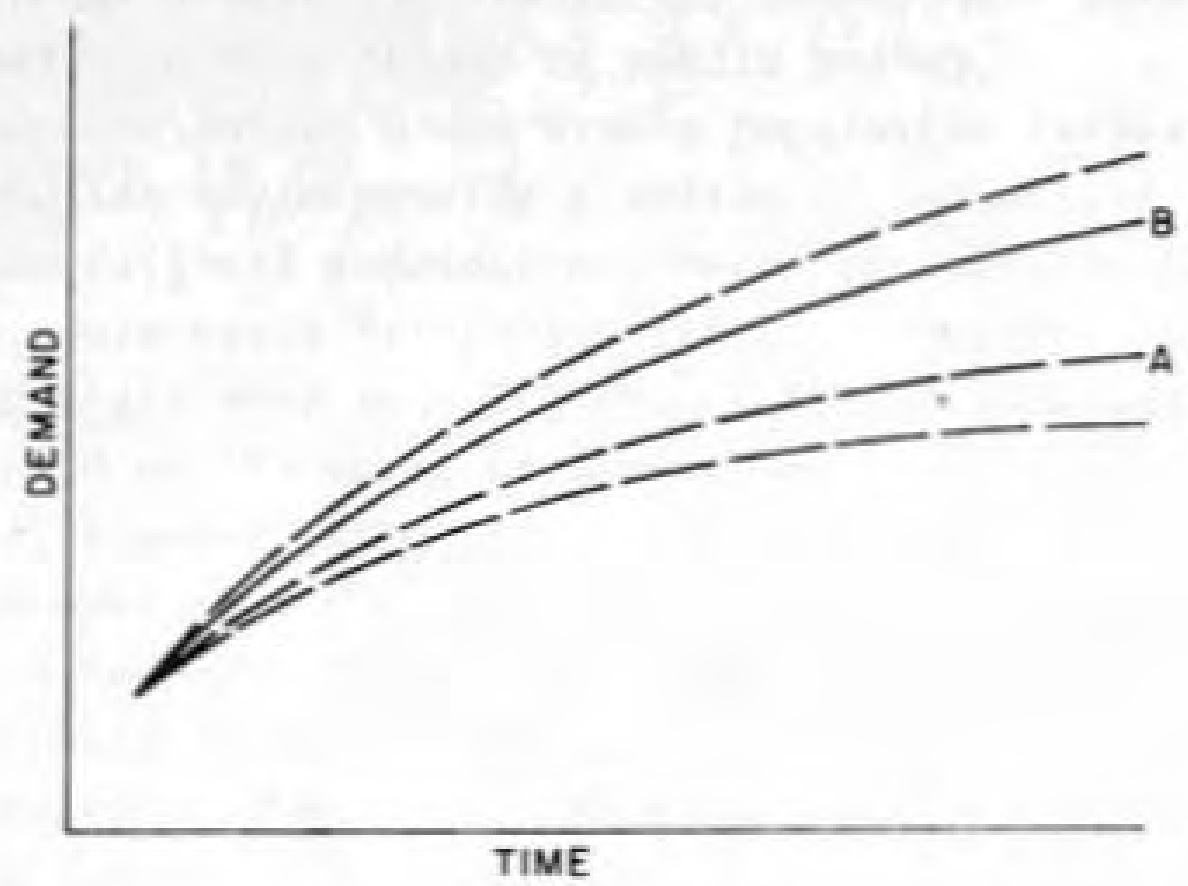

(a)

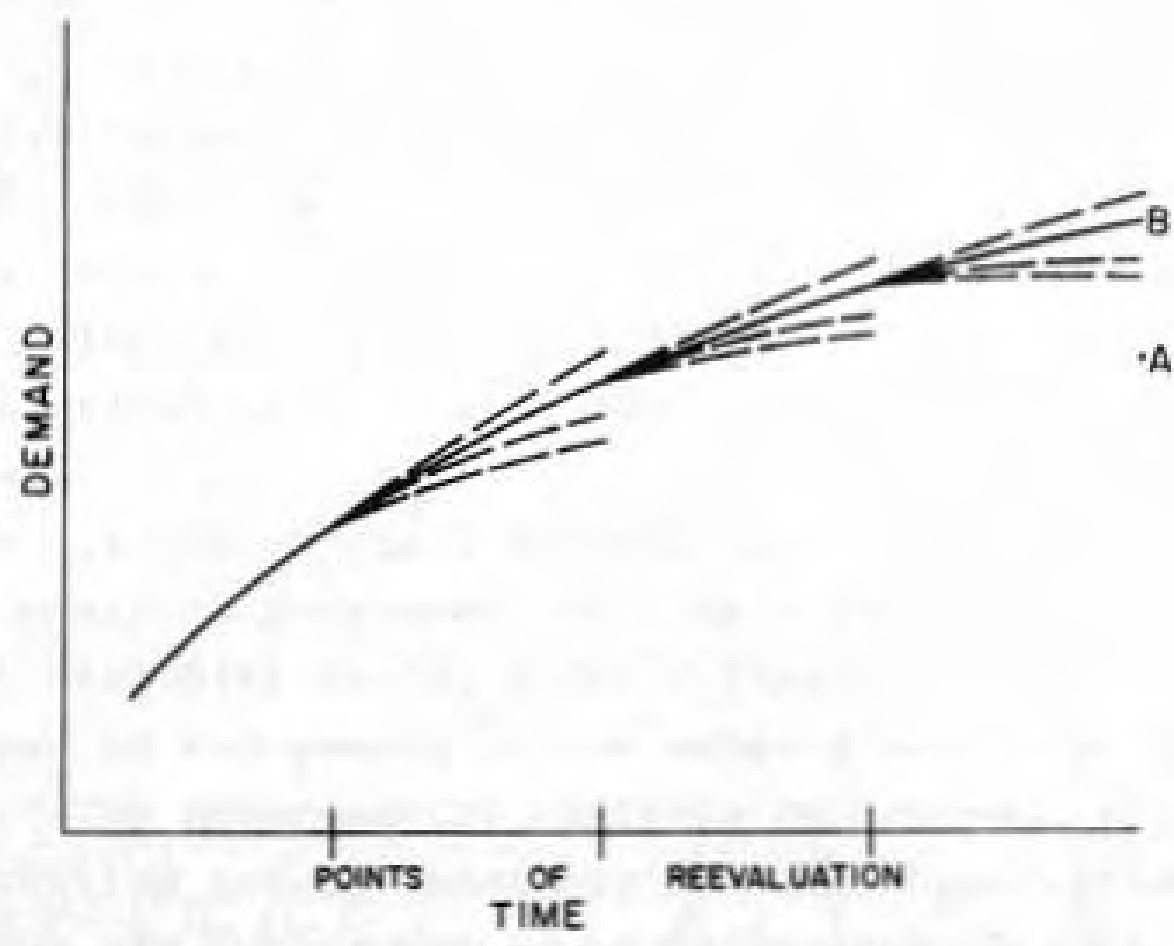

(b)

Figure $V-3$

Conceptual Forecasted Outcomes 
very well result less of this use and the public policy could change public culture in the community. This is a relatively low $\mathrm{r}$ isk change in public policy.

Suppose points A and B were population forecasts. Public policy could provide a system of incentives and penalties to 1 imit population growth, perhaps the public culture would react favorably with these programs and the forecast might move away from point $B$ towards point $A$. But to plan on the forecast significantly moving is probably a high risk undertaking.

In practice, the criticality of decisions of this type is muted by three factors. First, planning is continuous, not only within the process as outlined here, but also "from process to process" over time as inputs change. Changing inputs include changing personalities, changing resources, changing demands, changing values and changing complimentary or supplementary programs and conditions. Thus, although planning may consider effects fifty or even one hundred years into the future, the programs generating those effects will be reviewed almost as many times in the interva1. The forecast conceptually shown in Figure $V-3$ (a) actually occurs in a pattern similar to Figure V-3 (b) as time goes by, with resultant corrective programs (if the hypothesis is still valid) or (should conditions change) new plans entirely.

The second muting influence has as its basis the linited power of government in a democratic society. Although some key variables could, under different circumstances, be considered as endogenous to the urban planning process, they are not. The governmental controls on economic activity and population growth necessary to make these vartables endogenous are too severe to be in consonance with the laissez-faire tradition of United States government. As a result, these variables are considered exogenously with, at most, only a inild warping of their expected outcomes resulting from governmental activity. 
The third muting influence is operational in nature. In order to get on with the design of alternative solutions to any problem, that problem must be bounded, perhaps assumptively, but bounded nonetheless. There is a clear need for rigorous urban theory and for this reason the planner and client constiuency must not be capricious in cutting off debate. That point must come, however, and when it does, the conclusions then reached are taken as "givens" and the problem solving process proceeds. This does not preclude the important concept of feedback, but for the substance of forecasting, the feedback loop is too long and awating its information is antithetical to planning. To the philosophers we leave the rest.

\section{Area}

Concerning the areal scope axis of the conceptual model of planning activity, only a few points need be made regarding forecasting.

In the inventory phase of the process, it was recognized that delimitation of the study area could have a significant impact on the inventory. As might be expected, this holds true for the synthetic inventory, the forecast, as well. In particular, however, some measures of economic activity are very sensitive to areal delimitation. Further, some forecasting techniques make use of historical areal relationships to "step down" greater area forecasts to their lesser area conponents. This occurs because large area forecasts can be made with greater confidence than small area forecasts, a11 else being equal.

The problem with large area forecasts rests with the loss of refinement. This becomes especially apparent when the object of the study at hand is to locate some particular facility. The large area forecast may indeed warrant the location of that facility but the question of where, within the area, may require an additional subdivision of the 
large area, an additional analysis making that already done wasteful by reason of being inconclusive.

In general, the area under consideration in the planning process is subdivided according to the homogeneity of the forecasted variable. There may be areas of a certain kind of residential land use, areas of a certain population density, areas of a similar family income, areas of similar transportation demand, or whatever else may be under consideration. The homogeneity of the forecasted characteristic enables the planner to treat these variables in aggregate rather than to have to deal with each family, each automobile and each residence.

Thus the problem of areal subdivision for forecasting involves balancing the three characteristics of largeness for methodological simplicity, smallness for refinement and the degree of homogeneity of the important forecasted variables.

\section{Procedure}

The point was made earlier in this chapter that the substance of the forecasted key variables for all types of urban planning is one or more of economic activity characteristics, population characteristics, land use characteristics and transportation characteristics. Those characteristics dealing with economic activity and population tend to be much more exogeneous than the remaining two, and procedurally are usually forecast first. They are as near to primary inputs as exist in urban planning, whereas transportation and 1 and use characteristics are more clearly associated with whatever the nature of the plan in question happens to be.

Population and economic activity characteristics can methodologically be forecast independent of each other. This then provides a cross check of at least some of the characteristics. From population studies one could deduce 
employment and income; and from economic activity studies one could deduce employment thence population.

Land use and transportation characteristics are less independent of each other. Different land uses affect the transportation system differently, and differest transportation facilities tend to promote different land uses. The forecasting techniques for these characteristics are recursive, involving trial distributions and tests for internal compatahility as well as satisfaction of boundary conditions.

Some of the forecasting techniques are quite sophisticated and draw from academic disciplines not orly supportive of urban planning but also with a body of knowledge and methodology unique to them. This is particularly true with regional economics and demography. Accordingly, the question of hiring professional staff to execute these forecasts must be addressed in the organization phase of the planning process.

\section{Forecasting Techniques}

This section on the forecasting phase of the urbau planning process concludes by stepping back from conceptuat considerations and operationally considering some of the commonly used specific forecasting techniques. Many are adapted from other original uses and combinations and permutations of techniques which have been used ir. the past. There are clear favorites, but the application of any is a strong function of not only the end use of the forecast, but also the resources available to execute it.

\section{Economic Activity Forecasts}

Almost all economic activity forecasts make use of national or regional forecasts as primary inputs, and selectively apply this data to smaller areas of influence. The selectivity of application ranges from the nost relined to the most crude. 
In general, the planner must seek to answer the question "What are the effects on the area in question if a certain industry with a certain number of jobs moves into or out of the area?" The most crude method of analysis is to assume average conditions for the industry, area, and jobs and to apply national averages supplied by such, organizations as the II.S. Chamber of Conmerce. Onc streh set if averages (Community Relations Fact Rooklet, 1969) might say that, for every one hundred new factory worker: there will be:

359 more people,

$\$ 710,000$ more personal income per year,

3 more retail establishments,

100 more households,

97 more passenger cars,

$\$ 331,000$ inore retail sales per year,

91 more school children,

$\$ 229,000$ more bank deposits, and

65 more people employed in non-manufacturing.

One of the most refined methods is that of inputoutput analysis (Leontief, 1951). The conceptual basis of this method is that every industry in a given area has it relationship to every other industry in the area, and that these relationships are measureable and can be expressed by a series of mathematical equations. For each industry, an analysis is made of the distribution of its output and the sources of its input. Many of the inputs are themselves outputs of another industry requiring another analysis and iterations continue until the process converges. What results is a many level model of the area economy in terms of production. The use of input-output analysis in forecasting occurs when some share of national or regional forecasted demand can be inferred to the areil in question. Then the impacts of this larger demand can be traced through the axdel of the area economy resulting in area forecasts. 
As an example, consider a simplified hypothetical area with only three industries, printing, paper, and chemicals. For every dollar's worth of printing output, fifty cents is spent on paper, five cents on chemicals, and a penny is spent by the printing industry itself. For every dollar's worth of paper output, a penny each is spent on printing and paper and five cents is spent for chemicals. And for every dollar's worth of chemical output, a penny each is spent on printing and paper and forty cents is spent for other chemicals. The transaction table is shown below.

Table V-1

Cents Worth of Input per Dollar Output

Printing

Paper

Chemicals

$$
\text { Printing }
$$

1

50

5
Paper

1

1

5
Chemicals

1

1

40

Suppose the national or regional paper production is forecasted to rise and that this hypothetical area's share of that rise is forecast to be one hundred dollars. The biggest assumption in the technique is that the inputoutput relationships w111 continue to hold true, so that the first effect is a dollar rise in printing production, a five dollar rise in chemical production and an additional dollar rise in paper production. This is entered in the first round of input requirements shown in Table $\mathrm{V}-2$.

These first round requirements likewise require inputs in the same fashion. The five dollars worth of chemicals generates $f$ ive cents worth of printing ( $\$ 1$ input/ $\$ 100$ output $X \$ 5$ output); five cents worth of paper ( $\$ 1$ input $/ \$ 100$ output $X \$ 5$ output); and $\$ 2$ worth of additional chemicals ( $\$ 40$ input $/ \$ 100$ output $X \$ 5$ output). So too for 
As an example, consider a simplified hypothetical area with only three industries, printing, paper, and chenicals. For every dollar's worth of printing output, fifty cents is spent on paper, five cents on chemicals, and a penny is spent by the printing industry itself. For every dollar's worth of paper output, a penny each is spent on printing and paper and five cents is spent for chemicals. And for every dollar's worth of chemical output, a penny each is spent on printing and paper and forty cents is spent for other chemicals. The transaction table is shown below.

Table $V-1$

Cents Worth of Input per Dollar Output

$\begin{array}{lccc} & \text { Printing } & \text { Paper } & \text { Chemicals } \\ \text { Printing } & 1 & 1 & 1 \\ \text { Paper } & 50 & 1 & 1 \\ \text { Chemicals } & 5 & 5 & 40\end{array}$

Suppose the national or regional paper production is forecasted to rise and that this hypothetical area's share of that rise is forecast to be one hundred dollars. The biggest assumption in the technique is that the inputoutput relationships will continue to hold true, so that the first effect is a dollar rise in printing production, a five dollar rise in chemical production and an additional dollar rise in paper production. This is entered in the first round of input requirements shown in Table $\mathrm{V}-2$. These first round requirements likewise require inputs in the same fashion. The five dollars worth of chemicals generates five cents worth of printing ( $\$ 1$ input) $\$ 100$ output $X \$ 5$ output); five cents worth of paper ( $\$ 1$ input $/ \$ 100$ output $X \$ 5$ output); and $\$ 2$ worth of additional chemica1s ( $\$ 40$ input $/ \$ 100$ output $X \$ 5$ iutput). So too for 
Table V-2

Input Requirements in Dollars

First Round Second Round Third Round Total

\begin{tabular}{|c|c|c|c|c|c|c|}
\hline Printing & 1 & $\begin{array}{l}.01 \\
.01 \\
.05\end{array}$ & .07 & $\begin{array}{l}.007 \\
.006 \\
.021\end{array}$ & .034 & 1.104 \\
\hline Paper & 1 & $\begin{array}{l}.50 \\
.01 \\
.05\end{array}$ & .56 & $\begin{array}{l}.035 \\
.006 \\
.021\end{array}$ & .062 & 1.622 \\
\hline Chemicals & 5 & $\begin{array}{r}.05 \\
.05 \\
2.00\end{array}$ & 2.10 & $\begin{array}{l}.004 \\
.028 \\
.840\end{array}$ & .872 & 7.972 \\
\hline
\end{tabular}

the dollar each of printing and paper generated in the first round to complete the second round input requirements.

These second round requirements generate third round inputs, and so on until the process converges.

In the example, it is seen that after three rounds, the one hundred dollar increase in paper production generated 1.104 dollars worth of printing, 1.622 dollars worth of additional paper, and 7.972 dollars worth of chemicals.

The construction of the input-output model for an actual urban area is very complex and this technique suffers from the general lack of necessary published data. As a result its use is limited by resource constraints.

Another refined technique is based upon the economic base of an area (Tiebout, 1962). The conceptual basis is that any area contains but two classes of economic activities; firms and individuals serving markets outside of the area, and firms and individuals serving markets inside of the area. The economic activities serving export markets are "basic" and those serving local markets are "non-basic". The basic economic activities are the prime movers of the area economy. Non-basic economic activities follow from and are a result of basic activities. The measure of "activity" could be 
employment, sales, value added, or income accruing to residents. Economic activity serving both local and export markets is prorated accordingly.

Just as in the input-output technique, the economic base technique traces the flow of this economic activity from industry to industry. What results is another model of economic behavior, this one showing the impact on both basic and non-basic activity for any exchange in the basic portion of any activity.

As an example of this tracing or linking of economic activities, consider again the simplified economic area composed of the printing, paper, and chemical industries. Suppose that the printing industry sold $80 \%$ of its output to private concerns outside of the area under consideration, the "exports private" sector. Another $17 \%$ is sold to the federal government, "exports government", and the remainder is sold locally, a percent each to other printing, the paper and chemical industries. Similar data are inventoried for the paper and chemical industries and the results are tabulated below.

\section{Table V-3}

\section{Allocation of Sales by Percent}

Private Government

Exports Exports Local Printing Paper Chemicals

$\begin{array}{lrrrrrr}\text { Printing } & 80 & 17 & 3 & 1 & 1 & 1 \\ \text { Paper } & 28 & 20 & 52 & 50 & 1 & 1 \\ \text { Chemicals } & 10 & 40 & 50 & 5 & 5 & 40\end{array}$

Before the planner can say that the printing industry is $97 \%$ export $(80 \%+17 \%)$ or that the paper industry is $48 \%$ export $(28 \%+20 \%)$ he must investigate how the 1ocal percentages are distributed. Consider the local consumption of paper, $52 \%$ of the paper production. The majority of this goes to the printing industry. And printing will export 
some of that. Printing will export to private concerns $40 \%$ of the paper production ( $50 \%$ of paper to printing $\mathrm{X}$ $80 \%$ of printing to exports private); to the government 8.57 of the paper production ( $50 \%$ of paper + printing $\mathrm{X} 177$ of printing to exports government) and distribute locally $1.5 \%$ of paper production, ( $50 \%$ of paper to printing $\times 30 \%$ of printing to local). In the same manner printing will redistribute the $5 \%$ of production it gets from the chemical industry and the $1 \%$ of production it gets from its own industry. So that the three industries are tied to exports both directly and indirectly. This is shown in the table below.

Tab1e V-4

Allocation of Sales by Percent Direct and Indirect

$\begin{array}{lll}\text { Export } & \text { Export } & \text { Local (to be } \\ \text { Private } & \text { Gov't } & \begin{array}{l}\text { distrihuted } \\ \text { in the next } \\ \text { round) }\end{array}\end{array}$

\begin{tabular}{|c|c|c|c|c|c|}
\hline Printing & $\begin{array}{l}\text { Direct } \\
\text { Indirect } \\
\text { Total }\end{array}$ & $\begin{array}{r}80.00 \\
1.18 \\
81.18\end{array}$ & $\begin{array}{r}17.00 \\
.77 \\
17.77\end{array}$ & $\frac{1.05}{1.05}$ & $100 \%$ \\
\hline Paper & $\begin{array}{l}\text { Direct } \\
\text { Indirect } \\
\text { Total }\end{array}$ & $\begin{array}{l}28.00 \\
40.38 \\
68.38\end{array}$ & $\begin{array}{r}20.00 \\
9.10 \\
29.10\end{array}$ & $\frac{2.52}{2.52}$ & $100 \%$ \\
\hline Chemicals & $\begin{array}{l}\text { Direct } \\
\text { Indirect } \\
\text { Total }\end{array}$ & $\begin{array}{r}10.00 \\
9.20 \\
19.20\end{array}$ & $\begin{array}{l}40.00 \\
18.05 \\
58.05\end{array}$ & $\frac{22.75}{22.75}$ & $100 \%$ \\
\hline
\end{tabular}

Considering the paper industry, its first round indirect private exports is composed of the $40 \%$ that printing will export, the $0.28 \%$ that paper will export $(28 \%$ paper to private exports $\times 1 \%$ paper to paper), and the $0.10 \%$ that chemicals will export ( $10 \%$ chemicals to private exports $\times 1 \%$ paper to chemicals). 
The first round indirect government exports is composed of the $8.5 \%$ that printing will export, the $0.2 \%$ that paper will export ( $20 \%$ paper to government export X $1 \%$ paper to paper), and the $0.4 \%$ that chemicals will export $(40 \%$ chemicals to government export $\times 1 \%$ paper to chemicals). The residual of $2.52 \%$ will continue to be distributed in a like manner, round by round, until it becomes insignificant.

In this simple example, there are no local sectors of ultimate consumption. In reality, of course, there are. Some of the paper, printing, chemicals or whatever will he consumed locally and some will eventually be consumed hy such local sectors as business investment, housing investment, local governmental operations and export governmental investments.

In forecasting with this model inferences are drawn from national or regional forecasts for those industries that are hasic to the area, the inferred shares of the large area basic industry forecasts inputed to the model, and the result is the forecasted impact on the local area. This is clearly analogous to forecasting with the input-output bodel.

The sample inventory shown in Chapter TII 1 ists the input information necessary for this type of economic lase study. The technique is somewhat sensitive to the unit of measure of the economic activity and more so to the delimita$t$ ion of the area studied.

Both the input-output technique and the economic base technique result in models of economic hehavior of the study area that are at once sophisticated and cost $1 y$. If, for the purposes of the plan, such analyses are not required or are prohibitively expensive, there are a number of cruder, quicker and less costly techniques which may suffice. One of these is the Hoyt (1939) economic base theory of which the Tiebout technique is a sophisticated extension. In the Hoyt technique, the employment in each basic industry in the area is calculated. The judgement of the degree to which an industry may le basic 
is not traced out, as with Tiebout, but estimated by interviewing the industries or using national averages and proration techniques. If, for example, a national average shows that there are three retail trade employees per one hundred population and the area under consideration has four, the fourth employee is considered to be serving some undiagnosed export function and is considered lasic. Similarly, if the area in question receives one percent of the national income and a local industry markets a product nationally, ninty-nine percent of that industry's cmployees are considered basic and one percent non-basic.

Given the hasic employment and the total employment, the hasic/non-basic employment ratio is calculated. This ratio is then applied to forecasted shares of national changes in employment for each hasic industry. This application results in a forecast of non-basic employment, and hence total employment, likely to occur as a result of changes in the area's basic economic activity.

The basic/non-basic employment ratio is a comparative tool and its value is more relative than absolute. A very high ratio is typical of an area of intense export activity. It may also describe an area of service activity so weak that it is difficult to obtain a doctor's appointment or to get a carpet cleaned or a haircut. If the export activity is dominated by a single industry, a high ratio may indicate that the area under investigation is dangerously dependent on changes in the economic behavior of that industry.

A very low basic/non-basic employment ratio could describe an area of many duplicative and marginally performing service industries selling each other gasoline and doing each other's wash. Here is a clear need for the nutritive impact of additfonal basic industry for the area's economy.

There are two remaining classes of economic activity forecasting techniques, differentiated ly their use or nonuse of large area or perhaps national economic forecasts. 
By the use of large area or national economic forecasts the planner can, through a series of proration techniques, successively apply historical relationships of smaller area participation in bigger area economic activity. For example, historical data on a county's share of state employment can be obtained and plotted on a time scries. $A$ curve is fitted and a likely ratio obtained for a future time period. When this future ratio is applied to the forecasted state employment, the result is the forecasted county employment. The future state employment was obtained in the same manner from forecasted regional employment, and that from the forecasted national employment.

This technique can be used to forecast any economic indicator in addition to employment, providing the input data are available. It also can be used to forecast any of these indicators by component sector such as heavy manufacturing employment, retaj 1 trade employment, and agricultural employment.

The technique is probably best used when forecasts are obtained for al1 the component parts of each larger area. Then internal consistancy checks can be made to insure that the sum of the parts does indeed equal the whole and that the relationships of the parts to each other remain rational at each stage in the process. When this is done this technique is commonly called the apportionment method.

If, however, the proportioning is done without reference to the complimentary areas, as a regional share may he proportioned to a state without considering the other states making up the region, or a state share may be proportioned to a county without considering the other counties, then the technique has come to he called the ratio step-down method.

Every forecasting technique so far outlined depends upon the readily available national forecasts of specific economic indicators as exogenous variables. Should these for some reason be suspect or not applicalsle, the only 
recourse is to forecast based upon an extrapolation of present and historic local trends. This last class of techniques is the most crude and only as good as the Imagination and intuition of the forecaster.

\section{Population Estimates and Forecasts}

As in economic activity forecasting, population forecasting methods range from the refined to the crude, but in each case they are inherently simpler to execute owing to the consideration of only three central variables; births, deaths and migration. Of these, migration offers the most difficulty owing to the lack of a good basis for forecasting it.

In the cohort-survival method, the population is separated by sex and perhaps race into convenient age groups each covering typically five years. Using specific mortality rates for each sex-race-age group, called a cohort, the survivors are forecast into the same sex, same race, hut five year older cohort. This is done for all cohorts and then a forecasted net migration is distributed over these groups and added to or subtracted from the survivors. Using specific birth rates for the women in each race-age cohort, the zero to five year old sex-race-age cohorts are generated to fill the vacancies caused by the five year aging process. The procedure is repeated until the forecast year is met. The strength of the cohort-survival method is that it recognizes that the vital birth and death rates vary from cohort to cohort.

The use of the cohort-survival method is at the same time limited by the availability of forecasted specific rates and the judgement involved in computing and distrihuting migration. A simpler case of the cohort-survival method involves considering the aggregate population rather than sex-age-race cohorts and applying aggregate fortcasted rates. Thus is called the migration and natural increase method. 
If national or large area population forecasts are available, they can he prorated down to the smaller area being considered by either the apportionment or ratio stepdown methods in a manner analogous to that for economic activity.

Cruder population forecasts can be obtained from the forecast of employment made in the economic activity forecasts or from a conceptual technique which forecasts the population holding capacity of an area based upon forecasted zoning, land characteristics, availahle water and other utilities, etc. Also, if the city in question is clearly analogous in development to another older city, some forecasts can be based on the present day development of the older area.

Again as in the case of the economic activity studies, local trends can be used exclusively to forecast population, these trends being identified by any of a number of common mathematical techniques. A strong basis must be held for assuming that historical rates will continue and that specific correlative relationships will remain constant.

Because of the relative ease of employing any of these techniques, it is a recommended practice to use several simultaneously in an attempt to gain greater confidence in the accuracy of the forecasted population, yet writers have heen hard pressed to state a best method. If the migration of an area were known to be zero, the simple natural increase method might prove to be the "best."

Estimating the present population is a lesser included case of forecasting the future population. This is so lecause some of the input data is presently available. The nost refined methods deal with migration and natural increase in a manner first developed by the Pureau of the Census (chapin, 1965). The method is to take the most recent census enumeration, compute the natural increase hy any of the methods above, estimate the net migration and loss or 
gain from the armed forces, and the resultant sum is the present population. The net migration is estinated in either of two ways. In one case the ratio of the census year total population to the census year school population is multiplied by the current year school population. This would give current year total population if local and national school enrollment trends were the same. This is usually not the case so the resultant figure is corrected hy multiplying it by the percent change in local school enrollment minus the percent change in national school enrollment.

An alternative method develops an estimate of current school population based upon natural increase alone using for example, a cohort survival approach with one year cohorts. The difference hetween this estimate and the current school enrollment is attributable to net migration.

other methods of population estimating depend upon symptomatic data. As deaths are commonly a matter of puhlic record, for instance, one could apply to them known average death rates to arrive at the estimated population of each death group for which a rate exists. The same holds true for birth rates to arrive at the number of women of childbearing age, thence the rest of the population. Changes in the number of dwelling units, automobile registrations or similar such data could be used, in conjunction with known rates, to arrive at population estimates. As with population forecasting, it is not uncommon for several of these methods to be used in an attempt to gain confidence in the resultant estimate.

\section{Land Use Forecasts}

Land use forecasting is of a different genre than population or economic activity forecasting because it is tied very closely to design considerations. It also enjoys an interdependent relationship with transportation forccast ing. Further, of all the types of forecasting, that of land usc. 
has the strongest association with forecasted standards of use. For these reasons as well as the fact that specific land use forecasting techniques are typically unique to the circumstances of their application, it is only with reluctance that land use forecasting can be discussed outside of the context of a specific problem.

Nonetheless, the conceptual basis is clear. Iand use forecasting predicts the amounts and kinds of land use likely to occur as a result of the fulfillment of the population and economic activity forecasts. Further, it forecasts the 1ikely locations of these uses and in this sense, enters the whole area of design considerations discussed in the next chapter. Included in these considerations are the careful balancing of uses to each other, the impacts of uses on the transportation system, and the possible plan elements and public policies which might favorably change the forecasts.

Chapin (1965) calls these considerations location and space requirements, and Martin (1961) calls them location, activity and intensity considerations. The manipulation of these considerations and the affixing of them to pieces of land is typically accomplished through the use of one or more of the following four classes of models.

The first class of forecasting model is judgemental in nature. The planner simply studies the area under consideration, its relationship to the rest of the area, the characteristics of the supply of 1 and and the expected population and economic demands on the land, its present or future zoning, accessibility and like considerations, and intuitively forecasts what the likely development will he. This is not to imply that intuitive and creative judgement is not used in the other methods, but here there are no computational or procedural techniques employed to aid in judgment.

The second class of forecasting model adds to the first some procedural rules. Martin calls this land use accounting 
and from the balance of available land after each forecast are successively subtracted out public open space and recreational land, singular uses such as ceneteries, airports and public buildings, then major commercial use, streets, industrial use, residential use, and finally, non-residential uses within residential areas such as schools, churches and fire houses.

The third general class of models uses mathematical abstractions to allocate total 1 and use requirement: to each available land unit. This includes all forms of the gravitv model and a good example is the Hansen (1959) model for Washington, D.C. In this class of models, population and economic activity growth forecasted for the whole area is distributed to various zones in the area based upon cach zone's attractive force compared relative to the attractive. forces of the remaining zones.

The fourth class of land use forecasting models is composed of mathematical abstractions of economic l chavior. This analysis can be micro or nacro in approach, and typical examples include the work by Herbert and Stevens (1960), Stewart (1969), and Lowry (1964). Models of this type allocate to zones amounts of population and economic activity based upon observed economic behavioral patterns used hy individuals and firms in location decisions.

\section{Transportation Forecasts}

This introduction to transportation forecasting concludes this chapter on the forecasting phase of the urban planning process and is necessarily limited to urban ground transportation. The forecasting techniques for this type of activity are part of a large and strong body of knowledge, primarily due to a favorable set of federal, state and local legislation supportive of both research and operations.

This body of knowledge includes more than forecasting methods, of course, and has come to be called Urban 
Transportation Planning or UTP. A brief review of UTP is in order here in relation to the conceptual model of planning activity.

In the organization phase, UTP has become somewhat nore institutionalized than planning in general; first, because of a generally more refined and widely applicable set of procedures, and second, because of various legislative and administrative requirements imposed by state and federil agencies. In the inventory phase, UTP concentrates on four major classes of information: demographic, social and conomic characteristics of the area; a complete facilitics inventory of the urban transportation system; land use characteristics; and an origin-destination survey composed of home interviews or widely sought after substitutes, a truck and taxi survey, and cordon counts of traffic across boundaries of the study area. In the analysis phase a network is constructed to simulate the transportation system together with these inventoried characteristics. Land use, demographic, social, and economic relationships are constructed to explain the amount, location and timing of inventoried trips. Distributional relationships are constructed to explain movements observed from one traffic zone to another. These generally balance the desire to travel, measured by some propensity to interchange, against the resistance to travel, measured by a decay of this propensity due to zonal separation, which is in turn measured by time, distance, cost, etc. If the application of these and other relationships (for instance, the split of trips between the automobile mode and the mass transit mode) to the network results in a duplication of the inventoried observations regarding the amount, location, timing, mode and distribution of trips, both the network and the rolationships are hypothesized to be valid. UTP then moves to the forecasting phase. 
The first step in UTP forecasting is to determine the amount of trips produced at, or attracted to, each traffic zone for the forecast year. Separately forecast demographic, economic, social and land use characteristics serve as inputs to the various techniques.

One method, first used by the Chicago Area Transportation Study (1960), constructs from the inventoried data a trip rate per acre for different land uses. The land ises are differentiated by character, location and density characteristics. New trip rates are forecast and applied to forecasted land uses resulting in the amount of forccasted trips.

Another method, developed by Walker (1960) for the Puget Sound Regional Transportation Study, uses cross classification analysis, a statistical technique in which average values of a dependent variable can be obtained for different combinations of two or more independent variables. The independent variables are considered in ranges or classes and, in this case, there were three classes of environmental factors and six classes of household characteristics. For each of the eighteen combinations of these independent variables, trip production rates and trip attraction rates were calculated from the inventoried data by cross classification. For each zone, the forecasted environmental and household characteristics then determined the applicable rate of trip production or attraction.

Another method uses the statistical technique of multiple regression analysis. Equations are typically constructed with trip production or attraction being some function of independent variables such as trip purpose, family income, vehicle ownership, land use, distance from the $\mathrm{CB}$, length of trip, mode of trip, and time of day. The analysis calibrates this model to present and historical data for the area in question. Any forecasted changes in 
the independent variables are then inserted by zone and the equation solved for future trip generation by zone.

A11 these methods base trip generation on the demographic, economic and 1 and use characteristics of the traffic zone. Another type of trip generation model includes as well consideration of the transportation subsystem that serves the zone and connects it to other zones. Zones with relatively more accessible destinations should produce more trips and zones that are themselves relatively more accessible should attract more trips. Nakkash (1969) has developed a model that considers this accessibility which states that the relative accessibility of a zone to an activity for a certain purpose is equal to the accessibility of that zone to that activity for that purpose divided by the sum of al1 the accessibilities of all the zones to that activity for that purpose. The accessibility of any one zone to any one activity for any one purpose is the sum over all the zones of the size of the activity in each zone multiplied by a friction factor corresponding to the travel time from the zone in consideration to each of the other zones for the purpose under consideration.

Trip generation models forecast the likely number of trip ends, either productions or attractions. The links between these ends are next distributed from zone to zone in the area. The several distribution models used to forecast these interzonal transfers can be broadly classified into two types, synthesis models and growth models.

Synthesis models forecast interzonal transfers hased upon the behavior patterns of travelers observed in the inventory and analysis phases. One type of synthesis model is the opportunity model which mathematically states that the probability that a trip will terminate within a zone is equal to the probability that the zone contains an acceptable destination times the probability that an acceptable destination closer to the point of origin has not been found. The 
probabilities are determined empirically from the inventoried data and follow the observed trend that the longer the trip, the more selective is the destination.

Another synthesis model is the gravity model which mathematically states that the number of trips from one zone to another zone is directly related to the total number of trips originating in the first zone and to the total number of trips ending (a measure of attractiveness) in the second zone, and is inversely related to a "friction of space" as measured in travel time, distance, cost or a combination of these factors. The friction defined by these factors varies; by trip purpose.

Tomazinis (1962) formulated a combination of the gravity model and the opportunity model called the competing opportunity model. This model states that the probability that a trip is going into a zone is the ratio between the number of trip destinations in the zone divided by the number of destination opportunities an equal tine away from the origin as the zone in question. This model considers the land uses at the origin and destination as well as the intervening land uses. It uses zone productions and the resultant attractions may not be in accord with the attractions as forecasted by trip generation techniques. This is resolved by successive approximations.

Grecco (1962) has developed a synthesis model based upon the theory and mechanics of linear graph theory. Trip flow is a function of demand and travel time. In the linear graph, flow sums to zero at each vertex or zone, and demand sunis to zero around each circuit or interzonal distribution.

The other general class of distribution models are growth factor methods and they differ from synthesis nodel in that they project current demands rather than synthesize future demands. 
In the uniform factor method, a single growth factor is estimated for the entire area under consideration. The interzonal transfers inventoried by the origin-destination study are then multiplied by this factor to yield future interzonal transfers.

In the average factor method, different growth factors are forecast for each zune and the average of the two appropriate factors is used to multiply the inventoried interzonal transfer between any two zones. Adjustnients are successively approximated to satisfy the control totals.

Fratar (1954) has developed a growth factor based upon the present distribution and the growth factors of the future destinations. The ratios of the present attractions for each destination divided by the total present production for the origin in question, are multiplied by the respective destination growth factors to yield distributional factors. These distributional factors are then normalized and applied to the future trip productions from the origin in question.

Although the use of growth factors to distribute trips is simple, it does require the input of an origin-destination survey and constant zonal boundaries. The growth factor mechanics also break down when considering low volume zones that are likely to greatly increase from the base year to the forecast year.

The next step in the forecasting phase of UTP is to split these distributed trips between those likely to be accomplished by automobile and those likely to be accomplished by mass transit. The four most important factors affecting mass transit usage are automobile ownership, density of development, transit service characteristics, and the economic status of the tripmaker.

The Pittsburgh Area Transportation Study (1961) has shown that an automobile ownership increases from no cars to three cars per household, transit usage decreases from 
sixty percent to eleven percent of all trips made per household. The reasons for the decrease are intuitively clear.

Transit usage increases with density or intensity of land use development. Again the reasons are simple. High density residential development is generally inhabited by low income - low auto ownership families. High density non-residential development is typically associated with high attractiveness for tripmaking together with difficult and expensive driving conditions.

Four factors govern the level of service offered by mass transit; travel time, travel cost, travel comfort and trivel convenience. Each of these has a preferred direction of improvement is perceived by the potential user.

Increasing family income is correlated with a decrease in transit usage. This decrease is not quite so severe with work trips as it is with non-work trips because of the continued use of rapid rail mass transit for work trips in some areas as a cultural phenomenon rather than an economic one.

These four factors are not independent of each other. They are also related to and vary according to trip purpose such as the work trip or the school trip. Accordingly, modal split models variously consider combinations of some or all of these factors, based upon intuitive and statistical evidence, to forecast the probable split between the automobile and mass transit usage. The mechanics of these considerations typically involve graphical techniques or regression analyses, the interdependence of the independent variables notwithstanding.

Graphical techniques of modal split forecasting include the use of diversion curves which are a function of system characteristics. For various ratios of mass transit cust to automobile cost, or of mass transit travel tinu to autwmobile time, curves are constructed showing the probable 
percent of total trips diverted to mass transit usage. These curves are actually several families of curves, each family classifying and cross classifying the factors affecting transit usage such as trip purpose, trip direction, time of day, levels of service, economic status of the traveler, trip destination, and many more.

Mechanically, these diversion curves either deal with trip ends, origins and destinations, or trip interchanges, the movements or trips themselves.

Trip end modal split models are applied to generated trips, and only after the modal split are these trips distributed as outlined in the previous discussion. Fertal (1966) has sumnarized the key features of some of the trip and mudels. In the Chicago model, modal split was explained by automobile ownership and orientation to the CBD. The Pittsburgh model introduced the concept of "captive" and "choice" riders, the former being totally dependent upon the transit system for their needs. The Erie model added employment accessibility as a means to differentiate between transit usage and automobile usage. The Puget Sound model considered accessibility by four trip purposes.

Trip interchange modal split models are applied to distributed trips. Fertal notes that the washington D.C. model considered only the morning peak hour, and then by trip purpose and classes of tripmaker characteristics. The Twin Cities model used multiple regression analyses to construct two equations for work and non-work trips. These equations were then plotted to result in diversion curves of travel time ratio, income, residential density, employment density, and parking cost for each of the two purposes. The Buffalo model introduced the concept of "auto availability." If an automobile is used for a work trip it is no longer available for other trips and this concept was used to replace auto ownership. 
The result of all the work to this point in the UTP forecasting phase is a trip table. This table shows the forecasted traffic flow from all origins to all destinations by mode. Thus the forecasting phase dealing with demand has ended.

It has been noted, however, that the conceptual model of planning activity includes forecasting considerations of resource supply and standards. These considerations lead quite naturally to the final phase of UTP, traffic assignment.

Traffic assignment is the process of allocating trips to an existing or proposed system of transportation facilities. Just as in land use forecasting, traffic assignment brings design and evaluation considerations to bear and the discussion of these in the conceptual model of planning activity is deferred to the next two chapters. These design and evaluation considerations arise because traffic assignment techniques evaluate and compare alternative transportation systems by allowing proposals to be synthetically tested for their traffic carrying capabilities according to various design standards.

The computational technique for traffic assignment is one of network analysis. Traffic is assigned to a minimum path tree in the network from an origin to all possible destinations. The minimum path is that which minimizes some travel function such as time, cost, distance, accidents or a combination of these factors.

Al1 the traffic from one origin to one destination seeks the same minimum or equally minimum paths. The result simulates how the trips would be made in the absence of any capacity considerations along this otherwise minimum path. This is called the "all or nothing" assignment technique and is useful as a design consideration to see how the system should operate unrestrained by resource considerations. 
In contrast, "capacity restraint" assignment techniques have been developed. These recognize that the all or nothing technique tends to overload some links in the network. The capacity restraint technique applies a restraint function as the links in the network become overloaded in successive ainimum path assignments. This restraint function could be static, as a certain naximun number of trips at any tine, or it could be dynamic relating capacities to volumes and speeds at all times.

Another method developed by Mclaughlin (1965) incorporates linear graph analysis to assign traffic. One component is the number of trips from the centroid of any origin zone to the centroid of any destination zone as displayed in the trip table. The other component is the street and its intersections. The trips sum to zero at each vertex and are the flow variable. The pressure variables is the value that travelers perceive in the choice of a route. Melaughlin formulated a value function based upon cost to reflect otherwise indeterminate subjective values held by travelers.

\section{Summary}

This chapter has considered forecasting both as a phase in the conceptual model of planning activity and as a collection of techniques constituting this phase. The purpose of forecasting is to manufacture a synthetic inventory of future planning conditions. There is feedback to the analysis phase for the interpretation of this inventory and feedforeward from the earlier phases of the planning process for its construction and scope.

Given this information and interpretation, the planner is now ready to design a plan, or a set of alternative plans, tw weet these forecasted conditions in a manner arising from and consistent with the goals and ahjectives of the client constituency. 
CHAPTER VI

DESIGN

The design phase of the conceptual model of planning activity is both simple and complex. It is simple because, in its most basic sense, urban design is a bounded problem. Prior phases have resulted in the identification of demands. These demands translate into facilities through the application of standards. Urban design is the locating of these facilities on the land surface of the area in question. The amount of 1 and is bounded by physical constraints, the amounts and types of facilities are bounded by demand constraints. The problem is simplified to a locational and distributional one.

While this view of urban design has a conceptual clarity and an operational ease that make it attractive, it could easily result in a design that is sterile, harsh, repulsive and inhuman even though it may be mechanically functional. The design process becomes complex because it cannot be approached from the standpoint of mechanical functionality alone. True, machines and systems of services must function if an urban area is to survive. But the most important functional operative in an urban area is man and his refined sensibilities demand an environment that is not only mechanically functional but also harmonious, fitting, comfortable and aesthetically in balance with himself, other men, his machines and facilities, and nature.

This is as awesome a mandate as has ever been presented by man to himself. It is not new and will never be old. It is a mandate that comes from everyone in contact with the area in question. The attempts to satisfy the mandate affect 
everyone and, for that reason, urban planing enjoys no lack of spirited criticism, at limes, it would secm, from all sides. So it is with a mixture of reverence, wonder and fear that the urban planner takes up his pen and accepts the charter to design.

Fortunately, the urban planner is not alone. It is widely recognized that nearly equal participation in the design phase of urban planning is required of architects, landscape architects, and engineers as well as urban planners. No one of these professions is necessarily preordained to take the lead in this effort. In fact, this consideration is ancillary to the need for all to participate. The composition of the design team is, of course, a function of the problem at hand and the resources available. Iir the ideal case of a large and well supported undertaking, the design team should include these professions as well as those of sociology, regional economics, political science, operations research, education and many more.

The orchestration of these individuals and their jdeas is a problem not without danger, and it could well be that the single most important member is identified because of his administrative capability as well as his professional contribution.

The composition of the design team is ad hoc in nature and it would be difficult to construct a normative example. Referring to the organizational aspects detailed in Chapter II, the key planning staff and principal consultants would certainly be expected to participate. If the Technical Advisory Committee has been intimately involved in the planning process thus far, they certainly should be consulted. It is not beyond feasibility that the Citizens' Advisory Committee could be represented on the design team.

There is, of course, a strong element of evaluation in any design judgement. When the design team cannot agree on a clearly superior design facet among those considered, 
Alernative plans should be prepared to reflect the differing: points of view. Although evaluation metheds are considered in the next chapter, a system of staged design and evaluation cycles could be employed, each more detailed in agenda than the previous to keep the number of alternatives currently viable to a manageable level. In this way, as soon as an alternative becomes undesirable, its development ceases, and only those judged to be still possible continue to the next stage.

An operational device such as this only reflects, of course, the continuum design effort from the general to the specific. As the design process travels along this continuum, the input of the urban planner gradually diminishes in relation to that of the architect and engineer until, finally, specific design facets of a particular facility come to bear. Recognizing that is is quixotic to cstablish the point along the continuum where the theory and practice of urban planning defer to the theory and practice of architecture and engineering, this work nonetheless proposes that this point occurs somewhere between the gross locational characteristics of a facility and the design of the facility itself. The continuum continues through this point as locational characteristics affect the design and the design affects locational characteristics.

A11 along the design continuum, the urban planner and the design team as a whole must consider many ideas. These may be pedagogically grouped into considerations of form and considerations of quality.

\section{Considerations of Form}

Webster's New World Dictionary defines a palimpsest as "a parchment, table, etc. that has been written upon or inscribed two or three times, the previous text or texts having been imperfectly erased and remaining, therefore still part1y visible." Martin (1968) uses this marvelous 
word to describe the form of the city and it is most appropriate. Throughout the history of the city, wave after wave of influence has left its mark on the city form, never quite obliterating the prior images.

In recent American history, several individuals have sought to identify these influences as determinants of form. Colby (1933) identified opposing centrifugal and centripetal forces as locational determinents. Centrifugal forces are those that cause a move away from the central part of the city. Examples are spatial force owing to central congestion, site force owing to intensity of use in the central city, situational force owing to the unnatural juxtaposition of land uses in the central city, a force of social evolution owing to climbing land values and taxes in the central city, and a force relating to the status and organization of occupance. The centripetal forces of attraction to the central city are those associated with site attraction. functional convenience, functional magnetism and functional prestige.

Burgess (1929) proposed that, as a city grows, it expands radially from its center resulting in a series of concentric circles, each two enclosing a discrete zone. Recognizing the exceptions caused by natural or artificial barriers, he proposed that each zone has the tendency to expand to the next outer zone as city growth occurs. In Chicago, he identified five such zones; the CBD, the zone surrounding the $\mathrm{CBD}$ in transition, the zone of independent workingman's homes, the zone of better residences, and the commuter zone.

Hoyt (1939) proposed that, instead of forming concentric circles, zones of similar land use tended to be wedge shaped, radiating outward from the CBD. New development on the arc of the wedge tended to be of the same character as the wedge itself. 
Harris and U11man (1945) agreed that such city Eorms as the concentric circle and the wedge do occur, but they noted that there were several such centers of circles and origins of wedges in the typical American city. Among them are the CBD, various districts of wholesale operations, 1 ight manufacturing, heavy industry, residential districts of various kinds, and suburbs and satellites. The centers are places of high accessibility such as provided by the intersection of important autonobile routes, rail lines or rapid transil 1 ines.

Models such as these have become classics in modern urban planning, and survive to this day despite the now formal influences caused by the post-war population growth, increase in disposable income, housing and shopping facilities, and the rapid rise in automobile uwnership. Factors such as these have made urban dwellers more mobile than ever before, and this is recognized in the more recent studies of urban form which consider the dimension of time.

Vance (1966) has mapped seven sequential stages of the development of the CBD. The first stage is the process of inception which includes the original siting of the town and is intimately associated with the functional characteristics of the landscape. Next occurring is the process of exclusion whereby the high rent paying abilities of certain functions tend to locate these functions in the CBD, and functions with lesser rent paying ability locate in descending ability along a rent gradient that has its apex at the CBD. The third stage is one of segregation in which one class of high renters becomes so large that it naturally subdivides and segregates into smaller units to maintain identity. Vance notes that the New York financial district has segregated into a stock-exchange district around Wall Street, the ship company district on Park Row, advertising on Madison Avenue, and other corporate headquarters on Park Avenue. In the next temporal stage of growth, the CBD extends itself 
outward in long thin alignments along arterial streecs With individual mobility, these sections become an incegral part of the CBD and typically offer business services and equipment for example. The next stage of readjustment occurs because of the development of areas outside of the CBD which attract functions formerly occurring in the $\mathrm{CBD}$. In the sixth stage, physical redevelopment of the $(: B D$ takes place so that in the last stage, many of the functions atsociated with the CBD at the beginning of the cycle are now porformed in satelite districts, and the CBD now performs new, unspecified and highly specialized functions.

The cycle reoccurs for both the new CPD and the satelite districts.

Birch (1971) has proposed and tested the concept of seven stages of residential growth. Stage one is rural in nture and characterized by very low density single family units. Stage two is characterized by a high rate of new construction of single family units. Stage three occurs when the area becomes fully developed, with high quality relatively new single family structures and perhaps some imlti-unit structures as we11. Property values and rents are at their maximum. In stage four, the structures built in stage three have aged and rents have fallen. Lower income groups nove into the area and live at a higher density than the original inhabitants. In stage five, building deterioration continues and the grown children of the stage four inhabitants leave for other stage four or stage two areas of the city. Population declines and average age of the inhabitants is high. Stage six occurs when the land becomes too valuable for stage five use and the inhabitants do not have enough political strength to retain it. The land is acquired and redeveloped into a stage three residential area, but with typically higher densities. Stage seven vecurs: when the recaptured areas themselves decay. 
Theories such as these emphasize the temporal as we11 as the spatial aspects of urban form. Hlumenfeld (1967) likened the city not to a work of visual art but rather to a work of music or literature. He notes the single fallure of this analogy arises from the fact that a symphony or a novel is the work of one man in a definite period of time. Once completed, it remains so. On the other hand, the city changes over time, with each new wave of influence altering what was there before and adding new forms. Additions to the palimsest never cease.

Urban planners recognize that their symphonies will be "unfinished"; that their plans will be subject to the exigencies of politics and finance; that their plans are based on an incomplete knowledge of causal relationships; and that their plans may be diluted, misunderstood, and possibly wither.

One way out of this problem is to "make no little plans" and to drive for acceptance through sheer audacity. force of will and personality. An equally preferred method is to accept the complexity of the problem and treat it as one of stimulus provision - response classification in the classic manner of black box simulation.

The goals and objectives of the client constituency map the desired response. Included here are private entrepreneurial, household, and individual decisions desired as part of that response.

The stimuli are public policies, the policies of the client constituency, the resources operationally available for both planning and implementation, and, not to be overlooked, short range changes in current methods of operation.

The task of the planner is to assemble one or more sets of stimuli which, when added to the form and policy now existing in the city, will, in his professional opinion, provoke varying degrees of the desired response. 
The considerations of form begin with statement of the desired response. As an example, Safdie (1970) prepared an environmental code for urban residential living.

Every family or individual must be provided with an outdoor space equal to or greater than its interior living space. This is essential to proper functioning of the family. The nature of the spaces themselves would vary from climate to climate.

The outdoor space must be continuous with the indoor spaces for family functions.

Sleeping facilities for young children should he close to those of their parents. Teenage or ulder children should have separate sleeping accomodations. Families with children of different ages should have two children's sleeping areas.

Every child should have a private sleeping space (a North American criterion; other cultures may be different). Children should have work and play space of sufficient size for these functions.

House design must allow the individual to adapt and change the dwelling.

A family should be able to function normally without hearing or being heard by its neighbors. "Normal" functioning includes occasional fights, playing loud music or instruments, children playing and running around. A decibel rating similar to that of a single family house walls with a six-foot air space should be considered minimal.

The family should be able to carry on normal functiuns without being observed by others.

The living and dining spaces should not be observable from another dwelling closer than one hundred feet.

In the Florida climate, glass area should not face south or west unless adequately protected. In the Quebec climate, some openings and living spaces should receive sun. A dwelling should receive at least three (four, six) hours of sunshine per day.

In hot climates, openings should be arranged to capture any prevailing winds and make dwellings less dependent on mechanical air-conditioning. 
North America is traditionally a single-family-house culture. It is mandatory that the dwelling mit must be recognizable and definable from the outside by the occupant when he is in its immediate vicinity.

Access to the house should be through pleasan space in which there is daylight. It should be possible to sit or talk to people. No accumulation of odors. Provision for children similar to the experience of a residential street.

A child of this age should be able to leave his family dwelling on his own and wander to a minimum distance of me hundred and fifty feet, meet at least six to ten children of his age, and find some play areas.

Access to play areas and play fields within an area of five acres.

Access on their own to cultural and recreational facilities such as movie houses, libraries, parks, sport centers, etc.

Within the community there must be spaces where adults can spontaneously meet or just sit around.

The ideal arrangement for the North American family of any income group is to be able to drive into the kitchen.

Within the inner community of 5,000 , pedestrians and vehicles should never cross.

Public transportation is mandatory so that the family will not be dependent on one (or two) cars.

Entrance to houses should be shared by about four families, to permit social inter-dependency. This assumption may be wrong in number or even in its basic form, but something of the sort must be established. It is certainly true in the selfbuilt favellas of Latin America.

People need to be able to identify with a larger community unit. This can be observed in most vernacular village architecture.

The ideal community is a mixture of various individuals and families of different size and make up. Older people, families with young or older children, single people. 
The cominity must also have within it a mixture of

families of varying professions and racial origin

(this of course is a value judgment that can be

challenged, but writing it down forces one to face it).

Facilities beyond the reach of individual low income

families, such as work shops, car shop facilities,

furniture making shops, greenhouses and plant supplies, should be provided by the community.

Within fifteen minutes' walking distance the family should find a medium-size park, shopping facilities of a minimum of 100,000 square feet, a variety of cultural and recreational facilities, elementary school, and some employment opportunities.

Within ten minutes by mass transportation or car must be major employment opportunities of varying types, regional shopping facilities of a minimum of 500,000 square feet, high schools and trade schools, a major regional park.

The community must be designed so as to take full advantage of natural amenities, existing tree areas, natural topography, views.

New construction in an existing city must achieve physical and social continuity with existing construction. 1

Similar sets of criteria could be devised to describe the working environment, the recreational environment, the travel environment, the shopping environment and so forth. These desired responses set constraints on the forms of the stimuli.

It is important to note that the effect of these stimuli over time has some important secondary and tertiary aspects. There is first of all a period of debate on the stimuli and expected response. There is a period of flux during which the stimuli are instituted or constructed. There is a period of reaction and response to the stimuli, hopefully in the direction expected. These stimuli may provoke a response that is itself a stimulus to further response. And lastly, the response may be time lagged, dampened or amplified beyond the expected. It is important 
to consider all these considerations in assessing the value of likely responses.

of course it is recognized that the separation between form and quality is artificial as they affect each other in a manner similar to site selection and building design. Safdie's criterion that every family should be able to drive into its kitchen tells us something about form but it is clear that the quality of that design must be examined.

\section{Considerations of Quality}

In the practice of urban design, there exists an often repeated 1itany of adjectival calls-to-arms exhorting the practitioner to excellence. Such terms as color, texture, grain, lightness, symmetry, proportion, balance, fitness, size, density, harmony, difference, extension, contrast, accent, expression, vista and scale are familiar to the profession.

Unfortunately, there is no formula that combines these qualities in ways to insure design of high quality. Rather there are general guidelines for each of them which state that, in the absence of deliberate discordance for effect, some combine in ways more pleasing than others. Considered sing $1 \mathrm{y}$ and in combinations, they are known to evoke certain responses as viewed, used and lived in.

Since the urban planner is interested in evoking certain responses, however complex or ill-defined they may be, he needs to be familiar with these relationships, although on a scale larger than that used in buflding design. He must design for the response, for human experience.

Because both the response set and the qualitative conditions are so complex, urban planning, like architecture and engineering, is a true creative effort. Proficiency is established through practice and urban planners undergo internships similar to those of other professions with the same degree of creativity. 
The urban planner must have highly sharpened sensibilities to urban life and an intimate and personal knowledge wf the natural and man-made landscape. For this reason, considerations of design quality begin with a personal and lechnical site analysis.

The technical site analysis is relatively straight foreward and is comprised mainly of base maps and surveys noted in Chapter III. Simonds (1961) details an excellent version of a personal analysis in which the planner gets the feel of the area, its relationship to its surroundings, and the character of the area. This character includes the best views, the poor views, the objectionable views, the vegetation which should be preserved or removed, off site nuisances, logical avenues of ingress and egress, the direc$t$ ion and force of the sun and wind, protection from these elements or their emphasis as appropriate, natural and topological features affecting development and the overall effect of buildings, roads and structures currently in place.

Site qualities by themselves suggest qualitative design considerations. Simonds classifies several such site conditions as the pastoral site, the heavy industrial site, the site oriented to major vistas, the windswept site, the site dominated by the highway, the resort site, the site oriented to a body of water and many more.

Consider, by way of example, the steeply sloped site. If it were proposed that this might be a candidate for residential land use, certain qualitative design considerations come to bear arising from the site itself. Table VI-1 lists the site features and the corresponding design considerations in this case.

It has been noted earlier that there is a large crossover of influence between form and the response that a form tends to evoke. Lynch (1960) has distinguished five such 
Table VI -1

Site Features/Design Consideration:

Steeply Sloped Site ${ }^{2}$

Site Features

1. Contours are major plan factors.

2. Areas of equal elevation are narrow bands.

3. Sizeable level areas are nonex istant.

4. The top of the slope is most exposed to the elements.

5. The essence of slope is rise and fall.

6. Perhaps the slope grade is too steep for automobile traffic.

7. The pull of gravity is down.

8. The slope has a dynamic landscape quality.

9. The slope emphasises the meeting of earth and air.

10. A sloping site affords great interest in view.
Qualitative Design Considerations

1. Placing of plan elenents parallel to contours is indicated.

2. Bar and ribbon plan forms are suggested.

3. To create such, earth moving and retaining walls are suggested.

4. Perhaps the top should be developed for its $v$ iew and protection of the slope.

5. Terraced, split-level, and multideck schemes are suggested. Ramps and steps are indicated.

6. Access is necessary from the side.

7. Excepting those structures designed to look daring, designs must express stability.

8. Dynamic plan forms are indicated.

9. The land side might express an anchoring and the air side fly free.

10. Artifical landscape development to create interest may be minimized. 
Table VI-1, cont.

11. The slope is oriented 11. Plan orientation is outwards. normally outward and down with necessary protection from the elements.

12. A sloping site has particular drainage problems.

12. Water must be intercepted and diverted or allowed to pass under and through.

13. A slope brings out many desireable qualities of water.

13. The play of running water is a plan opportunity. 
forms and has proposed that they serve to define the imagery of the city as experienced.

One such response is evoked by pathways. These are the channels along which people move and are comprised of walkways, streets, transit lines, canals, escalators, elevators and the like. They can further be grouped into networks, major ones for the street system, minor ones for the neighborhood, and micro ones for the avenues of ingress and egress of a facility. Structures and landscape along the path give it identity. Paths have qualities of importance, proximity, activity, direction, continuity, uotion and scale.

Another response is evoked by edges. These are the linear boundaries of different parts of districts of the city or of the city itself. Edges have the qualities of penetrability or impenetrability, disruption of continuity, visual impact and limit.

As opposed to the linear qualities of paths and edges, districts evoke areal responses. Districts are arcas of uniformity of interest, sometimes poorly defined however. Examples are uptown, downtown, the CBD, residential areas, industrial areas, the "Near North Side", the "Back of the Yards", "The Block", the "Vieux Carre", and so forth. Depending on their degree of definition, districts have the qualities of entry and exit, thematic continuity, and spatial extent.

Landmarks are places of reference, generally nondimensional in nature. They are promient visual images even though they may be relatively small, as a clock or a statue. Landmarks have the qualities of singularity of image, orientation, contrast, prominence, distinction and identity.

The fifth formal image identified by Lynch is the node. A node is a center of activity distinguished from a landmark by its active rather than passive nature. They are the focal 
points of the city, typically located at the intersections of major paths. Nodes have the qualities of dynatuics, centrality, interchange, focus, junction and decision.

Lynch suggests that the anilysis of such fortus and their qualities, via interpretive studies of the citizens' responses to them, will enbale the city planner to compose a composite image of the city. Then design would take the direction of preserving attractive images, enhancing mediocre images and changing objectionable images.

Some aspects of the essential mobility of urban life have been examined. This motion may be controlled by the urban planner to evoke certain responses such as speed, direction, and ease of mobility. Simonds has catagorized a number of qualitative aspects of design in accordance with their effect on nian.

Man is affected by horizontal motion, for instance, because horizontal motion provides efficiency, frecdom, choice of direction, change of direction, stability, control, and ease of vision of and in motion. Nownward motion has the qualities of less effort, retreat, refuge, return to the primitive, nature, confinement, protection, privacy, economy, simplicity and increased interest in the things of earth. Upward motion has the qualities of force, exhilaration, accomplishment, potential, detachment, supremacy, comand, increased concern for safety and visual interest in overhead planes and the sky.

Man is encouraged to move in logical sequences of progression, along paths of least resistance, towitrd that which pleases, is fitting and wanted, toward change, toward that which is interesting and curious, towards points of highest contrast and richest color. He moves toward exposure, if adventurous; toward order, if tired of confusion; toward confusion, if bored with order; toward protection, if threatened; and toward objects, areas or spaces that suit his mood or need. 
However, man has some degree of difficulty in moving. Indeed, it has been the technological goal of urban planning, and urban transportation planning in particular, to ease this difficulty, generally called the friction of space (Haig, 1927).

Hawley (1950) noted that the physical pattern of urban life is largely the result of this friction of space as manifested in time-cost distance. Actual distance, as it effects human response, is largely dependent on the technological developments which overcome the friction of space. If the technology is such that the time-cost per mile ratio if high, the accessibility of any one area is small and that area is therefore 1 imited in its number of potential uses. If the technology is such that the time-cost per mile ratio is low, differentiation and specialization of land use can be high.

Isard (1960) noted that this measure of the friction of space could include fuel comsumption, the number of stops, the number of intervening opportunities, and the social distance defined by factors such as the quality of information possessed by interacting units, cultural patterns, and economic and social linkages.

To this concept of the friction of space one may conveniently add the Simonds qualitative descriptors of the unpleasant, monotonous, uninteresting, dul1, obvious, undesireable, uninspiring, forbidding, demanding, dangerous, ugly and unsuitable.

The futility of attempting to consider qualitative aspects of urban design out of context is fully acknowledged here. The designer must indeed be an artist, working in the sincere hope that, in the application of his knowledge, he can provide an environment that is both functional and aesthetic to the user and beholder. Functionality comes casier than taste, discrimination, style and halance. It has been noted earlier that functionality alone is not 
sufficient. But functionality combined with an insensitive use of style is not sufficient as well. To use the material outlined here in such a recipe-like fashion will result in a design that is not aesthetic but arty, mannered, stylized and fey.

The question, ultimately, must be begged. The urban planner must design for the appropriate human experience. He must be sensitive enough, by way of his own training, to experience fully and personally an abstract design concept. He must be sensitive enough to vicariously experience the feelings of those for whom he plans. In addition to being technical and operational, he must be humanist in philosophy and temperment, contempletive and universal in interest. The boldest plans are fired in the crucible of humility.

\section{Operational Considerations}

Urban design is so large and complex a problem that it is helpful to conceive of modi operendi. The various approaches depend upon the constraints of the problem and the goals and objectives of the client constituency. The first general constraint is that the development of a city occurs over a long period of time. Add to this the fact that the client constituency changes over time and the design constraints become at various times changeable, transient, competing and subject to different emphases. Add to this the fact that, in most cases, the substance of the plan deals not with a clear unobstructed plane, but with 1 and currently in use, with a city current $1 y$ composed of structures, people, systems and many planning problems, and the planner is genuinely challenged.

Spreiregen (1965) has noted several approaches to this problem. The idea central to all of them is to design a skeletal outline based on the principles of urhan activity systems, spaces, masses, circulation patterns, growth and change, urban scale, and the ability of man to comprehend his surroundings. 
The skeleton is such that there is ample emphasis and direction for the proper fleshing in of it, in due time. This, of course, is a matter of risk but the changeable nature and immensity of the problem to begin with preclude it having a determinate solution.

What part of the skeleton to begin with is a function of the goals and objectives of the client constituency. If these goals and objectives reflect the fact that the constituency is most concerned about aspects of circulation and accessibility, then the logical place to begin is with the transportation system. There is no quarrel that the urban transportation system is one of the primary determinants of urban form and quality. Nor is there argument that the system must not only satisfy functional constraints, but that it has socio-economic, political and psychological effects. These considerations make it a favorite starting point in urban design.

Closely allied with the transportation system are various questions of land use. From a design standpoint, the first problem is to determine what uses to site first. Again, clues may be found in the goals and objectives of the client constituency and the primary community function. These should not normally be in conflict.

If the client constituency demonstrates most concern for family housing conditions, then the logical place to begin is with residential land use. In the absence of such specific direction, the urban planner often begins by considering the placement of open space. Spreiregen notes that this is a most flexible position, with open space not only reserved for use as such, but for possible future development of residential, commercial, industrial and transportation uses. A clear distinction needs to be made, however, between open space reserved for future development and open space reserved for "non-development", that is, to remain open space permanently. The latter suffers from the unfurtunate 
quality of always being "in the market" for subsequent proposals and strong justification and support are necessary to establish permanent open space as a viable and necessary land use in the public mentality.

often it is best to first site those land uses that are the most conceptually constrained, secondly, the next so, and so forth. Typically, industrial land uses are the most constrained owing to their need for transportation, access to employment, juxtaposition to complimentary use and need for large and integral areas. Another constraint arises from the protection of other land uses from the nuisances of industry. If the goals and objectives of the client constituency and the economic analyses of the planner demonstrate the need to attract industry, this argument is greatly strengthened.

Another design emphasis could be one of unifying the impact of public decisions in the areas of not only transportation facilities, but also to include urban renewal, the construction of governmental facilities, and the improvement of governmental operations across the whole spectrum of governmental concern. An area could he designated as one of intense, cooperative and unified change, so scheduled and budgeted, with other areas to follow in a priority according to their need.

closely allied with this is the design technique of siting even a single governmental facility or complex, and the changes, private incentives, and ramifications that occur within and about the area in question.

Another important design consideration deals with the integration rather than separation of land uses. Jacobs (1961) has had a profound effect on the practice of urban planning by clearly noting that the vibrant and cosmopolitan life style of the city comes about because of an admixturc. of land uses over different times of the day. A familiar technique is to integrate commercial, residential and 
recreational land uses as in 1.e Corbusier's Marseille Block and Safdie's Habitat.

Once again it is recognized that many of these considerations lose meaning when discussed outside of the context of a specific problem. Within this context, even the same approach is likely to diverge into several alternatives. This is entirely consistent with good planning practice and many times it becomes difficult to select the best plan from those that, at the surface at least, appear equally good. Before proceeding to these concepts of evaluation in the next chapter, this chapter concludes with a simplified design example based upon the operational considerations of demand.

\section{An Example}

Consider the hypothetical example of siting two types of recreational activities, swimming pools and golf courses, for the residents of three residential areas, each alike in characteristics germane to the problem. There are no such facilities currently available and the goals and objectives of the client constituency reflect the need for them to the exclusion of all other considerations. There is no problem associated with the finances necessary to construct and operate these facilities, be they public or private in nature.

Admittedly, this problem is simplified to make the following point: these facilities can be sited on the basis of demand satisfaction.

Suppose that there are 800 families in each of the three areas and that, through the use of surveys or analogy or national averages or any of the other techniques detailed earlier, the planner can construct demand curves for these facilities as shown in Figure VI-1 (a).

The abcissa of Figure VI-1 (a) is a measure of the friction of space, including all the factors earlier detailed 


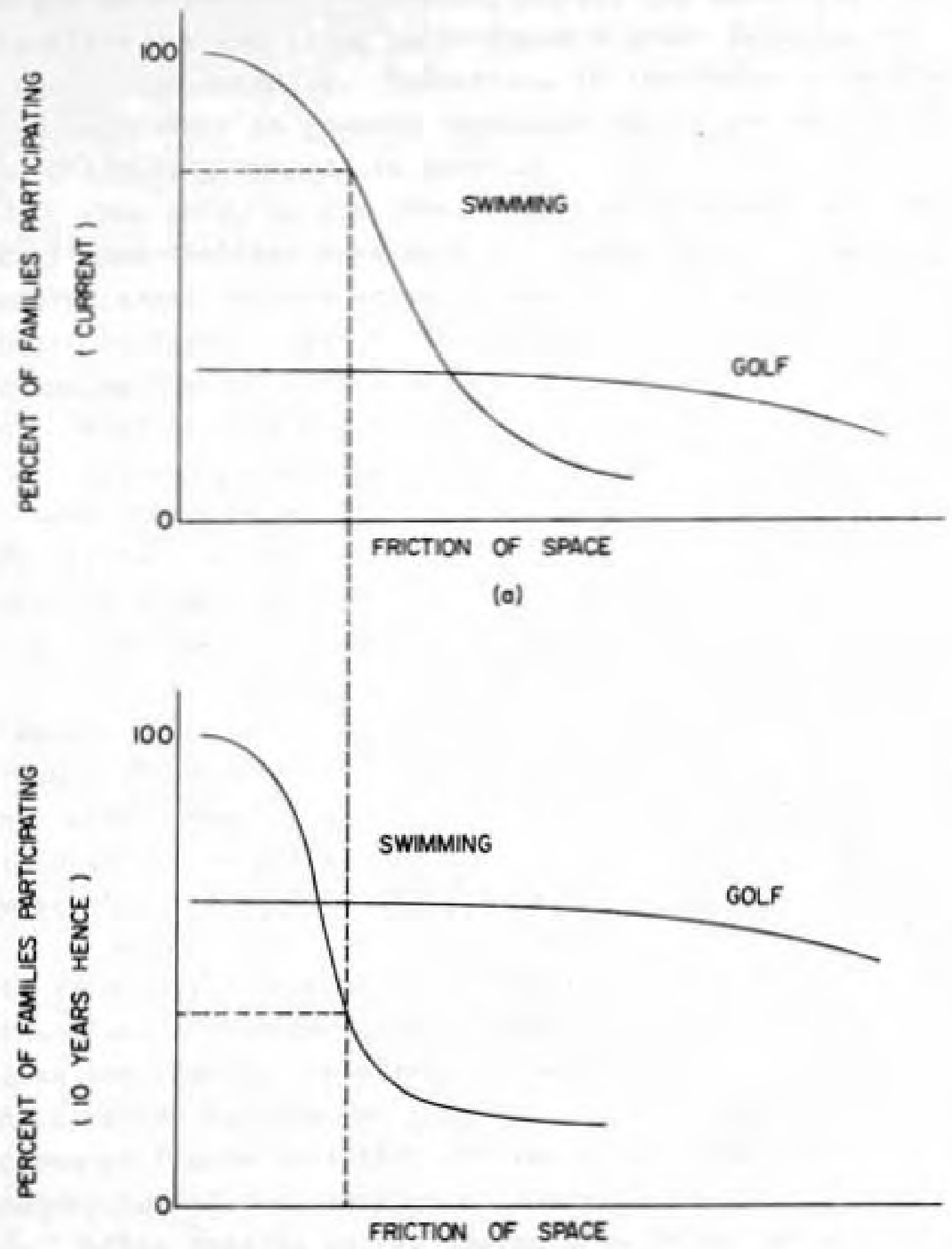

(b)

Figure VI-1

Example Demand Curves, Golf and Swimming 
that make it difficult or unpleasant to participate. As wight be expected, the curves in VI-l (a) show that the fanilies are unwilling to overcome a great friction of space to go swimming. Reductions in the friction at the low end result in great $1 \mathrm{y}$ increased participation until some 1 imiting maximum is reached.

For golf, on the other hand, the curve demonstrates that some families have such an "investment" of time, money, and interest in this activity that they are willing to overcome large frictions to participate. Conversely, reducing the friction of space will not materially effect the level of participation.

If the planner were operating to provide for today's demand alone, he would only need to know the size of these facilities in order to site them properly. If the standard size of a swimming pool were such to accomodate 300 families and, a golf course, 1600 families, one could proceed.

But let us assume we are also planning for ten years hence. Suppose the planner forecasts that there will be then 1000 families in each of the three areas. This is the new gross demand. But what of the new standards of satisfaction? In prior sections, it was noted that standards must be forecast as we11 as demand.

Suppose that the planner feels that people will tend to swim only if the pool is more accessible than is today the case. Otherwise, their interests will be such that, even considering the effect of more leisure time, they will be diverted to other activities. This is shown as the swim curve of Figure VI-1 (b), and reflects a change in the perception of the friction of space.

This results in two design considerations and, quite possibly, two design alternatives. One involves the retaining or assuming the same friction of space and designing a greater number of smaller pools, the greater number resulting from the rise of the gross demand and the change in the 
demand curve from VI-1 (a) to VI-1 (b). The pools would be smaller because they would not be accessible to, say 300 fanilies, but to some lesser number because of the steepening of the demand curve. The other design alternative involves retaining the present size pool, or possibly even increasing $i t$, and reducing the friction of space or access to the pool sufficient to utilize its size. In this case, the number of pools may only go up as a result of the rise in the gross demand and the siting would revolve about reducing the friction of space.

Suppose that the planner, in forecasting the yolf denand, feels that the nature of this demand will not change, but that the percent of participating fanilies will rise as shown in Figure $V I-1$ (b). Suppose he feels too that the rules of play will not change and that his current standard is applicable. Then his problem is much simpler than that with the swiming pools and he need only plan for gross demand factored for increased participation. The location of the one or more golf courses can be based upon considerations other than the friction of space. The demand function for golf closely approximates those constructed for recreational boating and camping in this respect.

The overall solution to the problem (no matter which of the swimming pool alternatives is deemed better) is to locate these facilities such that they satisfy the forecasted net demand according to the forecasted demand curves. These curves describe a surface, of course, radiating outward in all directions from one ordinate (at the facility) over an abcissa plane (the land surface). The swiming demand surface undulates as the falling surface graient from one pool intersects the rising surface gradient of a second pool as it is approached. The golf demand surface hardly undulates at all.

The undulations are not a function of distance but of the friction of space. If, for instance, a pool abutted some 
physical, social, economic, or political obstacle which greatly added to the friction of space from that direction, residents near that pool on the other side of that obstacle may $f$ ind a further (in distance) pool to be nearer (in overcoming friction). Through the examination of this denand surface then, the planner can properly site the swimining pools.

\section{Summary}

The problem faced by the planner in urban design is to provide programs and facilities that will evoke certain human responses when used. The nature of these responses is largely determined by the client constituency. These responses to facility or program demands are accomplished through the professional education and experience of the planner, coupled with a highly empathic sense of what is not only functional but also fitting.

\section{Notes}

1. After Moshe Safdie, Beyond Habitat, pp. 158-163.

2. After J. 0. Simonds, Landscape Architecture: The Shaping of Man's Natural Environment, Pp. 62-63. 
CHAPTER VI I

EVALUATION

This chapter discusses the concepts of urban plan evaluation with the implicit notion that these concepts are used in decision making. It specifically addresses the means of evaluating alternative plans that are rather fully developed. It is recognized that, within the planning process to this point, much evaluation has already been made; that decisions arising from such evaluations have occurred from the start.

The fact that the substance of this chapter affect: earlier phases of the planning process is not a fatal defect. This is just another example of the point already nade that urban planning is cyclical and iterative with feedforeward and feedhack from each phase. Indeed, it is not uncoman to design staged or nested evaluations within the process to accomodate this.

At each of these stages, or perhaps only at this one should the planning permit, the urban planner needs to consult with the decision maker to pursue one alternative among those considered feasible to that point. From this "short list", one alternative is selected as being preferable to the rest, the decision made, planning or implementary effort consolidated, and all resources are then directed foreward along a single path.

Normally, many such consultations are necessary. Sometimes the decision maker is an individual, sometimes a group, for various decisions sometimes different individuals and different groups. All these people participate in the client constituency and sometimes the client constituency itself may make the decision. 
However the decision maker is identified, it is his everlasting and sole prerogative to make the decision. However obdurate and arbitrary it may seem in context, it is his prerogative and he is not about to relinquish it. If, on the other hand, he enlists the aid of the urban planner in evaluating the alternatives open to him, such aid may take one or several of the forms described here.

As before, the urban planner does not stand alone as the sole source of evaluative aid. Steger and Lakshmanan (1968) have noted that the urban planning decision maker should ideally have access:

to historian, architect, ecologist and anthropologist, for what articulate human beings have said, and say, about the quality of their environment;

to sociologists for the application of content analysis;

to opinion pollsters for what people claim they want, directly;

to the econometrician and statistician for measuring what has and actually is chosen by consumers; to social scientist for descriptive and normative models of consumer behavior;

to the social psychologist, for structural and constrained methods for conducting interviews; to system analysts, for structured experimental situations;

to the political scientist and statistician, for intensive analysis of voting behavior, and for methods to simulate voting behavior; and, to pub1ic administrators, for improved ways to ascertain the trade-offs between effects measures desired by community leadership. 1

Steger and Lakshmanan have further detailed a global solution that takes into account the differentiated effects over the variables of investments, times, populations, economies, areas, social indicators and projects. It describes the different response sets of various plans over the ranges of these variables.

Later in this chapter, various operational evaluative techniques will be detailed, beginning with the must simple and proceeding along a continum to those that approximate this global conceptual solution. Before this however, the 
conceptual model of urban planning activity will be examined to elaborate on each of these variables.

The Conceptual Model of the Evaluation Phase

Consider Figure VII-1. It shows the conceptual model of planning activity developed to this point, emphasizing the evaluation phase. Sociologists and political scientists have long been interested in the general question: "Who governs, where, when, why, how and to what effect?" These considerations are reviewed within the context of the model.

\section{Substantive Scope}

The substantive scope axis reflects and measures the range of issues (Bolan, 1969) or outputs (Clark, 1968) associated with the evaluation of alternative urban plans.

Bolan hypothesizes that if the issues are such that the consequences of action are easily predictable, if the action is easily accomplished, and if the issues are generally congruent with the social values of the client constituency, more favorable evaluation of the issues can be expected than otherwise. If there is minimal conflict over the ideological content of an alternative, it will tend to be evaluated higher than one with social values less widely held. If many people are intensively affected by the alternative, it will generally tend to be evaluated lower than one with a less comprehensive effect in both distribution and degree of influence.

Another issue attribute concerns its flexibility. An irreversible alternative will generally be evaluated lower than one which permits modification or abandonment altogether. If the implementary and programing action for an alternative would require complex and coordinated action by many agencies, it will tend to be evaluated lower than an alternative with a single focus and manager. It is widely recognized that there is a tendency to procrastination involving alternatives 


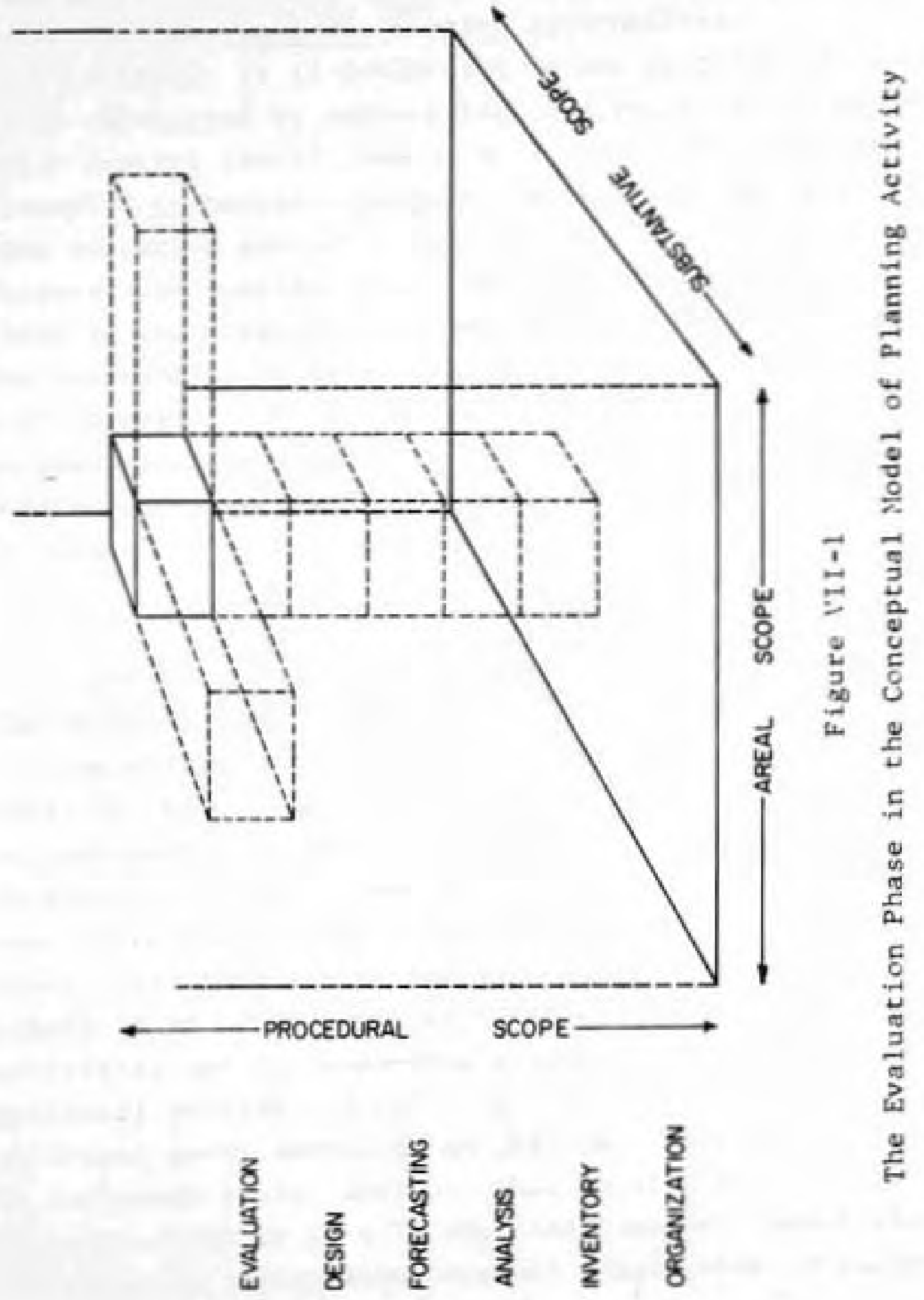


with perceived high risk and uncertain consequences. Abstract and sophisticated alternatives have a built-in bias toward rejection owing to the relative difficulty of communication vis à vis simpler alternatives.

Although it is comforting to see propositions such as these recognized by sociologists and political scientists, their content should come as no surprise to anyone who has attempted to manage a program. With any issue there is some educative and motivative effort, and as the program increases in complexity and sensitivity, as is typical of those in the urban aegis, that effort must be redoubled. The substantive scope axis of the conceptual model provides a rough measure of the intensity of education and motivation as precursors to evaluation. As the substantive scope is more and more narrowly defined, less such effort is generally required.

\section{Areal Scope}

Bolan terms areal scope attributes as those influencing the decision field. This field may be considered as comprising attributes of the evaluative environment and attributes of the evaluating unit or agency. An evaluation by a focused decision center and competent and articulated bureaucracy is more likely to provoke a decision than an evaluation carried out where these attributes are diminished. Clark notes that faster and more direct evaluations are likely in an environment with large demands for governmental activities and correspondingly large bureaucracies, large political parties and full time political roles. The political party serves as an informal integrating mechanism to implement social action. This applies also to the labor movement which in less intense organization decentralizes the decision making structure but which, when intensively organized, has the opposite effect. 
Without these and other such integrative mechanisms, increasing horizontal and vertical differentiation in a community will result in greater differentiation between potential elites and more decentralized evaluation of alternatives. This, in turn, makes evaluation less predictable and tends to dilute the effect of dominent publics of the client constituency.

Differentiation of publics is a reflection of the degree of homogeneity of the client constituency. Bolan notes that the more homogeneous and free of political and social tradition that a client constituency may be, the more likely will be common evaluations. Conversely, a heterogeneous tradition-laden client constituency may tend to indecision unless one of the publics has a clear dominence over the others.

The power base of the agency or individual making the evaluation has an effect on the evaluation. If the power base is stable and unthreatened or obscure, favorable action is more likely than if the evaluative unit is challenged or continuously accountable. Thus appointed bodies, or those with a long term of office, are more likely to decide a difficult issue than short term elected bodies. Bolan continues that an evaluative body that is highly cohesive, that sees itself in a position of high status and narrowly focused areas of responsibility is more prone to evaluative action than a body seen as less important and with nu clear mandate other than that of comprehensiveness.

These attributes are characteristic of the areal scope axis of the conceptual model in the sense that the client constituency is a function of that same axis. Whether the planner is dealing with a group of states or cities or a group of families or individuals, the jurisdictional nature and the degree of authority of the client constituency and specifically, the mandates perceived by the decision makers, affect the evaluation of alternative proposals. 


\section{Procedural Scope}

The procedural scope axis of the conceptual model of planning activity is of most interest to this work because it is here that the most clear conceptual measures can be taken of the remaining three sets of variables out lined by Bolan; evaluation steps, evaluation roles and evaluation strategies. Clark formulates two procedural generalities that summarize this work. First, as a function gains importance in a community, the community members from the sector performing that function will have an increased sway over the nature and direction of evaluation, and decision making. Secondly, as the number and value of the resources available to a sector increase, that sector will have similar increased influence.

Evaluation steps for communal evaluation and decision making are the same as those in the classical model of individual behavior. Some stimulus, perhaps external, brings into attention some need or opportunity deemed desirable. As time and other resources permit, alternative means of satisfying this need or seizing this opportunity are formulated. Again, as time and resources permit, each of the identified alternates is examined for costs, benefits and feasibility. The best such alternative is then acted upon or not.

Evaluation roles measure the specialization and dimension of each actor's ability to marshall the most resources, to occupy favorable positions in the evaluative and decision making structure, to negotiate with skill, and to generally influence the behavior of others. Some of the specialized roles in the context of urban plan evaluation are the critic, the initiator, the technical expert, the analyst, the socialenotional expert, the strategist, the organizer, the advocate, the arbiter, the propagandist, and many more including the planner himself. The dimension of each of these roles is a measure of each actor's motivation, opportunity and personal skills. 
Evaluation strategies, according to Bolan, are reflections of both the nature of the planning and the nature of the programming proposed to execute the plan. If the planning was done by an agency or individual attached to a center of power, it will have a greater influence than that planned by independent or advisory agencies or individuals. Incremental and opportunistic planning tends to be evaluated higher than the classic grand comprehensive planning, owing partially at least to the previously discussed problems of interdependence, coordination and complexity. Planning dealing with immediate or short range objectives and having a narrowly constrained influence will tend to be evaluated higher than long term, goal oriented planning.

As for programming, plans that envision moderate to small redistribution of resources, minor changes in behavior both on the individual and aggregate level, and minor changes in institutions and organizations have a built-in favorable bias over programing actions requiring massive such changes.

Within the conceptual model then, the planncr should not arbitrarily propose an evaluative procedure. Rather any such procedure must necessarily be tailored to the actors involved, to identify them as they themselves change through the evaluative steps, and to recognize that alternative planning strategies may be necessary to reach each of them in turn.

\section{Summary}

There is nothing particularly Machiavellian in recognizing that there are facets of evaluation outside of the substance of an alternative, and in maneuvering to ameliorate their consequences, as long as the planner remains professionally disinterested in the eventual outcome of the evaluation. In this way, each alternative comes closer to being judged on its merits rather than through some of the procedural bias outlined here. 
Evaluation is by its nature a series of personal preference decisions, made somewhat less so by being firmly grounded in scientific analysis with a recognition of bias. This tends to make the evaluation more univeral, which is an attribute much to be desired when the evaluator speaks for a client constituency.

There is no denying that evaluation of urban planning alternatives is extraordinarily complex. Returning to the Steger and Lakshmanan model, it is seen that not only must the urban planner be concerned with the variables of investments, times, populations, economies, areas, social indicators and projects, but he must also understand (and make known to the decision makers) the conditions under which each of these is valued and the extent to which that valuation is a function of the variables themselves, their interdependence and externalities.

Some plan aspect may be judged utile; but to whom? Why? Where? When? To what effect? Some plan aspect may be judged costly. The same questions must be addressed. This plan aspect may be utile to one sector, costly to another, and indifferent to a third. Is there a balance of costs and utilities to each sector? Should there be?

The plan alternative was designed to evoke a set of responses. In evaluating it, the planner and decision maker must be aware of the distribution and differentiation of that set.

\section{Evaluation Techniques}

As has been the pattern in previous chapters of this work, the discussion now turns to operational considerations of evaluation, beginning with those simpler in concept and proceeding along a continuum to those that approach the conceptual Steger and Lakshmanan model. As a general comment, the use of any of these operational techniques is partially a function of the resources available for the 
planning effort and the prior phases of planning. Few, if any of these can be artitrarily applied to a planning process without the necessary organizational, inventory, analysis and forecasted precursors. The study design must take into consideration the probable evaluative techniques to be ased some months hence.

\section{Intuitive Methods}

The simplest and most direct evaluative methods are those based on intuition. The decision makers sclect their preferences from anong the alternatives open to them seemingly without analysis, drawing intuitive guidance from their own experience. As outlined earlier, this is their prerogative and, once taken, the discussion is closed. There is little the planner can do but acquiesce.

There is nothing necessarily wrong in this method as long as three conditions are met. First, the alternatives prepared by the planner must each be viable and not, as may occasionally be the case, consist of one or two viable alternatives with the remainder being "straw men". Indeed the providing of non-viable alternatives to the decision maker is non-professional behavior and implies decision making by the planner, a violation of his advisory authority. A11 the alternatives considered should be feasible and the choice of any should be a matter of relative preference, not rightness or wrongness. The second condition follows from the first, that while the planner may indeed harbor personal preferences he should remain professionally disinterested in the outcome. Third, the client constituency should have such faith and trust in the decision makers that the decision makers need not have to analytically defend their preferences.

The most seldom met of these conditions is the third. There is also no a priori reason to catagorize decision makers as so naive that they will consciously ignore the 
manifold difficulties of evaluation of urban alternatives. Accordingly, some type of more open if not more rational analysis is usually employed.

Monetary Valuation Methods

A very widely used measure of utility is monetary valuation. All benefits and costs are reduced to a monetary value, dollars in this discussion, to compare future flows of benefits and costs over a specified time frame. The general objective is to establish the probable net return For each of the competing alternatives or, conversely, determine the most economical alternative producing a specified minimum net return.

The dollar valuing of costs and benefits is acknowledged to be frought with danger, but it also very conveniently meshes with administrative procedures and cominon cultural values. On a micro level, the question of how much an individual might be willing to pay for an urban service is answered every day. In both the private and public sectors, the one document that ties all facets of a 1 if c style together is the budget. Further, in the private sector, nearly all entrepreneurial decisions are based on the expected monetary return, and this exerts a large crossover influence on the public sector.

There is no lack of literature on the general subject of engineering economics with the unfortunate side effect of a multiplicity of terms. The convention maintained here is from Winfrey (1969) and the material follows from his work.

The equivalent uniform annual cost method disregards benefits and combines all investment costs and all operating costs into a single annual figure. This annual figure is equal to all costs associated with the alternative if such costs were distributed equa11y over the economic 1ife of the alternative. Residual or terminal values at the end of the 
economic life are treated as negative capital costs. This method assumes non-valuable and equal benefits will accrue from each of the competing alternatives. This assumption may approximate the real situation in only a very limited scenario.

The present worth of costs method again disregards differentiated benefits and combines all costs into a single figure, the value of which is the money necessary at time zero to finance the project over its economic life. This value can be directly converted to the equivalent uniform annual cost by multiplying it by the appropriate capital recovery factor. The present worth of costs method is likewise 1 imited by the assumption of equal and non-valuable benefits among the competing alternatives.

The equivalent uniform annual net return method cumbines all benefit: into a single annual figure which is added to the negative equivalent uniform annual cost. The alternative having the most positive equivalent annual net return is the one preferred. The main assumption in this method is that the alternatives each produce an annual benefit that can be dollar valued. A minimum attractive rate of return is used in the calculations so that as soon as the net answer hecomes positive, the alternative will be earning a rate of return more than this specified minimum. Since the benefits are valued, they do not have to be equal anong competing alternatives.

The net present value method compares the present value of both costs and benefits and is the same in principle as the present worth of costs method. Whereas the mothods outlined so far call for comparisons among competing alternatives, this method can compare alternatives to the present value of doing nothing, the null alternative. The assumption is that the money is currently earning a minimum acceptable rate of return. When the calculated net present value is positive, the alternative will earn at a rate higher than that currently. 
The benefit/cost ratio method provides a ratio of the equivalent uniform annual benefit to the equivalent uniform annual cost. The present worths of benefits and costs can be used in ratio form as we11. A ratio greater than one exceeds the minimum acceptable rate of return used in the calculations and the alternative with the highest ratio may be preferred. More typically the alternative that provides the greatest increase in the benefit-cost ratio is preferred. The use of a ratio masks the absolute values of the costs and benefits and may obfiscate considerations of magnitude. The benefit/cost ratio method allows for the differentiation of benefactors and beneficiaries and has been widely used in the public sector for this reason. Some discussion, outside the scope of this work, has centered about whether annual operative costs are a negative benefit (and thus in the numerator) or a cost (and thus in the denominator). Winfrey holds that because the objective of the analysis is to indicate an investment profitability, because of consistency with other methods, and because of general cost accounting procedures, the former position is most sound. For the same reasons, the terminal value factor should be placed as a deductive in the denominator.

The rate of return method identifies that discount rate which will equate the negative cash flows or costs to the positive cash flows or benefits. The alternative with the highest rate of return is preferred. There are no restrictive assumptions as to the equality of benefits anong alternatives as long, of course, as they can be monetarily valued. Alternatives can be compared to each other or to the null alternative. The rate of return method yields a direct measure of the profitability of an alternative that may be more meaningful than the benefit/cost ratio in some applications.

The six economic models of evaluation described here become somewhat mechanically limited as any of the following 
factors become significant; alternatives with unequal economic lives, reversals in the direction of cash flows, fluctuation in the magnitude of cash flows over time and rates of reinvestment. There are, however, procedures and assumptions which can be used to accomodate these considerations. The models could also be sensitive to changes in the terminal values of the alternatives, to changes in the length of the analysis period, and to changes in the discount rate. Certainly good procedure would call for sensitivity analyses of these factors.

of course, the overriding burden of these methods of economic analysis is not on the methods so much as on their input data, the dollar valuation of costs and benefits. Hill (1968) has noted that by the very indivisible nature of some collective social benefits there is no market by which to measure or value them. There are indeed some social benefits that are valued because they are produced privately and marketed; there are some that are never marketed but may be subject to monetary valuation; but there are many more that are simply outside the scope of monetary valuation. Although some recognition is given these intangibles, Hill suggests that the net effect of economic analyses alone is to automatically enhance the importance of effects that can be monetarily valued to the detriment of the effects that cannot. This may be a reversal of the true order of things. One way out of this dilema might be to consider what might be called second order market effects. If, for example, real property appraisal were a more exact science, and if property values could be considered to reflect social effects not otherwise monetarily valued, perhaps such appraisals of the effects of each alternative could aid in distinguishing among them by imputing the market. The values thereby imputed could then be used in economic analyses. This approach seems to be of most immediate use in evaluating alternative land use plans. 
More likely than not however, economic evaluation methods will not alone suffice to properly judge urban planning alternatives.

Social Accounts Valuation Methods

Litchfield (1964) has proposed and used a systen of social accounts to measure the costs and benefits of urban planning alternatives. The costs and benefits so identified need not necessarily be included in the overall measure of economic efficiency. Sectors of producers and sectors of consumers are identified and for each sector he forecasts the costs or benefits that will accrue under each alternative. The values given these costs and benefits may be monetary, they may be numerical values in non-monetary terms, or they may be intuitively valued in descriptive tcrms. For each alternative, a complete set of social accounts is constructed which Litchfield terms the planning balance sheet. With the use of this balance sheet the decision maker has a firmer base from which to compare tangibles with intangibles, the incidence of costs and benefits over different sectors if brought to 1 ight, and those design elements that are high in cost and low in benefit may be identified.

In discussing this technique, Hill recognizes that it is a step foreward along the evaluative continuum from strict economic methods but notes that the planner's evaluation of the intangibles is groundless if it is made without reference to the goals and objectives of the client constituency. Benefits and costs are not necessarily absolute but have a relative and instrumental value defined by these goals and objectives. To maximize some benefit in the abstract is meaningless.

Still in the absence of resources for methods still further along the continuum, the construction of a set of social accounts is an improvement over purely economic analyses. 


\section{Utility Value Methods}

The concept of utility measures has been introduced in chapter I in the context of measuring the preferences of the community for goals and objectives. Mased upon these measures of preference, weights could be assigned to each goal and objective to approximate the value system of all or portions of the client constituency. Fishburn (1967) has sumarized twenty-four mathematical techniques for estimating additive utilities and three such were described in Chapter I, ranking, rating, and a method of successive comparisons.

Suppose urban planning alternatives could be assigned such utilities; each utility being defined as the sum of the cost utilities (negative) and the benefit utilities (positive) for each alternate plan under a specific set of external conditions or states of nature. If such utilities could be assigned, the results could be incorporated into a payoff matrix as shown below. A's designate alternates; U's designate additive utilities; and N's designate states of nature.

Table VII-1

Conceptual Payoff Matrix

\begin{tabular}{|c|c|c|c|c|}
\hline $\mathrm{N}_{1}$ & $\mathrm{~N}_{2}$ & $\mathrm{~N}_{3}$ & $\ldots$ & $\mathrm{N}_{\mathrm{i}}$ \\
\hline $\mathrm{u}_{11}$ & $\mathrm{v}_{12}$ & $\mathrm{U}_{13}$ & $\ldots$ & $\mathrm{u}_{1 \mathrm{j}}$ \\
\hline $\mathrm{U}_{21}$ & $\mathrm{U}_{22}$ & $\mathrm{U}_{23}$ & $\cdots$ & $\mathrm{u}_{2 \mathrm{j}}$ \\
\hline $\mathrm{U}_{31}$ & $\mathrm{u}_{32}$ & $\mathrm{v}_{33}$ & $\ldots$ & $u_{3 j}$ \\
\hline$\ldots$ & $\cdots$ & $\ldots$ & $\ldots$ & $\ldots$ \\
\hline $\mathrm{u}_{11}$ & $u_{12}$ & $v_{13}$ & $\ldots$ & $\mathrm{v}_{i j}$ \\
\hline
\end{tabular}


Given a payoff matrix, there are several well known operations research techniques for evaluating the alternatives and selecting the best (Miller and Starr, 1960). If the probabilities of occurrance are known, the best strategy is the one that maximizes the expected value, EV, where:

$$
\because v_{i}=\sum_{j=1}^{n} v_{i j} p_{j} \text { for } n \text { states of nature, each with }
$$

a probability of occurrance, $P_{j}$.

If the probabilities of occurrance of the states of nature are unknown, there is no one best criterion for selecting an alternative. There are instead several such criteria, the selection of which depends to a large degrec upon the policies and attitudes of the decision makers.

The wald maximin criterion suggests that the decision maker should always be pessimistic and select the alternative with the largest minimum utility, the maximum minimum or maximin.

The Hurwicz maximax criterion suggests that the decisiun maker should always be optimistic and select the alternative with the largest maximum utility, the maximum maximum or maximax.

The sensitivity of the decision to the range of criteria between the maximin and the maximax is easily investigated by synthesizing probabilities on the states of nature. This could result in a coefficient of optimism which approximates the expected value criterion.

The Savage minimax criterion suggests that the decision maker should select that alternative which will minimize the regret he may feel having chosen an alternative and then discovering which state of nature will occur. Regret is measured by the difference between the maximum utility and all others under each state of nature. The decision maker then selects the alternative with the minimum largest regret, the minimum maximum or minimax. 
Under all these criteria the probabilities of the state; of nature were unknown, yet the choice of criterion allows the decision maker to favor the probability of good or bad outcomes depending upon his personality, the stakes at hand and the environment of the decision.

Actually the Bayes' hypothesis would demand that the states of nature be explicitly considered equiprobable. In that case, for $n$ states of nature, the best alternative is tho one with the highest expected value, the probability of eich state of nature being $1 / \mathrm{n}$.

Goal Achievement Methods

The utility of a particular planning alternative only gains meaning in relation to a set of planning goals and objectives. The nature of the use of goals and objectives developed at the outset of the planning process has been amplified in every phase of the process to this point. It is fitting that this feedforeward should continuc through the evaluation phase.

Hill (1968) has proposed the construction of a goalsachievement matrix for each planning alternative under consideration, conceptually shown in Table V11-2.

$\alpha, \beta, \gamma$ and $\delta$ are goal statements and $2,3,5$ and 4 are their respective weights which could be determined in a manner described in Chapter I. The incidence column lists those groups of people, institutions, economies or establishments that are affected by the alternative. A relative weight is determined for each group for each goal. Hill does not specify the manner of this determination. The letters A, B, C ... are the costs and benefits accruing to each group measured by each goal. They may be in monetary units, utiles, or descriptors. A dash (-) indicates that no cost or benefit to a group would occur if that plan were implemented. For some of the goals, $\sum$ indicates the 
Table VII-2

The Goals Achievement Matrix ${ }^{2}$

\begin{tabular}{|c|c|c|c|c|c|c|}
\hline \multicolumn{2}{|c|}{$\begin{array}{l}\text { Coal description: } \\
\text { Relative weight: }\end{array}$} & \multicolumn{2}{|l|}{$\alpha_{2}^{\alpha}$} & \multirow[b]{2}{*}{$\begin{array}{c}\text { Relative } \\
\text { weight }\end{array}$} & $x_{3}$ & \multirow[b]{2}{*}{ Renefits } \\
\hline Incidence & $\begin{array}{c}\text { Relative } \\
\text { weight }\end{array}$ & Costs & Benefits & & Costs & \\
\hline Group a & 1 & A & D & 5 & E & - \\
\hline Group b & 3 & $\mathrm{H}$ & & 4 & - & $\mathrm{R}$ \\
\hline Group c & 1 & L & $\mathrm{J}$ & 3 & - & $\mathrm{s}$ \\
\hline Group d & 2 & - & & 2 & & - \\
\hline Group e & 1 & - & $\mathrm{K}$ & 1 & & u \\
\hline
\end{tabular}

\begin{tabular}{|c|c|c|c|c|c|c|}
\hline \multicolumn{2}{|c|}{$\begin{array}{l}\text { Goal description: } \\
\text { Relative weight: }\end{array}$} & \multicolumn{2}{|l|}{$\gamma_{5}$} & \multicolumn{3}{|c|}{$\delta_{4}$} \\
\hline Incidence & $\begin{array}{c}\text { Relative } \\
\text { weight }\end{array}$ & Costs & Benefits & $\begin{array}{l}\text { Relative } \\
\text { weight }\end{array}$ & Costs & Benefits \\
\hline Group a & 1 & ) & N & 1 & Q & R \\
\hline Group b & 2 & & - & 2 & $\mathrm{~s}$ & $\mathrm{~T}$ \\
\hline Group c & 3 & $\zeta M$ & - & 1 & v & W \\
\hline Group d & 4 & & - & 2 & - & - \\
\hline Group e & 4 & & $\mathrm{P}$ & 1 & - & - \\
\hline
\end{tabular}


summation of their effects may be valid. Hill also notes that ranges of costs or benefits could be specified to bracket those which are uncertain. Braces indicate that some costs or benefits are indivisible among the braced groups. Among the alternatives, the preferred is the one whose matrix demonstrates the highest goals achievement index.

This index may be intuitively arrived at, with the greatest benefit of the goals achievement matrix being merely the surfacing of the complexity of the intuitive interpretation. On an ordinal basis, a simple measurement of $-1,0,+1$ could be used to describe a decrease in goal achievement, no effect on goal achievement, or an increase in goal achievement, respectively. On a ratio basis, more complete information could be imputed to the model, with the attendant risk of the choice of units and the masking of considerations of magnitude.

Hill recognizes that the goals achievement index, however arrived at, is difficult for the decision maker to digest. There may be no single index at all in contrast to that of, say, the economic efficiency of earlier described methods.

Schimpeler (1967) has proposed two evaluative decision models based upon the measurement of goals achievement. Referring back to Chapter I, assume that a set of community goals and objectives has been developed, $G_{j}, j=1,2,3$ ... $n$; and for each $G_{j}$ a numerical utility value has been assigned, $U_{j}, j=1,2,3 \ldots n$,

$$
\sum_{j=1}^{n} v_{j}=1 .
$$

Schimpeler proposes that a group of professionals associated with urban planning be assembled to consider the alternative plans. Without knowledge of the values of the 
client constituency, $U_{j}$ for each $G_{j}$, they are instructed to render dispassionate professional judgments as to the probability that a given alternative plan will affect each göal or objective, $G_{j}$ : A modification of the Schimpeler techniques would require that, if there are $i$ alternative plans, this effectiveness measure, $e_{i j}$, would be 1 if objective $j$ is assured under alternative $i$. An $e_{i j}$ of 0 implies that alternative $i$ has no effect on objective $j$. An $e_{i j}$ of -1 ineans it is practically impossible to achieve objective $j$ with alternative $i$. Values of $e_{i j}$ between 1 and -1 reflect this professional judgment of the probability of effectivness and the degree of that effectiveness of each alternative-goal combination.

The result is an effectiveness matrix which, when multiplied by the value matrix for the goals and objectives, yields the cumulative utility, $U_{i}$, of each alternative plan. Thus;

$$
v_{i}=\sum_{j=1}^{n} e_{i j} \cdot u_{j} \text {, where there are } i \text { plans and } j
$$

goals and objectives.

The alternative with the highest cumulative utility is preferred.

Schimpeler has also developed an extension of his model to weight the values cf various socio-economic groups of the total population according to their numerical participation in that total.

$$
\begin{aligned}
& u_{i}=u_{i}^{1}+u_{i}^{2}+\ldots u_{i}^{k}+\ldots u_{i}^{p} ; \text { and } \\
& u_{i}^{k}=a_{k} \sum_{j=1}^{n} u_{j}^{k} e_{i j} \text {, where }
\end{aligned}
$$

$U_{i}=$ the total utility of alternative $i$; 
$U_{i}^{k}=$ the utility of alternative $i$ as determined by the kth socio-economic group, $k=1,2, \ldots p$;

$u_{j}^{k}=$ the criterion weight for objective $j$ as determined by the kth socio-economic group;

$e_{i j}=$ the effectiveness of plan i relative to objective $j$; and,

$a_{k}=$ the fraction of the total population represented by the kth socio-economic group.

\section{Psychological Valuation Methods}

This work has repeatedly recognized that the ultimate charter of the urban planner is to design physically and programmatically to evoke a desired set of human responses. Human response to stimulus is the business of the psychologist and Craik (1968) has proposed that psychological measures of evaluation may be most appropriate to differentiate among plan alternatives.

If some sort of display of the alternatives could be presented to the client constituency, psychological measures of the constituency interpretation, interest and response to the display could be made. The display may be an actual real life situation, or simulations of such through audiovisual methods or three dimensional models.

Craik has classified thirteen methods to measure the constituency response to such displays. Free descriptions, adjective checklists, and activity and mood checklists may be used to measure constituency reaction. A Q-sort method may be used to measure reactions along a continuum from "most characteristic" to "least characteristic". A Semantic Differential Rating or Thematic Potential Analysis are sensitive to subtle differences in observations. In the latter, observers would be asked to compose a brief story about "something which might fittingly happen here".

The use of symbolic equivalents, such as appropriate metaphors, or multisensory equivalents, such as color 
sequences or music themes, betray human response perhaps otherwise hidden.

People make inferences as to the kinds of people that might live, work or play in selected environments. These social stereotypic cues offer insights as to their own relation to the environment, as does empathic role playing.

If the client constituency could describe the effect upon them if they lived in the environment displayed, this could be compared to their current self evaluation to investigate the change in response.

Salesmen are very aware of the effects of viewing time and viewing sequence on their customers and the most popular or the most returned to or the longest viewed display might evoke the best responses when considering urban alternatives.

A full discussion of psychological measurement procedures is far afield of the scope of this work, but the use of professional psychologists in evaluation of urban alternatives is an intriguing possibility.

\section{Summary}

The previous section has considered some operational or near operational methods of evaluating alternative urban plans. If it is clear that there is no global operational solution to the problem of plan evaluation, it is also clear that progress toward that solution is being made.

It remains for the urban planner, working in context, to design evaluative procedures somewhat ad hoc. In addition to the conceptual and operational constraints out lined here, he will find, of course, institutional, legal, and resource constraints affecting his chosen methodology.

Manheim (1962) has conceptually described evaluative methodológies as necessarily being communicable, repeatable, comparable and revisable. To be communicable, the process of evaluation should be explicitly enough defined so that a second party may follow it. If the process yields the same 
result from the same inputs, it is repeatable. When different results can be traced to different inputs, the process is comparable. Revisability allows for new information or feedback.

Perhaps the greatest lesson of the discussion is this: because of the nature of urban planning, evaluation may always incorporate large elements of intuitive thinking. Thus, each of the methods outlined here as well as any combinations, permutations, and extensions that the planner may devise, can only serve as an aid to intuition and must never be taken dogmatically. A corollary to this would state that the evaluation method should affect the evaluation as little as possible, and every parameter should be examined for its sensitivity.

Boyce, Day and McDonald (1970) have proposed a set of conceptual guidelines for this ad hoc effort which sumarizes the material covered above. Any evaluation of an urban planning alternative should include the following characteristics: technological and fiscal feasibility; distributional effects and equity; conservation of economic, social and natural resources; flexibility to respond to changing conditions; levels of service and systems performance; economic efficiency; organization of facilities and services; social interaction and diversity of opportunities; the nature of cooperative action and joint decision by conflicting groups; and the distribution of control among the various types and levels of the public and private sectors.

\section{A Note on Practice}

Boyce, Day and McDonald have researched the evaluation strategies and techniques of several major transportation and land use planning processes. Their research is beyond the scope of, but an excellent adjunct to the material covered in this chapter. Some of their conclusions are herewith included to demonstrate how various emphases of 
technique have occurred within the constraints of working in context.

In researching evaluative methodology, the authors readily admit to the difficulty of reconstructing evaluations based upon a wide variety of source material ranging from precise technical memoranda to furtive verbal allusions. Many facets were apparently not documented at al1.

Five of the major transportation and land use planning evaluative processes that were summarized by them are those of Baltimore, Boston, Chicago, Milwaukee and the Twin Cities.

The Regional Planning Council of Baltimore had a legislative mandate to develop and adopt a comprehensive plan for the region. Boyce et al. termed their evaluative processes and methods to be generally "ad hoc and eclectic".

The Boston Regional Planning Project, and later, the Eastern Massachusetts Regional Planning Project was a joint program, rather than a specific agency, instituted to provide a comprehensive development plan for its region. The authors termed its evaluative methods and processes to be "distinctive", articulated, and "to have achieved a more realistic compromise with diplomacy and planning resources, than any other(s) currently in operation." 3

The Chicago Area Cooperative Land Use Transportation Project was a joint venture of the Northeastern I11inois Planning Commission and the Chicago Area Transportation Study. Its charter was to prepare a comprehensive land use, public facility and natural resource plan for the six counties of northeastern Illinois. Their evaluative methods and processes were characterized to be "hasty and austere", partially due to an unfavorable political climate and budget limitations, but it was pointed out that "a classical

'narrowing down' process was fully worked through, and concrete moves were taken to foster public participation and implementation." 4 
The Milwaukee work was guided by the Southeastern Wisconsin Regional Planning Commission, composed of members appointed from area counties. The commission was authorized to prepare and adopt regional plans for the physical development of the area. Boyce et al. term the Milwaukee effort "The epitome of a solid and exhaustive study, by all prevailing standards. It was outstanding for the amount, rigor and relevince of its technical contribution, and for its highly structured and coherent program..." 5

The work in the Minneapolis-Saint Paul area was directed by the Joint Program whose organization structure is described in Chapter II. It is a form of quasi-metropolitan government authorized to deal with problems at that level, and to coordinate the activities of all public agencies serving the region. Boyce et al. characterized the operation as "innovative", "involved", and successful. "Whatever may have been lost through the accompanying de-emphasis of technical assessment in favor of intuition, was more than made up by a demonstration of informed, sensitive and shrewd diplumacy, and by the crystallization and enunciation of a refreshing philosophical approach." 6

Table VII-3 has been prepared to demonstrate the strategic emphases employed during the five planning processes. A distinction is made between the examination of a single alternative and the comparison of two or more alternatives. Network performance measures refer generally to the techniques of traffic assignment as previously presented in Chapter v. The "cost of systems" heading refers to the general criterion of economic efficiency. Public activity systems are typically utilities, services, public policies regarding land use and natural resources. Private activity systems were largely commercial in character, but could include industrial and residential incentives. Efficiency analysis refers to the conceptual balancing of costs and benefits. 


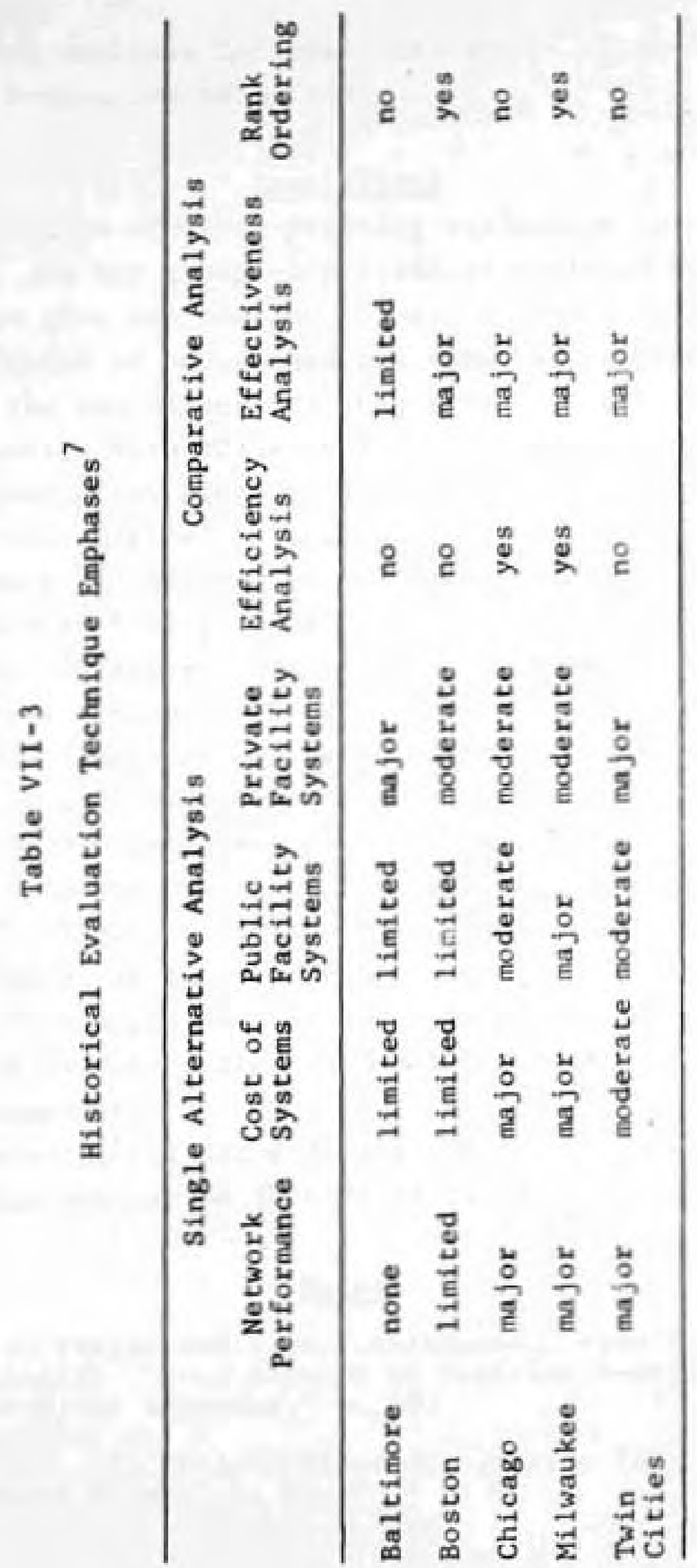


Effectiveness analysis includes the concept of goal achievement as an evaluative technique.

\section{Conclusions}

The problem of urban planning evaluation is multidimensional and any group of procedures employed by the planner must give due account to each of these dimensions.

The states of nature and the a1ternative plans themselves are the two dimensions that provide the framework for the others. With these, the planner must consider the groups of people (or economic sectors or industrial sectors, etc.) and their degree of participation, their values, and the distributional effects of the alternatives over these groups. He must consider the likely effectiveness of the alternatives, judged in some way that is relevant.

To these dimensions, the planner must add the social and cultural effects of evaluation with attendant consideration: of roles, strategies and procedures.

A11 these effects must usually be reduced to measures of resources to compare costs and benefits and to guide programing. The best alternatives are those that are the most profitable, in the grandest sense of the word.

All of this occurs over time, is projected into time, will operate in future time, and will have effects which are time dependent.

Considering all these dimensions, the only absolute of urban plan evaluation is that it is relative.

\section{Notes}

1. Wilbur A. Steger and T. R. Lakshmanan, "Plan Livaluation Methodologies: Some Aspects of Decision Requirenients and Analytical Response," p. 69.

2. Morris Hil1, "A Goals-Achievements Matrix for tivaluating Alternative Plans," p. 23. 
3. D. E. Boyce, N. D. Day and C. McDonald, Metropolitan Plan Making: An Analysis of Experience with the Preparation and Evaluation of Alternative Land Use and Transportation Plans, p. 140.

4. Ibid.

5. Ibid.

6. Ibid.

7. Ibid., p. 6. 
CHAPTER VIII

IMPLEMENTATION

It would be manifestly inappropriate to conclude this work without a consideration of the natural and logical conclusion of the substance of the planning process - the implementation of the plan, its policies and programs. That this is difficult however, mirrors the difficulty of plan implementation itself and the attitude certainly exists to simply state that such matters are best left to politicians, to present the fee statement, and to steal quiet $1 \mathrm{y}$ into the night.

Such behavior assumes that a recognizable end of the planning process has been reached, Even this may not be the case. Without belaboring the point, it is recognized that much of planning is continuous and changing. Such characteristics are among the poorest reasons and even less of an excuse for the failure of planning to reach sound conclusions, even though they may be conditional on future as sumed scenarios.

Perin (1967) has noted that an obsessional disorder is one:

where an individual is incapable of bringing a task to a conclusion and substitutes continuously repetitive behavior that assures no ending - stresses that what is being avoided is acknowledgement of incompetance for the task at hand, whether real or imagined... The way in which comprehensive planning work is (sometimes) organized and undertaken, being pointed as it is toward the production of one plan, has patently obsessive characteristics. The 'incompetance' being masked by endless and diffuse studies may relate closely to the fact that analytic work in city planning has yet to make its peace with the tolerable range of error appropriate to each topic it deals with: fear 
of being found 'wrong' in a recommendation or

'incomplete' in the range of variables studied has

led to an abuse of 'open-endedness' and 'flexibility'

as important to the planning 'process'. The leap to action must be made. 1

Throughout this work, the concept of operationality has been given a high precedence. In fact, the identification of planning as a process presupposes a beginning and an end. The material presented in earlier chapters has been oriented not only to operationality alone, but also operationality with direction, purpose and conclusion. It is hypothesized that such procedural considerations as are outlined here are both an incentive to implementation and a necessary beginning of implementation.

The professional position of the planner relative to implementation is analogous to that of the planner relative to evaluation and decision making. As in the case of the latter, implementation actions are an executive function and it is the prerogative of the executive to retain such functions unto himself. If he so chooses, so be it.

Again as in evaluation and decision making however, the planner should stand ready to aid the executive in these functions and should make his capabilities and recommendations known to him. Because programs and plans are sometimes redirected, even unconsciously, in their implementation; because the specific application of general programs may sometimes cause injustice; and because simply not every consequence can be foreseen; Davidoff and Reiner (1962)

pose for the planner the role of an overseer, one who aids policy makers by observing the direction programs are given and by suggesting means for redirecting these toward their intended goals. ${ }^{2}$

Such a role clearly brings the planner out of an advisory staff position closer to one of execution. A secondary benefit of such a role occurs because, faced with the possibility of thus being hoisted by his own petard, planners are then likely to give due consideration to the conditions of operationality. 
Care must be taken lest such a prospect dampen the necessary innovation required of the urban planner. Wurster (1964) has made note of the inherent tempermental conflict between the skepticism necessary to scientific endeavor and the emotion necessary to effective reform.

By and large, science can only help to explain why things are the way they are. Since there are always good reasons, there is a tendency for good studies to make current conditions seem inevitable. And this can lead to a kind of paralysis with respect to issues which require bold innovation... In a field where there can never be full factual proof of what ought to be done in the future, moreover, too much respect for scientific methods means timidity in making positive inferences and bold judgements. ${ }^{3}$

As exampled by these comments, planners have come to recognize that their professional responsibilities extend beyond the preparation of technical planning documents. Planning is a political process as well as a technical process. The political aspects of the process, although occurring throughout, are most apparent in the implementation phase. In the discussion which follows, these aspects are examined with reference to the conceptual model of planning activity.

The Conceptual Model of the Implementation Phase

Figure VIII-1 shows the conceptual model of planning activity, emphasizing the implementation phase.

\section{Substantive Sčope}

The substantive scope axis of the conceptual model measures the continuum of implementation actions dealing with the substance of the plan. Of course, such actions are themselves a function of many variables, but measured along this axis they can be said to approximate two largely inseparable conditions: first, the degree to which the goals and objectives of the client constituency identified in the planning process are congruent with those actually 


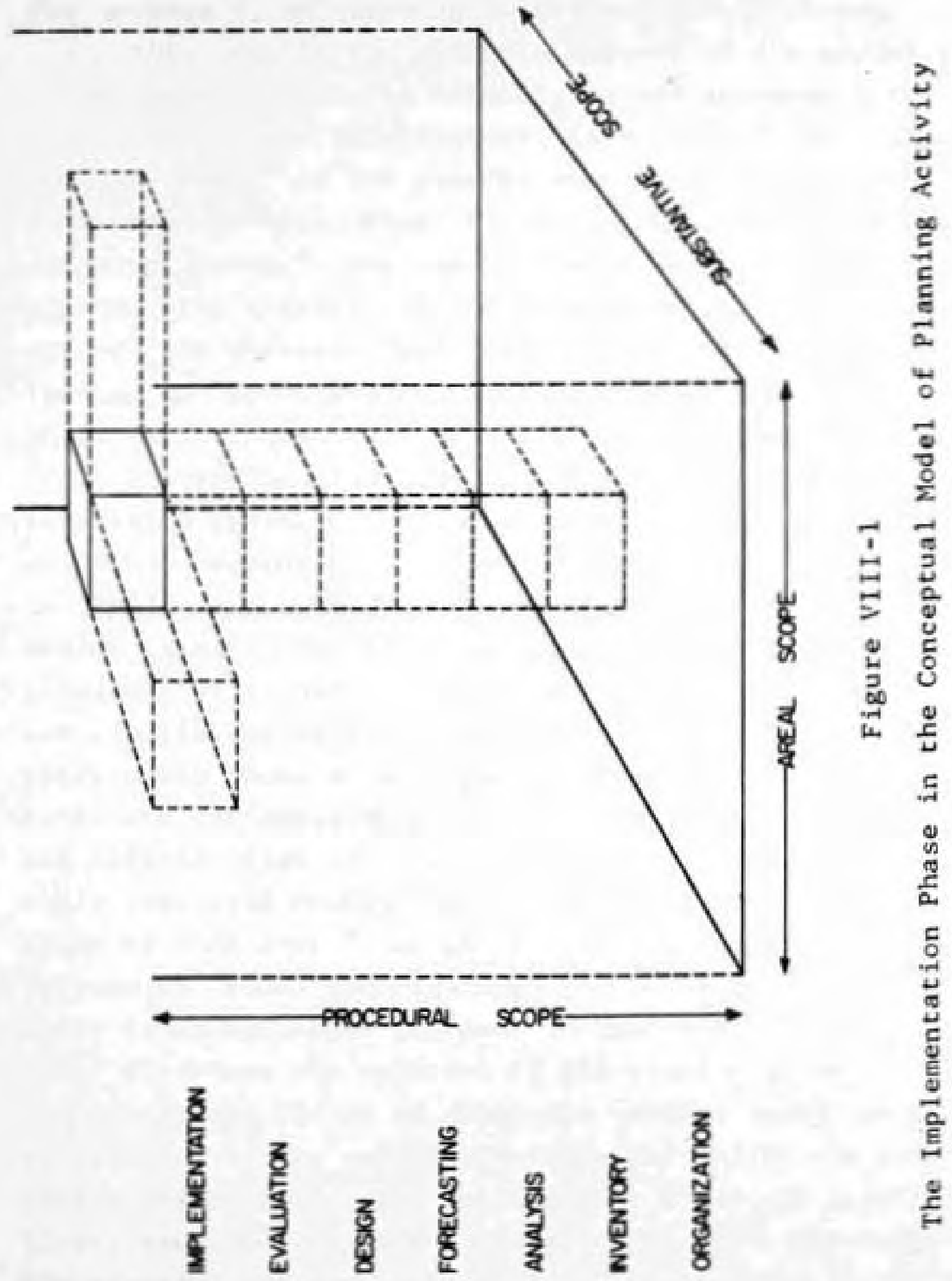


held by the client constituency; and second, the degree to which the identified goals and objectives are fulfilled by the proposals, balanced against the costs incurred.

This axis is the ultimate measure of the adequacy of the planning process in identifying and satisfying the value set of the client constituency, from the most general to the most specific. At the general end of the continuum, this axis measures such things as the appropriateness of the planning approach, the reasonableness and economy of the process, the morality of the philosophy and, in apologia, answers the question "Why plan?". As each of these measures is seen as "good" and "fitting" by the client constituency, there is an increased tendency to implementation.

Proceeding along the continuum in the direction of increasing specificity, the value set of the client constituency becomes more refined in definition and narrowed in application until at the end of the continuum, a specific design facet is valued. As long as that facet, perhaps the placement of a chair in a room or a tree in a park, does not violate any of the higher order goals and objectives (previously enunciated or perhaps just "felt") it remains a candidate for acceptance. It is then judged by the narrow and refined value set. In this case, "I am tired. Does the chair look comfortable?" or, "I am warm. Can I rest in the shade of that tree?" As before, as each of these measures is seen as "good" and "fitting" by the client constituency, there is an increased tendency to implementation.

of course the majority of the planner's concern involves implementation issues of substance between these two extremes. In response to the need to identify and refine the goals and objectives of the client constituency along the continuum, to the need to carry and use these value sets throughout the planning process, and, in fact, in response to the public demand to participate in planning, it is appropriate to formally develop statements of policy against which implementation actions can be measured. These statements of policy 
are at once an input, a throughput and an output of the planning process. The input manifestations have been discussed in Chapter I; the throughput manifestations have been developed and used in each succeeding chapter; this chapter is concerned with output.

Statements of policy are a series of documents of differing refinement as necessary but of consistent valuc when considered as a whole. In terms of horizontal integration, there may be one for implementation of transportation policy, one for implementation of recreation policy, one for implementation of land use policy, and so forth. In terms of vertical integration, there may be one for industrial land use, industrial land use by type, a specific industry unique in some characteristic, and that office responsible for industrial zoning changes.

These statements of policy serve as guides to implementation. These guides can be used by executives, administrators, commissioners, department heads, foremen or anyone in position of planning and programing implementation as a reference against which to measure his behavior and guide his decisions.

Goodman and Freund (1968) have called this "policies planning" and have cited the general benefits which accrue to it.

1. The essential and uncluttered character of the policy statements facilitates public understanding and public participation in the planning program.

2. The policy statements permit and encourage imtimate involvement in the planning process by elected officials.

3. The policies plan serves as a coordinative device, bringing together under a single framework the diverse agencies that may have an impact on development. In this respect it is particularly useful in multijurisdictional areas. 
4. The policies plan provides an element of stability and consistancy in the planning program in that it will not be made obsolete by changing conditions.

5. The policies plan can be useful as a guide to legislative bodies responsible for adopting land use controls, to boards and commissions authorized to administer the controls, and to the courts which must judge the reasonableness of the tion. 4 tion and the fairness of its administra-

Chapin (1963) has termed this an "urban development policies instrument" which serves as a "framework for steering public policy." He defines these instruments as "a recognized basis of co-ordinated action by all levels of government in policy decisions relating to urban development." 5

The development of policies statements serves as an aid to implementation by assuring proper implementation of the plan at the appropriate level of executive and administrative action and by establishing a clear basis for such implementation decisions.

\section{Areal Scope}

Along the areal scope axis of the implementation phase, the planner is most concerned with problems arising from the multiplicity of governmental units in the area affected by the plan. It is not uncommon for a metropolitan area in the United States to have tens of such units and, in larger metropolises, hundreds.

of these, a major fraction may be affected by the plan and, of more consequence in this discussion, a somewhat lesser fraction partake in its implementation. Hopefully one of these units will be designated and clearly recognized as the lead activity, with the others playing a suburdinate role. Whether or not such a hierarchal organization of units may exist, if the planner is to participate in the implementation phase, it will probably require him to 
coalesce the various units to insure the proper direction of implementation.

Friend and Jessop (1969) have addressed this questior. and have formally defines six classes of problems basic to multi-agency planning.

The problem of mechanisms for strategic control deals with connecting and disconnecting those agencies which have decision fields related to the plan. It includes the means of regulating and orchestrating these agencies into behavior consistant with and in the preferred direction of the plan. Such strategic control mechanisms bear the stresses arising from different interpretations, methods and procedures from agency to agency.

Closely allied with this problem of mechanisms is that of strategic control authority which addresses the question of where responsibility for control is to be centered, and how to establish such a nucleus effective and acceptable th the various agencies. Obviously if a hierarchal arrangement already exists, these problems are somewhat relleved. An alternative arrangement is a division of mechanisms of strategic control to groups of agencies, all functioning under the same superior authority. In the case of clearly separate authorities, if mutual adjustment, indirect pressures, and the threat of public indignation are not sufficient to coordinate implementation, the need arises for the formation of yet a superior level of authority.

As implementation proceeds, the patterns of interdependency among agencies are 1 ikely to change. The strategic control authority must have sufficient information at its disposal to monitor these changes and regulate them with either anticipatory or remedial action. The problem of sufficient information deals with the questions of how much and what kinds of information are sufficient to monitor the implementation, and whether this information can be gleaned from already existent channels or if new sources are required. 
The problem of democratic guidance centers about the role of the client constituency in the implementation phase. The planning process so far detafled has included such participation and care must be taken that those agencies implementing the plan are accessible to the ideas that formulated the plan.

Closely allied with this is the continuing problem of common language among different professions and different segments of the client constituency.

of course the ultimate success of a multi-agency endeavor will depend upon the various motivations of the participant individuals. Friend and Jessop recognize this with their final problem, that of sufficient motivation. The key to success is to assure that the implementation processes remain acceptable to the individuals and groups who must operate them and who themselves have private and career motives which must be satisfied.

The coordination of these implementation agencies by the executive authority, or the planner working on behalf of that authority, demands astute managerial and political ability, the cultivation of which is discussed in these concluding sections.

\section{Procedural Scope}

Planning implementation is not apolitical and the procedural scope axis provides a conceptual measure of the planner's necessary behavior in the political arena. While not unprofessional, such behavior has been traditionally regarded by some as outside the professional skills of urban planning. Rabinovitz (1967) has noted this strain between the role of planning and the role of effectuation. Since, however, the success of planning is tied to the success of the political system, the planner must be prepared to marshall influence in those political systems too weak to support the necessary implementation. To require such behavior of the 
planner is to ask him to broaden his concept of professionalism to include those skills which he cannot monopolize, which is contradictory, of course, hence the strain between roles.

The only solution to this dilemma is to allow such political behavior to be recognized as a necessary adjunct to professional planning. This behavior could then include the preparation of an instrument variously called a political plan, implementation plan, or tactical plan (Guttenberg, 1964).

Throughout the planning process thus far, discussion has centered about the goals and objectives of the client constituency, In its variants and refinements through the process, this goal orientation has been maintained, modified by the constraints of operationality. Guttenberg has suggested that explicit recognition be given to these operational constraints in the form of a tactical plan, describing the means necessary to achieve the end state enunciated by the goals and objectives. The client constituency has already persuaded itself to the desirability of this end state, so the purpose of the tactical plan is not to win their assent, but rather "to overcome the self contradiction involved when the individual acts publicly and when he acts privately". 6 This is done by tactically changing the field in which private decisions are made so that these decisions are more likely to be oriented toward the public objectives.

A tactical plan is closely related to conventional capital programming. In the latter case, elements of the plan are scheduled for implementation based upon anticipated needs and trends and fiscal constraints. The tactical plan expands this concept to include those steps that need be taken not only to anticipate trends, but to control them, to shape the background market conditions and locational preferences necessary for the goals and objectives realization. This would include the possibility of deferring the common 
order of implementation to allow the private sector to take advantage of programmed incentives deemed desirable.

Guttenberg notes that such tactical planning requires the planner to shift his focus from ends to means. Admittedly these means can be relatively impotent and few in number. But for effective implementation, the planner must step foreward from his concern with long range objectives and subject these objectives to the difficult and sometimes contradictory effects of programing in time. The client constituency may already be impatient with the perceived time span between the present status and the status described by the endorsed goals and objectives. The circuitous route plotted to achieve such may increase this impatience to levels unacceptable.

In submitting the tactical plan to the public, then, the planner is presenting the implications of a goal plan, and in so doing he is subjecting it to a test far more critical than if he merely presents the 'bill' in terms of financial costs. In short, he is testing the seriousness and durability of the public purpose itself, for this is what the goal plan represents. As a result of this confrontation, the public may decide to rethink its objectives a little more carefully, perhaps a little more realistically. But if it retains its objectives, than it is better prepared to realize them because it is forearmed with knowledge of their implications in time. These considerations alone are enough to justify tactical thought and planning. 7

\section{Operational Considerations}

The conceptual model of the planning process has served as a means of establishing the need for the planner to take an active part in implementation. The plan as a document standing alone may indeed fire the imagination and enthusiasm of those who witness it, but its implementation occurs in the realm of politics with the attendant need for persuasion, incentives, penalities, codification and legislation, procedures, publicity, power and much supportive activity. 
This supportive activity is varied and takes its many forms essentially because the plan imposes some restrictions on individual behavior for the good of the public-at-large, and these individuals need to be convinced of the propriety of those constraints. Even if this were not the case, man does not behave with perfect rationality and needs the fear of penality and the desire for profit to help him interact with his fellows in ways which are socially acceptable.

So (1970) has assembled some of the supportive implementation activity into an illustrative and suggestive framework of seven catagories: "the classic method," gaining and strengthening allies, information, cooperation, coordination, ad hoc problem solving, and education and indoctrination. Recognizing that they are not often used singly, but in combinations, the salient characteristics of each are as follows.

The classic method of implementation activity regards the planning authority as the advocate of good planning, largely independent of the executive authority. This planning authority is typically a commission composed of the laymen and public officials. It passes judgment on the propriety of planning actions and, for those that are deemed desireable, attempts to convince various executive authorities to implement them. There is much emphasis on the plan, little emphasis on implementation, and the power marshalled in this classic method is advisory in nature.

By gaining and strengthening allies, the planning authority seeks the active support of its constituent local executive authorities and increases the capabilities of these executive authorities to plan for themselves. This give due recognition to the fact that these executive authorities have the power to implement, so they might as well have access to planning expertise commensurate with that power. For example, the planning authority can sponsor 
legislation, if necessary, to allow such local executives to plan; it can provide technical assistance in the planning effort, either in the form of personnel or. a library of appropriate information. This implementation activity dilutes somewhat the power of the plamning authority in exchange for the opportunity to inject its own point of view and provide a visible administrative service,

Another supportive activity recognizes that the provision of planning information may influence development decisions in both the public and private sectors. This is an expensive activity, as noted in Chapter III, and tends to be regarded as non-operational in that it does not provide answers, only elaborations of problens.

Planning authorities recognize that other similar authorities make decisions at equal and greater levels of government which directly affect their area of concern. By actively seeking to cooperate in these decisions, the planning authority can assure once again that its point of view is considered. Joint projects also expose the planning authority to the methods and procedures of its sister activities.

It is unlikely that the planning authority will have the power to resolve conflicts of implementation among several governmental agencies. Through the use of methods of coordination, thus necessarily circumscribed, the planning authority can, however, provide the forum in which such conflicts can be aired, and provide a quasi-arbiter role by surfacing potential conflicts, inconsistancies and duplicative programs.

By ad hoc problem solving, the planning authority can increase its implementary role by actively seeking to discover and then solve the problems of most immediate concern to its constituent executive authorities. Some staff time is diverted from long range planning to investigate recent and high impact local developments and thereby be in the vanguard of knowledge about their effects. 
The method of implementing plans by indoctrination and education was the one most frequently cited by planning authorities in the So study. This includes such activities as the publication of newsletters, brochures for the layman, news releases, special conventions and conferences and the like. The goal of such activity is twofold: to convince the public and its executive authorities that planning is necessary; and to convince this same audience that the plans and policies endorsed by the planning authority are appropriate to the problems at hand and should be implemented.

The outstanding feature of all these implementation actions is that they are based upon persuasion. As such they depend very strongly upon the personality of the planner and his acumen as a salesman. It seems not quite fair that such serious substantive issues as these may very well hinge upon the personal abilities of the participants rather than the issues themselves. Such, however, is the nature of the political system.

Implementation powers beyond persuasion are of two kinds; those allotted to the planning authority, and those retained by the executive authority even though possibly designed by the planning authority.

of the latter, at once the most familiar and complex are the implementation activities of zoning, subdivision regulation and urban renewal. Goodman and Freund (1968) provide a detailed treatment of each of these, the elaboration of which is outside the scope of this work.

For the purpose of definition, however, zoning may be considered the legal means of classifying urban 1 and into districts, each district being then regulated as to the height and bulk of structures that may be permitted, the area of land which may be occupied by these structures, the density of the resident population, and the use permitted of non-residential structures. It is the legal means of regulating land use. 
Subdivision regulation is the legal means of insuring that urban development occurs in a manner consistent with the community's goals and objectives. It serves many purposes, insuring that the subdivision public systems such as streets, schools, utilities, land ownership and tax records, and other such systems are both adequate for the subdivision and consistent with those of the city.

Urban renewal is the legal means whereby a city may use its power of eminent domain to purchase parcels of land for new development, both public and private. It is designed to remove areas with urban problems so excessive and complex that their piecemeal solution is beyond the capability of less sweeping measures.

Another great power of the executive authority rests with its own development of municipal real estate. As a land owner and the developer of public facilities, the executive authority exerts a great influence on the type and amount of private development occurring about these facilities.

Returning to the implementation powers available to the planning authority, there exist some such powers which, while not as strong as those available to the executive function of government, do go beyond those characterized by persuasion alone.

So, Goodman and Freund, and other authors have made reference to these powers, generally catagorized as mandatory referral. With this power, the planning authority has the legal right to review the development plans of any agency or private interest having an impact on the area under its purview. The right of review by the planning authority is mandatory; its recommendations are not usually binding however.

Although in this discussion the convention of So was used in classifying implementation actions, all such actions may be considered ad hoc in context. That is to say that, 
since the implementation powers of urban planning have traditionally been very weak or, when strong, narrowly defined, any and all such actions are generally marshalled as available, out of a due respect for the seriousness of the issue. Meshenberg (1970a) has constructed an outline of the suitability of environmental features to urban development and a conceptual measure of their tolerance to use by man. of interest to his discussion, he included in this outline the methods and techniques by which appropriate design development policies could be implemented. By his own admission, the outline is neither exhaustive nor specific. Rather it is intended to portray the range of available techniques in a manner suggestive to local application. With this in mind, Table VIII-1 has been adopted from Meshenberg's work as an example of the ad hoc use of many implementation techniques, in this case, organized by land form.

Many, if not al1, of the methods of planning implementation require the expenditure of public monies. If there is an ultimate test of urban planning, it must center about the willingness of the executive and the constituency for which he speaks to divert money from the manifold demands for urban services into that service provided by planning, including implementation.

In another survey, Meshenberg (1970b) cataloged the revenues and expenses of governmental planning agencies of various sized jurisdictions. He established that such agencies spend about one dollar per year per constituent. There was a range, of course, from about a half dollar to more than two dollars. The figures are somewhat troubled by the lack of consistency from authority to authority as to what constitutes planning, and by the expected differing accounting systems.

This money is raised through local taxation procedures and in many cases, supplanted by federal aid. This chapter concludes with a short discussion of the latter. 
Table VIII-1

Methods of Implementing Environmental Policies, by Land Form ${ }^{8}$

Land Form

Implementation Methods

Land Soll and Topography

Wet and

Impervious

Soil

Poor Load

Bearing Soil

Flat Land

Low S1ope

Moderate

slope

Steep slope

Major Ridge

Lines

Valley

Gorge and Canyon, Glacial Moraine

Promontory
Subdivision and sanitary regulations requiring public water supply and sewage disposal.

Building code and grading ordinance prescribing development standards.

Pollution control ordinances, land use controls.

Grading ordinances limiting terracing, topsoil and vegetation removal; subdivision controls setting appropriate street and utility design standards; zoning to limit density of development.

Density zoning, grading ordinance requiring sedimentation control; subdivision ordinance requiring maintenance of vegetation and design standards for streets, possible hillside development controls.

Public purchase in fee; open space zoning; scenic or other easements; reforestation.

Height and density restrictions in zoning ordinances.

Scenic qualities preserved by open space or agricultural zoning; public purchase; purchase of easements or development rights; conservation zoning.

Public purchase; zoning controls to 1 imit peripheral development

Zoning for high-rise buildings; view protection regulations. 
Abrupt Relief Changes

\section{Land Rock}

Weak Substructure

Minerals

Water

Surface water and Riparian Land

Floodland

Wetland, Marsh, Bog, Swamp

Estuary
Table VIII-1, cont.

Public purchase in fee; purchase of easements.

Zoning for low density and low-rise development and to exclude areas of assembly and uses which would create serious hazards cluring earthquakes; building codes prescribing special construction methods and materials.

Natural resource zoning including performance standards to prevent encroachment; performance bond to ensure site rehabilitation; preferential assessment.
Planned unit development controls; sanitary ordinance prohibiting use of septic tanks; water quality standards to restrict discharge of pollutants; water zoning to separate incompatable water uses; zoning to restrict shoreline development to water compatable uses; public works planning.

Same as for surface and riparian lands; zoning controls to exclude structures from the channel and floodway; building code requiring floodproofing of structures; limitations on grading, filling, dredging and diking.

Public purchase or purchase of easements; grading and filling ordinances; agricultural zoning; limitations on surrounding areas to preserve ecological processes, conservation zoning.

Increased state control over estuary and coastal zone use; more stringent control over dredging, filling, draining; zoning to restrict development to uses requiring coastal zone locations; pollution controls. 
Table VIII-1, cont.

Aquifer

Aquifer

Recharge

Area
Limitations on groundwater withdrawa1.

Subdivision and sanitary controls requiring public sewerage; pollution discharge controls; prevention of intrusion of salt water or other groundwater contaminents; special sewer construction techniques; limitations on dredging, stream widening, filling etc.

Air

Corridor

Land use controls restricting locations of polluters upwind of receptors;

source controls; performance standards in zoning ordinances.

Vegetation and Wildlife

Woodland

Forest conservation controls; zoning and subdivision controls limiting intensity of development, destruction of vegetation, and setting standards for improvements; authorization for limited lumbering.

Wildlife Habitat

Public purchase; purchase of scenic, hunting, fishing easements; zoning limitations on surrounding areas; very low density zoning for seasonal cottages and restrictions on access roads.

Prime Agricultural

Land

Exclusive agricultural zoning; preferential farmland assessment.

Pasture

Land

Open space zoning where appropriate.

Prairie

Public purchase; zoning and other limitations on surrounding areas.

Cu1tura1 and Landscape

Unique Remanent Public purchase; zoning and other limitations on surrounding areas. 
Table VIII-1, cont.

Scenic Vistas Purchase of easements or development rights; very low density zoning; open space or agricultural zoning.

Historical and Archeological Sites
Public purchase or purchase by civic groups; architectural control; historic area zoning; landmarks commission. 
A Note on Federal Assistance

In 1967, the office of the Vice President published a guide to federal assistance programs. While some of the programmatic information is dated, the philosophy behind federal assistance is not.

Federal assistance is designed to aid local governments in stimulating and cultivating the local private sector to perform the required services. The government provides the clinate and opportunity to enable the private sector to act through the provision of both technical and financial assistance.

The initiative for such assistance rests with the local government. It should identify the goals and objectives of its client constituency, plan to achieve these goals in an organized and coordinated manner, program the implementation in a way which is both appropriate and flexible, manage the implementation effectively and in coordination with the private sector, and, in short, carry out a planning and implementation program that is altogether feasible, appropriate and necessary.

Federal assistance is limited on the whole and well documented demands can be expected to exceed available appropriations. Accordingly, even among justified requests, assistance is parceled out according to various formulas. A state's share of available funds is generally determined through the use of both apportionment and matching provisions. Apportionment formulas specify the proportion of the total federal grant funds for which each state is eligible. Such formulas are usually based upon some combined measure of population, financial ability and need. Matching formulas specify to what extent participating states must share the program costs, and can be a ratio fixed from state to state, or varying, depending upon the ability of each state to participate. 
The use of federal assistance adds at least one and in some cases several levels of program administration. These levels insure that local program objectives are consistent with those of the national program and those of the state. Plans, prograns, specifications, contracts, procedures and administration are all subject to administrative action. During implementation, regular reports are required on program status, federal laws and regulations regarding personnel matters such as the hiring of minorities and the use of a merit system must be observed. Purchasing. accounting, and contract administration procedures must he followed. Final review and close out mechanisms may be made mandatory and, at least at project completion, a federal audit may be held.

Federal assistance is available in an ever increasing variety of substantive areas impacting on urban life. In addition to assistance in the general area of comnunity, metropolitan and regional planning and development, assistance is available in the areas of local economic and business development, transportation, welfare and social services, health, education and culture, manpower development and employment assistance, public safety, disaster assistance, civil defense, land, water and air resources, planning and development of physical facilities, housing and community development, public utilities, recreation, service centers and community buildings.

Information abounds in a great many places regarding these programs and a search could well begin at the state agencies dealing in these matters and the regional offices of the appropriate federal departments.

\section{Summary}

This chapter has attempted to trace the difficult and tortuous path of implementation, first conceptually and then operationally. 
The planner is seen in a dual role; first the provider of technical expertise, and second, the political advocate of proper implementation. In the latter case he must marshall those tools perceived as available to him, ranging from discrete policy statements to his own power of persuasion. He is faced with the difficulties of both the substance of the plan and the milieus in which it must be implemented. There are constraints of resources, time, money, social and bureaucratic systems, procedures, law and jurisdiction, all of which temper both the plan implementation and his behavior.

Each of these constraints serves to define and bound the general concept of operationality. To plan outside of this concept is not only useless, but criminally wasteful of public resources. In assuming the mantle of urban planning, the planner must also assume this responsibility.

\section{Notes}

1. Constance Perin, "A Noiseless Secession from the Comprehensive Plan," pp. 337-8.

2. Paul Davidoff, and Thomas A. Reiner, "A Choice Theory of Planning," p. 113.

3. C. B. Wurster, "Introduction", Explorations into Urban Structure, Melvin M. Webber et $\underline{\text { al., p. } 11 .}$

4. William 1. Goodman, and Eric C. Freund, eds., Principles and Practice of Urban Planning, p. 332.

5. F. Stuart Chapin Jr., "Taking Stock of Techniques for Shaping Urban Growth," p. 81 .

6. Albert Z. Guttenberg, "The Tactical Plan", Explorations into Urban Structure, Melvin M. Webber et a1., p. 199.

7. Ibid, p. 217.

8. After Michael J. Meshenberg, "Environmental Planning: 1, Environmental Information for Policy Formulation," pp. 30-34. 


\section{CONCLUDING REMARKS}

The overriding demonstration of the preceeding discussion is that methodological considerations can be used to tie together the diverse and numerous aspects of urban planning. The conceptual model of planning activity is a suitable framework for tying these methodological considerations together, in both an operational sense and a pedagogic sense. In neither sense, however, is the application of the model exhausted. Urban planning is probably too complex and too creative to allow for the existence of a universal methodology. Rather, the use of methodological considerations as suggested by the model provides for the planner and his client constituency a sense of direction, an ordered conceptual procedure and an operational beginning, middle, and end of the planning process. Such information is presented as showing the way without being dogmatic.

The theme of operationality is thus stressed because, creativity notwithstanding, urban planning is so expensive an undertaking and so clearly in the public trust that every effort must be made to carry it foreward in an environment of astute business practice. Considerations of methodology are thereby focused, and such an approach encourages and promotes a task oriented operationality which might otherwise suffer in the face of the many philosophical considerations that are necessary.

Lastly, it is thought that any phase of the planning process as outlined can never be obviated without making the process non-operational. To be sure, a phase may be done by someone else, it may be already done in terms of some prior effort, it may be deferred, abbreviated or even 
intuitively arrived at, but it must be addressed somehow and someway. Any such adjustments are not necessarily fatal and, when properly aligned with conceptual considerations, are in fact efficient refinements to the theme of operationality. 



\section{BIBLIOGRAPHY}

Alonso, William, "Predicting Bést with Imperfect Data," Journal of the American Institute of Planners, July, 1968.

Antom, Thomas $J .$, "Politics and Planning in a Swedish Suburb," Journal of the American Institute of Planners, July 1969.

Bacon, Edmund N., "Urban Process," The Conscience of the City, Daedalus, The Journai of the American Academy of Arts and Sciences, Fall, 1968.

Beer, Stafford, Cybernetics and Management, New York, J. Wiley and Sons, 1959.

Birch, D. L., "Toward a Stage Theory of Urban Growth," Journal of the American Institute of Planners, March, 1971 .

Blumenfeld, Hans, The Modern Metropolis: Its Origins, Growth, Characteristics, and Planning, Cambridge, The Mit Press, 1967.

Bolan, Richard S., "Community Decision Rehavior: The Culturc. of Planning," Journal of the American Institute of Planners, September, 1969.

Bolan, Richard S., "Emerging Views of Planning," Journal of the American Institute of Planners, Juty 1967.

Bolan, Richard S., "New Rules for Judging Analytical Techniques in Urban Planning", Analytical Techniques, Chicago, American Society of planning officials, 1970.

Boulding, D. E., "General Systems Theory - The Skeleton of Science," Management Science, Apri1 1956.

Bourne, Larry S., editor, Internal Structure of the City, Readings on Space and Environment, New York, Oxford University Press, 1971. 
Boyce, D. E., N. D. Day and C. McDonald, Metropolitan Plan Making: An Analysis of Experience with the Preparation and Evaluation of Alternative Land Use and Transportation Plans, Monograph Series Number Four, Philadelphía, Regional Science Research Institute, 1970.

Branch, Melville C., and Ira M. Robinson, "Goals and Objectives in Civil Comprehensive Planning," The Two Planning Review, January, 1968.

Braybrooke, David and Charles Lindblom, The Strategy of Decision, Glencoe, I11 inois, The Free Press, 1963.

Burgess, E. W., "Urban Areas", Chicago: An Experiment in Social Science Research, T. V. Smith and L. D. White, editors, Chicago, University of Chicago Press, 1929.

Chapin, F. Stuart, Jr., "Taking Stock of lechniques for Shaping Urban Growth," Journal of the American Institute of Planners, May, 1963.

Chapin, F. Stuart, Jr., Urban Land Use Planning, Urbana. University of I11inois Press, 1965.

Chicago Area Transportation Study, Final Report, Volume 11 , 1960.

Chisholm, Shirley, Member of Congress, 12th District, New York, "Planning With and Not for l'eople," Planning 1970. Sclected Papers from the A.S.P.O. National Planning Conference, New York City, April 4-9, 1970 , Chicago. American Society of planning officints. 1970 .

Churchman, C. West and Russe11 L. Ackoff, "An Approximate Measure of Value," Journal of the Operations Research Society of America, February, 1954.

Clark, Terry N., Community Structure and Decision Making, San Francisco, Chandler Publishing Company, 1968.

Cleveland Seven County Transportation/Land Use Study, "Operations Plan," Cleveland, Ohio, February, 1966.

Colby, C. C., "Centrifugal and Centripetal Forces in Urban Geography," Annals of the Association of American Geographers, March, 1933.

"Community Relations Fact Booklet," Industrial Public Relations Group, Lafayette, Indiana, 1969. 
Craik, K. H. "The Comprehension of the Everyday Physical Environment," Journal of the American Institute of Planners, January, 1968.

Crieghton, Roger L., "Recommendations", Transportation and Community Values, Highway Research Board Special Report Number 105, Washington D. C., Highway Research Board, 1969.

Dahl, Robert, Who Governs?, New Haven, Connecticut, Yalc University Press, 1961.

Davidoff, Paul, and Thomas A. Reiner, "A Choice Theory of Planning," Journal of the American Institute of Planners, May, 1962.

Deming, W. E., Some Theory of Sampling, New York, Dover Publications, Inc., 1966.

Fertal, Martin J., Edward Weiner, Arthur J. Balek and Ali F. Sevin, "Modal Split: Documentation of Nine Methods for Estimating Transit Usage," U.S. Department of Commerce, Bureau of Public Roads, December, 1966.

Fishburn, P. C., "Methods of Estimating Additive lltilities," Management Science, March, 1967.

Fox, Douglas M., "The Identification of Community leader: by the Reputational and Decisional Methods. Threc Case Studies and an Emperical Analysis of the Literature," Sociology and Social Research, Octubier, 1969.

Fratar, Thomas J., "Vehicular Trip Distribution by Successive Approximation," Traffic Quarterly, January, 1954 .

Friend, John K., and W. N. Jessop, Local Government and Strategic Choice: An Operational Research Approach to the Process of Public Planning, London, Tavistock Publications, 1969.

Goodman, William I. and Eric C. Freund, eds., Principles and Practice of Urban Planning, Washington, $\bar{D}$. C., International City Managers Association, 1968.

Grecco, William L. and S. M. Breuning, "Application of Systems Engineering Methods to Traffic Forecasting," Trip Characteristics and Traffic Assignment. Bullet in 347, Washington, D.C., Híghway Research Board, 1962. 
Grecco, William L., "Class Notes and Discussions, Planning Methodology and Techniques, C. E. 613, Purdue University," 1964-1971.

Guttenberg, Albert Z., "The Tactical Plan", Explorations into Urban Structure, Melvin M. Webber, et al., Philadelphia, University of Pennsylvania Press, 1964.

Haig, Robert M., Regional Survey of New York and Its Finvirons, Volume I, New York, 1927.

Hamilton, Calvin, S., "Monitor Systems for Urban Planning," Urban Information and Policy Decisions, Clark D. Rogers, Editor, Iniversity of Pittshurgh, September, 1964.

llansen, Walter G., "How Accessibility Shapes Land Use", Journal of the American Institute of Planners, May, 1959.

Itarris, Britton, "Quantitative Models of Urban Development: Their Role in Metropolitan Policy - Making," A paper prepared for the Committee on Urban Economics of Resources for the Future Inc. Conference on Urban E.conomics: Analytical and Policy Issues, Washington, D.C., January 26-28, 1967, revised, May 1, 1967.

Harris, Britton, "The Uses of Theory in the Simulation of Irban Phenomena", A paper presented at the $45 \mathrm{th}$ Annual Meeting Highway Research Board, January 1966.

llarris, Chauncy and Edward Ul1man, "The Nature of Cities," Annals of the American Academy of Political and Social Science, November, 1945.

Hawley, A. H., Human Ecology: A Theory of Community Structure, New York, The Ronald Press Company, 1950.

Hearle, Edward F. R. and Raymond J. Mason, A Data Processing System for State and Local Governments, Englewood Cliffs, N.J., Prentice-Hall, 1963.

Hensen, R. J., "Development of an Information Manual on the Urban Transportation Planning Process for Technical Comnittees in Smaller Urban Areas," Ph.D. Thesis, Purdue University, August, 1968.

Herbert, J. D. and B. H. Stevens, "A Model for the Distribution of Residential Activity in Urban Areas," Journal of the Regional Science Association, Fall, 1960. 
Hil1, M., "A Goals-Achievements Matrix for Evaluating Alternative Plans," Journal of the American Institute of Planners, January, 1968.

Horwood, Edgar, M., "A Fundamental Look at Urban Information Systems", Urban Information and Policy Decisions, Clark D. Rogers, Editor, lniversity of Pittshurgh, September, 1964 .

Hoyt, Homer, The Structure and Growth of Residential Neighborhoods in American Cities, Washington, D.C., Federal Housing Administration, 1939.

Hunter, Floyd, Community Power Structure, Chapel Hill, North Carolina, University of North Carolina Press, 1953.

Isard, Walter, Methods of Regional Analysis: An Introduction to Regional Science, New York, the MIT Press and Iohn Wiley and Sons, Inc., 1960.

Jacolss, Jane, The Death and Life of Great American Cities, New York, Random House, 1961.

The Joint Program: An Inter-Agency Land Use-Transportation Planning Program for the Twin Cities Metropolitan Area, "Meeting the Challenge of Metropolitan Growth," St. Pau1, Minnesota, January, 1963.

Kaplan, Marsha11, "Advocacy and the Urban Poor," Journal of the American Institute of Planners, March, 1969.

Kossiakoff, Alesander, "The Systems Engineering Process," Operations Research and Systems Engineering, C.D. Flagle, W.H. Huggins, and R.H. Roy, editors, Baltimore, Maryland, The John Hopkins Press, 1960.

Leontief, Wassily, The Structure of the American Economy, 1919-1939, Oxford, Oxford University Press, 1951.

Litchfield, N. "Cost Benefit Analysis in Plan Evaluation," Publication 165, Civil Engineering Systems laboratories, M.I.T., May 1962 .

Lowry, Ira S., "A Model of Metropolis," Santa Monica, The RAND Corporation, August, 1964.

Lowry, Ira S., "A Short Course in Model Design", Journal of the American Institute of Planners, May, 1965.

Lynch, Kevin, The Image of the City, Canbridge, The MIT Press, 1960. 
Manheim, M.L., "Model Building and Decision Making," Publication 165, Civil Engineering Systems Laboratories, M.I.T., May 1962 .

Martin, Brian V., Frederick W. Memmott, III and Alexander I. Bone, Principles and Techniques of Predicting Future Demand for Urban Area Transportation, Cambridge, Massachusetts, The M.I.T. Press, 1961.

Martin, G. H., "The Town as Palimpsest", The Study of Urban History, H. J. Dyos, ed., New York, St. Martin's Press, 1968.

Matthias, J. S., "Recreational Impact of Multi-Purpose Reservoirs", Ph.D. Thesis, Purdue University, August, 1967.

Maxman, R. J., "Development of the Environmenta1 Data Storage and Retrieval System", MSCE Thesis, Purdue University, June, 1968.

Mclaughlin, W. A., "Traffic Assignment by Systems Analysis," Ph.D. Thesis, Purdue University, 1965.

Meshenberg, Michael J., "Lnvironmental Planning: 1, Finvironmental Information for Policy Formulation" Planning Advisory Service Report 263, American Society of Planning Officials, November, 1970a.

Meshenberg, Michael J., "Expenditures, Staff, and Salaries of Planning Agencies, 1970," Planning Advisory Service Report 256, American Society of Planning, officials, April, $1970 \mathrm{~b}$.

Miller, D. W. and M. K. Starr, Executive Decisions and Operations Research, Englewood Cliffs, N. J., Prentice-Hal1, 1960 .

Moore, F. T., "Operations Research on Urban Problems," Paper 3414, Santa Monica, The Rand Corporation, June, 1966 .

Nakkash, T. Z., "Activity - Accessibility Models of Trip Generation," Ph.D. Thesis, Purdue University, 1969.

O'Brien, James J., Scheduling Handbook, New York, McGraw lli 11 Book Company, 1969.

01mstead, Donald W., "Organizational Leadership and Sucial Structure in a Smal1 City," American Sociological Review, June, 1954. 
Perin, Constance, "A Noiseless Secession from the Comprehensive Plan," Journal of the American Institute of Planners, September, 1967.

Perucci, Robert and Marc Pilisuk, "Leaders and Ruling Elites: The Interorganizational Bases of Community Power," American Sociological Review, November, 1970 .

Pittsburgh Area Transportation Study, Volume I, November, 1961 .

Pollard, William S. Jr., and Daniel W. More, "The State of the Art of Planning," Journal of the Urban Planning and Development Division, Proceedings of the American Soclety of Civil Englneers, April, 1969.

Preston, James D., "Identification of Community Leaders," Sociology and Social Research, January, 1969.

Rabinovitz, Francine, "Politics, Personality, and Planning," Public Administration Review, March, 1967.

Rhode Island Statewide Comprehensive Transportation and Land Use Planning Program, "Program Design Report," Providence, Rhode Island, February, 1965.

Safdie, Moshe, Beyond Habitat, Cambridge, The MIT Press, 1970 .

Schimpeler, Charles C., "A Decision-Theoretic Approach to Weighting Community Development Criteria and Evaluating Alternative Plans," Ph.D. Thesis, Purdue University, August, 1967.

Schulman, L. L., "Traffic Generation and Distribution of Weekend Recreational Trips", MSCE Thesis, Purdue University, June, 1964.

Siegelman, Leonore R., "The 1970 Census: A resource for Housing and C1ty Planning Studies," Planning Advisory Service Report No. 267, Chicago, American Society of Planning officials, March, 1971 .

Simonds, J. 0., Landscape Architecture: The Shaping of Man's Natural Environment, New York, McGraw-Hill Book Company, 1961.

So, Frank S., "Metropolitan Planning Policy Implementation," Planning Advisory Service Report 262, American Society of Planning offlcials, October, 1970. 
Spreiregen, P. D., Urban Design: The Architecture of Towns and Cities, New York, McGraw-Hill Book Company, 1965.

Steger, Wilbur A. and T. R. Lakshmanan, "Plan Evaluation Methodologies: Some Aspects of Decision Requirements and Analytical Response", Highway Research Board Special Report 77, Washington, D.C., Highway Research Board, 1968.

Stewart, W. Don, "An Urban Area Use Model to Maximize Return," Ph.D. Thesis, Purdue University, January, 1969.

Tiebout, Charles M., "The Community Economic Base Study," Supplementary Paper No. 16, New York, The Comit tee for Economic Development, December, 1962.

Tomazinis, Anthony R., "A New Method of Trip Distribution in an Urban Area," 41st Annual Meeting of the Highway Research Board, January, 1962.

U. S. Bureau of the Census, "Census Use Study: Genera1 Description," Report No. 1, Washington, D. C., U. S. Government, Printing office, 1970.

, "Census Use Study: Computer Mapping," Report No. 2 , Washington, D. C., U. S. Government Printing office, 1970 .

, "Census Use Study: Data Tabulation Activities," Report No. 3, Washington, D. C., U. S. Government Printing office, 1970.

, "Census Use Study: The Dime Geocoding System," Report No. 4, Washington, D. C., U. S. Governinent Printing office, 1970 .

, "Census Use Study: Data Interests of Local Agencies," Report No. 5, Washington, D. C., U. S. Government Printing office, 1970.

, "Census Use Study: Family Health Survey," Report No. 6, Washington, D. C., U. S. Government Printing office, 1970 .

, "Census Use Study: Health Information System," Report No. 7, Washington, D. C., U. S. Government Printing office, 1970 .

, "Census Use Study: Data Uses in Health Planning," Report No. 8, Washington, D. C., U. S. Government Printing office, 1970. 
"Census Use Study: Data Uses in Urban Planning," Report No. 9, Washington, D. C., U. S. Government Printing office, 1970.

," "Census Use Study: Data Uses in School Administration," Report No. 10, Washington D. C., U. S. Government Printing office, 1970.

, "Census Use Study: Area Travel Survey," Report No. il, Washington, D. C., U. S. Government Printing office, 1970.

, "Census Use Study: Health Information System-1I," Report No. 12, Washington, D. C., U. S. Government Printing Office, 1970.

, "Census Use Study: Computer Resource Allocation Modei (CRAM)," Report No. 13, Washington, D. C., U. S. Government Printing office, 1970.

, "Census Use Study: Geocoding with ADMATCH -

A Los Angeles Experience," Report No. 14, Washington,

D. C., U. S. Government Printing office, 1971.

, 1970 Census User's Guide, Washington, 1). C. .

U. $\overline{\mathrm{S}}$. Government Printing office, 1970.

Vance, James E., Jr., "Focus on Downtown," Community

Planning Review, Sumner, 1966.

Walker, J. R., "Rank Classification: A Procedure for

Determining Future Trip Ends," Developing Transporta-

tion Plans, Record 240, Washington D. C., Highway

Research Board, 1968.

Webber, Melvin M. et al., Explorations into Urban Structure, Philadelphia, University of Pensylvania Press, 1964.

Weimer, Arthur M. and Homer Hoyt, Principles of Urban Real Estate, New York, The Ronald Press Company, 1939.

Wetmore, Louis B. "Preparing the Profession for its Changins Role," Urban Planning in Transition, Frnest Erber, Editor, New York, Grossman Publishers, 1970.

Winfrey, Robley, Economic Analysis for Highways, Scranton, Pa., International Textbook Company, 1969.

Wurster, C. B., "Introduction," Explorations into Urban Structure, Melvin M. Webber et a1., University of Pennsylvania Press, 1964. 
The Vice President's Handbook for Local officials: A Guide to Federal Assistance for Local Governments, Washington, D. C., Office of the Vice President, November 1, 1967.

\section{Genera1 References}

Altshuler, Alan A., The City Planning Process, A Political Analysis, Ithaca, New York, Cornell lniversity Press, 1965 .

Altshuler, Alan A., "The Goals of Comprehensive Planning," Journal of the American Institute of Planners, August, 1965 .

Altshuler, Alan, "The Values of Urban Transportation Policy," Transportation and Community Values, Highway Research Board Special Report 105, Washington, D. C. Highway Research Board, 1969.

American Society of Planning Officials, "Threshold of Planning Information Systems," Selected papers from the A.S.P.O., National Planning Conference, Houstun, April 1967, Chicago, American Society of Planning officials, 1967.

Arnstein, Sherri R., "A Ladder of Citizen Participation," Journal of the American Institute of Planners, luly 1969 .

Atchley, Robert C., "Planner's Notebook: A Short-cut Method for Estimating the Population of Metropolitan Areas," Journal of the American Institute of Planners, July, 1968.

Austin, W. Burnet, "Better Forecasting for Better Planning: A Systems Approach," An unpublished paper delivered at the 1970 AIP CONFER-IN, Minneapolis/St. Paul, October, 1970.

Babcock, W. F., "The Changing Role of the Planner and Engineer in Transportation and Systems Design Process," an address delivered to the 50 th annual meeting, Highway Research Board, Washington D. C., January 18, 1971.

Barton-Aschman Associates, Inc., "Planning Organization and Administration, Memorandum Report \#10, Comprehensive Planning Studies, Beloit City Planning Conmission," Beloit, Wisconsin, 1965. 
Be11, Wende11, "The Utility of the Shevky Topology for the Design of Urban Sub-Area Field Studies," Journal of Social Psychology, XLVII, 1958.

Berton, A. H., "Bringing Society Back In - Survey Research and Macro-Methodology," American Behavioral Scientist, November-December, 1968.

Blalock, H. M., Jr., and A. B. Blalock, Methodology in Social Research, New York, McGraw-Hill Book Company, 1968.

Buck, Roy C. and Robert A. Rath, "Planner's Notebook:

Planning as an Institutional Innovation in the Smaller City," Journal of the American Institute of Planners, January, 1970.

Burke, Edmond M., "Citizen Participation Strategy," Journal of the American Institute of Planners, September, 1968 .

Catalog of Federal Assistance Programs, Washington, D. C. , Office of Economic Opportunity, Executive office of the President, June 1, 1967.

Chapin, F. Stuart Jr., Urban Land Use Planning, Second Edition, Urbana, University of Illinois Press, 1965.

Claire, William H., Urban Planning Guide Number 49, A.S.C.E. Series "Manuals and Reports on Engineering Practice," New York, The American Society of Civil Engineers, 1969.

Clave1, Pierre, "Planners and Citizen Boards: Some Applications of Social Theory to the Problems of Plan Implementation," Journal of the American Institute of Planners, May, 1968.

Cleveland Seven County Transportation/Land Use Study, "Preliminary Study Design," Cleveland, Ohio, February $18,1965$.

Coleman, Alice, "A Geographical Model for Land Use Analysis," Geography, January, 1969.

Cotham, James C. 3rd, and Frank L. Hendrix, "Mobilizing Community Leadership in Urban Transit Planning: An Overview," High Speed Ground Transportation, WinterSpring 1971 . 
Cullen, Gordon, Townscape, New York, Reinhold Publishing Corporation, 1961.

Dale, Ernest, and Lyndall F. Urwick, Staff in Organization, New York, McGraw Hi11, 1960.

Davidoff, Pau1, "Advocacy and Pluralism in Planning," Journal of the American Institute of Planners, November, 1965.

Davidoff, Paul, Linda Davidoff, and Neil Newton Gold, "Suburban Action: Advocate Planning for an Open Society," Journal of the American Institute of Planners, January, 1970 .

Davidoff, Paul and T. F. Reiner, "A Choice Theory of Planning," Journal of the American Institute of Planners, May, 1962 .

De Chiara, Joseph, and Lee Koppelman, Planning Design

Criteria, New York, Van Nostrand Reinhold Company, 1969.

Doggett, Rosalyn P., "The Development Sector Approach to Retional Planning," Journal of the American Institute of Planners, May 1969 .

Dohrenwend, Barbara, John Colombotos and Bruce Dohrenwend, "Social Distance and Interviewer Effects," Public Opinion Quarterly, Fal1, 1968.

Draper, N. R. and H. Smith, Applied Regression Analysis, New York, John Wiley \& Sons, Inc., 1966.

Dror, Yehezke1, "The Planning Process: a Facet Design," International Review of Administrative Sciences, XXIX, No. 1, 1963.

Dyckman, J., "Planning and Decision Theory," Journal of the American Institute of Planners, November, 1961.

Einsweiler, Robert C. "The Decision-Making Forum: Improving the Decision-Making Process," Highway Research Record $\underline{238}, 1968$.

Elias, C. E., Jr., James Gillies and Sveno Riemer, Metropolis: Values in Conflict, Belmont, California, Wadsworth Publishing Company, 1964.

E11is, Jack A. N., "The Quest for Rational Decision through Public Participation in Transportation Planning, Who Should Participate and When," an address delivered to the 50 th annual meeting, Highway Research Board, Washington D. C., January 18, 1971. 
Falk, Edward L., "Measurement of Community Values: The Spokane Experiment," an unpublished paper by the director, Spokane Metropolitan Area Transportation Study, January 2, 1968.

Fellman, Gordon, "Research Report: Neighborhood Protest of an Urban Highway", Journal of the American Institute of Planners, March, 1969.

Form, William, Joel Smith, Gregory Stone and Janes Cowhig, "The Compatibility of Alternative Approaches to the Delimitation of Urban Sub-Areas," American Suciological Review, August, 1954.

Forrester, Jay w., Urban Dynamics, Cambridge, The MIT Press, 1969.

France, Edwin A., "The Effects of Citizen Participation in Governmental Decision Making," an address by the administrative assistant to the Mayor of Chicago delivered at the 50 th annual meeting, Highway Research Board, Washington D. C., January 18, 1971 .

Friedmann, John R., "A Response to Altshuler: Conprehensive Planning as a Process," Journal of the American Institute of Planners, August, 1965.

Garnick, Daniel H., "Differential Regional Multiplier Mode1s," Journal of Regional Science, April, 1970.

Garnick, Daniel H. "Disaggregated Basic-Service Models and Regional Input-Output Models in Multiregional Projuctions," Journal of Regional Science, Apri1, 1969.

Gibberd, Frederick, Town Design, New Yori, Frederick A. Praeger, 1959.

Gibbs, Jack P., editor, Urban Research Methods, New York, Van Nostrand Company, 1961.

Gilbert, Neil, and Joseph W. Eaton, "Research Report: Who Speaks for the Poor," Journal of the American Institute of Planners, November, 1970.

Gore, William J., and J. W. Dyson, eds., The Making of Decisions: A Reader in Administrative Behavior, Glencoe, Illinols, The Free Press, 1964.

Harland Bartholomew and Associates, "Procedural Out lines for Major Thoroughfare Planning, Memphis, Tennessec," 1964 . 
Harral, Harry D., "Developing a Working Concept of the Physical Extent of a Metropolitan Area: A Case Study of the Philadelphia Metropolitan Area," Metropolitan Analysis, University of Pennsylvania, 1958.

Hemmens, George C., "Report: Planning Agency Experience with Urban Development Models and Data Processing," Journal of the American Institute of Planners. September, 1968.

Highway Research Board, "Data Requirements for Metropolitan Transportation Planning," National Cooperative Highway Research Program Report 120, Washington, D. C., 1971.

Highway Research Board, "Land Use Forecasting Concepts," Highway Research Record 126, Washington, D. C. Highway Research Board, 1966 .

Highway Research Board, Urban Development Models, Special Report No. 97, Washington, D. C., 1968.

Hillegass, Thomas J., Charles C. Schimpeler and William I.. Grecco, "Community Decision Structure and Urban Planning Process," Journal of the Urban Planning and Development Division, the Proceedings of the American Society of Civil Engineers, March, 1970.

Hoover, E. M. and R. Vernon, Anatomy of a Metropolis, Cambridge, Harvard University Press, 1959.

Holleb, Doris B., Social and Economic Information for Urban Planning, Volumes 1 and 2 , Chicago, Center for Urban Studies, University of Chicago, 1969.

Hoyt, Homer, "The Importance of Manufacturing in Basic Employment," Land Economics, August, 1969.

Hyman, Herman, "Planning with Citizens: Two Styles," Journal of the American Institute of Planners, March, 1969 .

Isenson, Raymond S., "Technological Forecasting in Perspective," Management Science, October, 1966.

Jacobs, Jane, The Economy of Cities, New York, Random House, 1969.

Kent, T. J., Jr. The Urban General Plan, San Francisco, Chandier Publishing Company, 1964. 
Krueckeberg, Donald A., "A Multivariate Analysis of Metropolitan Planning," Journal of the American Institute of Planners, September 1969.

LeBreton, Preston P. and Dale A. Henning, Planning Theory, Englewood Cliffs, N. J., Prentice-HaI1, 1961.

Levinson, R. S. and F. H. Wynn, "Some Aspects of Future Transportation in Urban Areas," Highway Research Board Bulletin 326, Washington, D.C., Highway Research Board, 1962 .

Levy, F. K., G. L. Thompson and J. D. Wiest. "The ABC's of the Critical Path Method," Harvard Business Review, September-October, 1963.

I,indbloom, Charles E., "The Science of 'Muddling Through'," Public Administration Review, Spring, 1968.

Luttveg, Norman R., "The Structure of Beliefs Among Leaders and the Public," Public Opinion Quarterly, OctoberDecember, 1968.

Lyden, Fremont J. and Ernest G. Miller, editors, Planning, Programming, Budgeting: A Systems Approach to Management, Chicago, Markham, 1967.

Mante1, Samuel J., Jr., and Burton V. Dean, "Community Values and Operations Research," Transportation and Community Values, Highway Research Board Special Report 105, Washington, D. C., Highway Research Board, 1969.

Marsha11, Dale K., "Who Participates in What?, a Bibliographic Essay on Individual Participation in Urban Areas," Urban Affairs Quarterly, December, 1968.

Maxunan, R. L. and W. L. Grecco, "An Operational Planning Information System for Smal1 Communities," Highway Research Record 322, Washington D. C. , Highway Research Board, 1970.

Mayer, Harold M., and Clyde F. Kohn, editors, Readings in Urban Geography, Chicago, The University of Chicago Press, 1959.

Mayer, Harold W., "Making a Living in Cities: The Urban Economic Base," Journal of Geography, February, 1969.

McCue, Gerald M., William R. Ewald, Jr., and The Midwest Research Institute, Creating the Human Environment, Urbana, University of I1linois Press, 1970. 
McGimsey, George, "Planner's Notebook: The 1970 Census: Changes and Innovations," Journal of the American Institute of Planners, May 1970.

McGrath, William R., "Land Use in Traffic Generation," Highway Research Board Bulletin 224, Washington, D. C., Highway Research Board, 1959.

Mcloughlin, J. Brian, Urban and Regional Planning: A Systems Approach, New York, Frederick A. Praeger, 1969.

Meshenberg. Michael J., "Expenditures, Staff, and Saleries of Planning Agencies, 1970," Planning Advisory Service Report No. 256. Chicago, American Society of Planning officials, April 1970.

"Metropolitan Transportation Planning Seminars," Anerican Institute of Planners and the U.S. Department of Transportation, December, 1971.

Mitchel, W. H., "Tooling Computers to the Medium Sized City," Public Management, March, 1967.

Mitchel, W. H. "Urban Planners and Information," Datamation, October, 1966.

Mogulof, Melvin, "Coallition to Adversary: Citizen Participation in Three Federal Programs," Journal of the American Institute of Planners, July, 1969.

Moore, Eric G., and Barry S. Wellar, "Technical Report: Urban Data Collection by Airborne Sensor," Journal of the American Institute of Planners, January, 1969.

Moyer, Ralph A., "Comprehensive Urban Transportation Study Methods," Journal of the Highway Division, Proceedings of the American Society of Civil Engineers, December . 1965 .

Moynihan, Daniel P., Maximum Feasible Misunderstanding: Community Action in the War on Poverty, New York, The Free Press, 1969.

Myers, Summer, "How to Sel1 New Ideas to the Cities," Harvard Business Review, July-August, 1968.

Nadler, Gerald, "An Investigation of Design Methodology," Management Science, June, 1967.

Northeastern Illinois Planning Commission, "The Plan Study: Methodology," April, 1968. 
Peters, W. S., "A Method of Deriving Geographic Patterns of Associated Demographic Characteristics Within Urban Areas," Soc1al Forces, October, 1956.

Pfouts, R. W., editor, The Techniques of Urban Economic Analysis, West Trenton, N. J., Chandler-Davis Co. 1960 .

"The Planner in Emerging Urban Society - A Confrontation," Proceedings of the 1965 Annual Conference in St. Louis, Missouri, American Institute of Planners, 1965.

Post, Arnold R., "Research Report: Mobility Analysis," Journal of the American Institute of Planners, November, 1969.

Preston, James D., "A Comprehensive Methodology for Identifying Community Leaders," Rural Sociology, December, 1969.

Proshansky, Harold M., William H., 1ttelson and l,eanne (i. Rivlin, eds., Environmental Psychology: Man and His Physical Setting, New York, Holt, Rinehart and Winston, 1970.

Rapoport, A. and R. Hawkes, "The Perception of Urban Complexity," Journal of the American Institute of Planners, March, 1970.

Reps, John W., The Making of Urban America: A History of City Planning in the United States, Princeton, N. J., The Princeton University Press, 1965.

Reps, John R., "Requiem for Zoning," Planning 1964, Chicago, American Society of Planning officials, 1964.

Rickert, John E., editor, Urban and Regional Information Systems: Federal Activities and Specialized Systems, Kent, Ohio, Kent State University, 1968.

Samuelson, Paul A., Economics, An Introductory Analysis, fifth edition, New York, McGraw Hill Book Company, 1961 .

Schellie Associates, Inc., "Operations Procedure Manual, A Detailed Work Program for the Greater Lafayette Area Transportation-Development Study," Area Plan Commission, 'rippecanoe County, Indiana, 1968. 
Schimpeler, Charles C., "Inventory Procedures and General Organizational Aspects of the Louisville Metropolitan Comprehensive Transportation and Development Program," Prepared for the 51 st annual Purdue Road School, Purdue University, Lafayette, Indiana, March 29, April 1, 1965.

Schnore, Leo F. and Henry Fagin, editors, Urban Research and Policy Planning, Beverly Hills, California, Sage 1967.

Shaffer, Margaret T., "Attitude Techniques in Action," an unpublished Paper delivered to the $49 \mathrm{th}$ annual meeting, Highway Research Board, Washington D.C., January 1970 .

Shunk, Gordon A., "The Journey to Work: A Singular Basis for Travel Pattern Surveys," Ph.D. Thesis, Purdue University, January 1968.

Smith, J., "A Method for the Classification of Areas on the Basis of Demographically Homogeneous Populations," American Sociological Review, April 1954.

Spicer, Richard B., "Increasing State and Regional Power in the Development Process," Planning Advisory Service Report 255, American Society of Planning officials, March, 1970.

Stamp, Dudley L., Applied Geography. Baltimore, A Pelican Original, Penguin, 1960.

Steger, Wilbur A., "The Pittsburgh Urban Renewal Simulation Mode1," Journal of the American Institute of Planners, May, 1965.

Steiner, George A., "The Critical Role of Top Management in Long Range Planning," Arizona Review, April, 1966.

Strand, Sverre, "Comment: Models and Ethics", Journal of The American Institute of Planners, January, 1971.

Stuart, Darwin G., "Information Systems in Urban Planning: A Review," Planning Advisory Service Report No. 260, Chicago, American Society of Planning officials, August, 1970.

Teitz, M. B., "Cost Effectiveness: A Systems Approach to Analysis of Urban Services," Journal of the American Institute of Planners, September, 1968.

Vedder, J., "Planning Problems with Multidemensional Consequences," Journal of the American Institute of Planners, March, 1970. 
Vogt - Ivers and Associates, Economic and Population Factors, Manual R, Ohio Procedural Manuals, ohio Department of Highways, 1966.

Vogt - Ivers and Associates, "An Intermediate Report for Project Number 32 - Community Goals and Objectives," Louisville Metropolitan Comperhensive Transportation and Development Program, Apri1, 1967.

Vogt - Ivers and Associates, "Social and Community Factors, Manual 9, Ohio Procedure Manuals," Ohio Department of Highways, 1966.

Voorhees, Alan M., ed., "Land Use and Traffic Models," Special Issue, Journal of the American Institute of Planners, May 1959 .

Wachs, Martin, "Basic Approaches to the Measurement of Community Values," an unpublished paper delivered to the 49 th annual meeting, Highway Research Board, Washington D.C., January 1970.

Walksberg, Joseph, "The Role of Sampling in Populatiun Concensuses - Its Effect on Timeliness and Accuracy," Demugraphy, 1968 .

Warburton, Ralph, "New Concepts in Urban Transportaticn Systems," Journal of the Frank1 in Institute, Special issue, November, 1968.

Warren, Ronald L., "Cities First Round: Politics Planning and Participation," Journal of the American Institute of Planners, July, 1969 .

Webber, Melvin M., "Alternative Styles for Citizen Participation in Transport Planning," an Address delivered to the 50th annual meeting, Highway Research Board, Washington D.C., January 18, 1971.

Webber, M. M., "The Roles of Intelligence Systems in UrbanSystems Planning," Journal of the American Institute of Planners, November, 1965.

White, Morton and Lucia, The Intellectual Versus the City, Cambridge, Harvard University Press, 1962.

Witwer, David B., "Solving Land-Use Determinations Electronically," The American City, February, 1965. 
Ylvisaker, Paul N., "O'Harrow Memorial Lecture: Utter Chaos or Simple Complexity," Planning 1970. Selected Papers from the A.S.P.O. Planning Conference, New York, April 4-9, 1970 , Chicago, American Society of Planning officials, 1970 .

Ylvisaker, Pau1 N., "The Resident Looks at Community Values," Transportation and Community Values, Highway Research Board Special Report Number 105 , Washington D.C., Highway Research Board, 1969.

Young, Robert C., "Goals and Goal Setting," Journal of the American Institute of Planners, March, 1966. 

VITA

Thomas Allan Dames was born in Oak Park, I11inois on June $30,1943$.

He graduated from Fenwick High School in 1961 and the United States Naval Academy in 1965. He holds the commission of Lieutenant, Civil Engineer Corps, United States Navy.

Lieutenant Dames has served at Great Lakes, Illinois, Phu Bai and Gia Le in the Republic of Vietnam as a Company Commander in the 133rd Seabees, and Pear1 Harbor, Hawaii. His duties have necessitated extensive travel in the Far East.

He is also a graduate of Purdue University, B.S.C.E., 1968 and M.S.C.E. in Urban Planning and Engineering, 1968.

Lieutenant Dames holds several American and foreign military awards, including the Navy Commendation Medal, the Army Commendation Medal, the Combat Action Ribbon, and the Republic of Vietnam Technical Service Medal and Civic Action Medal.

Lieutenant Dames is married to the former Ursula Anne Roberts of Annandale, Virginia. They have two children, Thomas Christopher and John Damien. 